\title{
SOLIDIFICATION OF THE HANFORD LAW WASTE STREAM PRODUCED AS A RESULT OF NEAR-TANK CONTINUOUS SLUDGE LEACHING AND SODIUM HYDROXIDE RECOVERY
}

J. R. Harbour

M.M. Reigel

F.C. Johnson

C. Crawford

C. Jantzen

K. Gustashaw

September 2011

Savannah River National Laboratory

Savannah River Nuclear Solutions

Aiken, SC 29808 
SRNL-STI-2011-00525

Revision 0

\section{DISCLAIMER}

This work was prepared under an agreement with and funded by the U.S. Government. Neither the U.S. Government or its employees, nor any of its contractors, subcontractors or their employees, makes any express or implied: 1. warranty or assumes any legal liability for the accuracy, completeness, or for the use or results of such use of any information, product, or process disclosed; or 2. representation that such use or results of such use would not infringe privately owned rights; or 3. endorsement or recommendation of any specifically identified commercial product, process, or service. Any views and opinions of authors expressed in this work do not necessarily state or reflect those of the United States Government, or its contractors, or subcontractors.

\section{Printed in the United States of America \\ Prepared For U.S. Department of Energy}




\section{REVIEWS AND APPROVALS}

\section{AUTHORS:}

M.M. Reigel, SRNL, Engineering Process Development

Date

F.C. Johnson, SRNL, Process Technology Programs

Date

C. Crawford, SRNL, Process Technology Programs

Date

C. Jantzen, SRNL, Process Technology Programs

Date

TECHNICAL REVIEWERS:

A. D. Cozzi, SRNL, Engineering Process Development

Date

\section{APPROVERS}

F. M. Pennebaker, SRNL, Manager, Advanced Characterization \& Process

Date

S. L. Marra, SRNL, Manager, E\&CPT Research Programs

Date 


\section{EXECUTIVE SUMMARY}

The U.S. Department of Energy (DOE), Office of River Protection (ORP), is responsible for the remediation and stabilization of the Hanford Site tank farms, including 53 million gallons of highly radioactive mixed wasted waste contained in 177 underground tanks. ${ }^{1,2}$ The plan calls for all waste retrieved from the tanks to be transferred to the Waste Treatment Plant (WTP). The WTP will consist of three primary facilities including pretreatment facilities for Low Activity Waste (LAW) to remove aluminum, chromium and other solids and radioisotopes that are undesirable in the High Level Waste (HLW) stream. Removal of aluminum from HLW sludge can be accomplished through continuous sludge leaching of the aluminum from the HLW sludge as sodium aluminate; however, this process will introduce a significant amount of sodium hydroxide into the waste stream and consequently will increase the volume of waste to be dispositioned. A sodium recovery process is needed to remove the sodium hydroxide and recycle it back to the aluminum dissolution process. The resulting LAW waste stream has a high concentration of aluminum and sodium and will require alternative immobilization methods.

Five waste forms were evaluated for immobilization of LAW at Hanford after the sodium recovery process. The waste forms considered for these two waste streams include low temperature processes (Saltstone/Cast stone and geopolymers), intermediate temperature processes (steam reforming and phosphate glasses) and high temperature processes (vitrification). These immobilization methods and the waste forms produced were evaluated for (1) compliance with the Performance Assessment (PA) requirements for disposal at the IDF, (2) waste form volume (waste loading), and (3) compatibility with the tank farms and systems.

The iron phosphate glasses tested using the product consistency test had normalized release rates lower than the waste form requirements although the CCC glasses had higher release rates than the quenched glasses. However, the waste form failed to meet the vapor hydration test criteria listed in the WTP contract. In addition, the waste loading in the phosphate glasses were not as high as other candidate waste forms. Vitrification of HLW waste as borosilicate glass is a proven process; however the HLW and LAW streams at Hanford can vary significantly from waste currently being immobilized. The ccc glasses show lower release rates for $\mathrm{B}$ and $\mathrm{Na}$ than the quenched glasses and all glasses meet the acceptance criterion of $<4 \mathrm{~g} / \mathrm{L}$. Glass samples spiked with $\mathrm{Re}_{2} \mathrm{O}_{7}$ also passed the PCT test. However, further vapor hydration testing must be performed since all the samples cracked and the test could not be performed. The waste loading of the iron phosphate and borosilicate glasses are approximately 20 and $25 \%$ respectively.

The steam reforming process produced the predicted waste form for both the high and low aluminate waste streams. The predicted waste loadings for the monolithic samples is approximately $39 \%$, which is higher than the glass waste forms; however, at the time of this report, no monolithic samples were made and therefore compliance with the PA cannot be determined.

The waste loading in the geopolymer is approximately $40 \%$ but can vary with the sodium hydroxide content in the waste stream. Initial geopolymer mixes revealed compressive strengths that are greater than $500 \mathrm{psi}$ for the low aluminate mixes and less than 500 psi for the high aluminate mixes. Further work testing needs to be performed to formulate a geopolymer waste form made using a high aluminate salt solution.

A cementitious waste form has the advantage that he process is performed at ambient conditions and is a proven process currently in use for LAW disposal. The Saltstone/Cast Stone formulated using low and high aluminate salt solutions retained at least $97 \%$ of the Re that was added to the mix as a dopant. While this data is promising, additional leaching testing must be performed to show compliance with the PA. Compressive strength tests must also be performed on the Cast Stone monoliths to verify PA compliance. 
Based on testing performed for this report, the borosilicate glass and Cast Stone are the recommended waste forms for further testing. Both are proven technologies for radioactive waste disposal and the initial testing using simulated Hanford LAW waste shows compliance with the PA. Both are resistant to leaching and have greater than $25 \%$ waste loading. 


\section{TABLE OF CONTENTS}

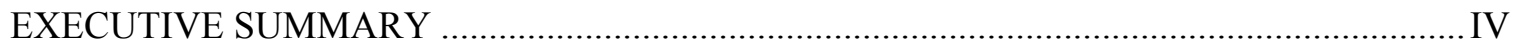

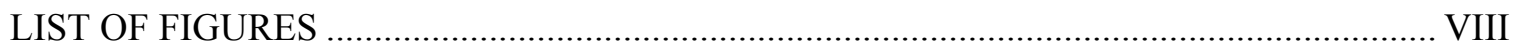

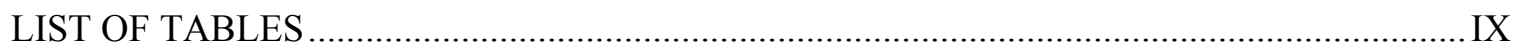

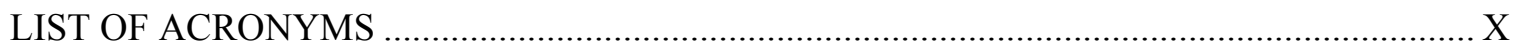

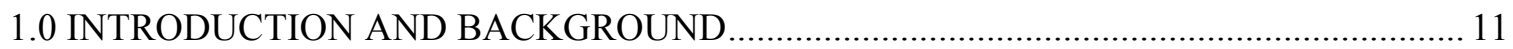

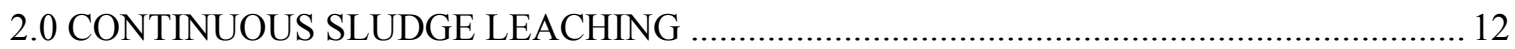

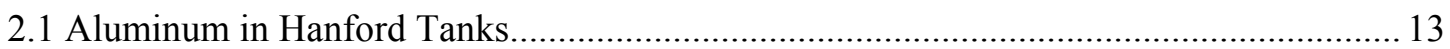

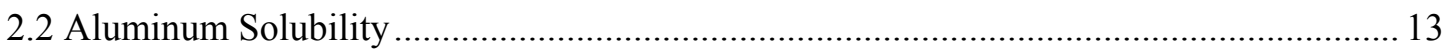

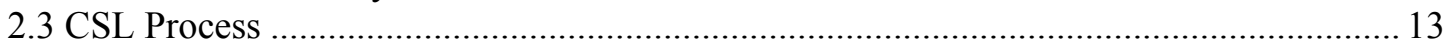

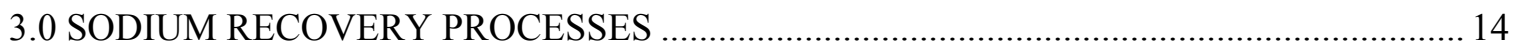

3.1.1 Ceramatec Process $\quad 15$

3.1.2 Areva Process 16

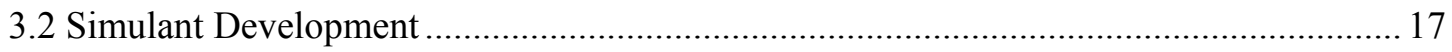

3.2.1 Ceramatec Simulant 17

3.2.2 Areva Simulant 21

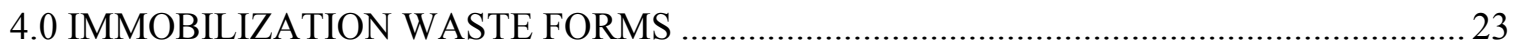

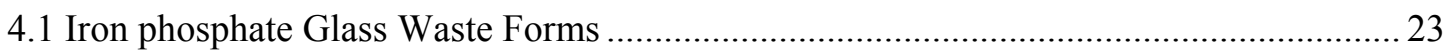

4.1.1 Formulation 23

$\begin{array}{ll}\text { 4.1.2 PCT } & 24\end{array}$

4.1.3 Vapor Hydration Test (VHT) 25

4.1.4 XRD 25

4.1.5 Volume and Mass Factors 28

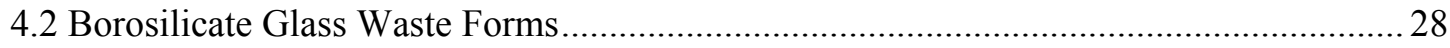

4.2.1 Formulation 28

$\begin{array}{ll}\text { 4.2.2 PCT } & 29\end{array}$

4.2.3 Vapor Hydration Tests 30

4.2.4 X-ray Diffraction 30

4.2.5 Volume and Mass Factors $\quad 32$

4.2.6 Doped Glasses $\quad 32$

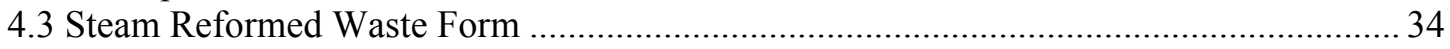

4.3.1 Formulation $\quad 35$

4.3.2 BSR Equipment Setup 36

4.3.3 BSR Processing Conditions 38

4.3.4 XRD 39

4.3.5 Projected Waste Loadings $\quad 40$

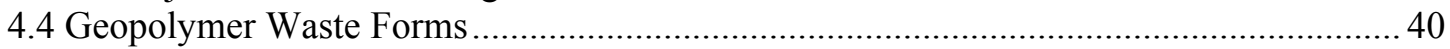

4.4.1 Cementitious Materials and Simulants 41

4.4.2 Experimental Design and Batching $\quad 42$

4.4.3 Measurement of Fresh and Cured Properties 43

4.4.4 Scanning Electron Microscopy 44

4.4.5 Heat Generation $\quad 49$

4.4.6 Volume and Mass Factors 51

4.4.7 Future Work $\quad 52$

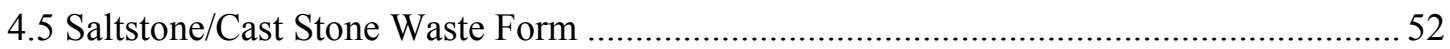

4.5.1 Saltstone Formulation $\quad 52$

4.5.2 Performance Properties of Saltstone $\quad 53$

4.5.3 Radionuclide Retention $\quad 54$

4.5.4 Future Work 56 
SRNL-STI-2011-00525

Revision 0

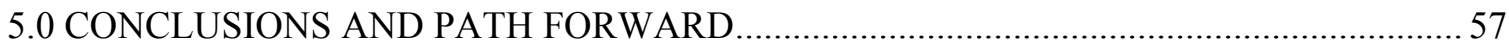

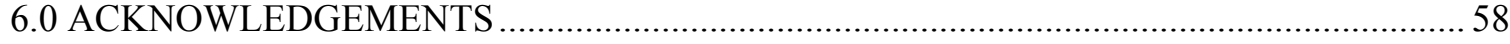

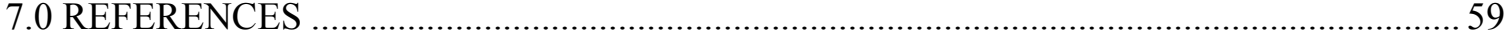




\section{LIST OF FIGURES}

Figure 1.1. Simplified Hanford Tank Waste Treatment and Immobilization Flow Diagram ${ }^{2}$................... 11 Figure 2.1. Near Tank Treatment System Process Flow Diagram. ${ }^{12}$.................................................... 14 Figure 3.1. Schematic of an Electrochemical Process Using the NaSICON Membrane. ${ }^{13}$........................ 15 Figure 3.2. Schematic of WTP Process with the Areva LHT Process for Sodium Recovery. ${ }^{19}$................. 16 Figure 3.3. Titration system showing alumina precipitation after all of the free hydroxide has been neutralized.

Figure 3.4. Results of titration of $50 \mathrm{~mL}$ of the low aluminate simulant precursor with $10 \mathrm{wt} \%$ nitric acid. The vertical lines identify the $200 \mathrm{mEq}$ of free hydroxide and the total $250 \mathrm{mEq}$ of hydroxide (includes $50 \mathrm{mEq}$ of bound hydroxide) in the $50 \mathrm{~mL}$ of this simulant.

Figure 3.5. Results of titration of $50 \mathrm{~mL}$ of the high aluminate simulant precursor with $10 \mathrm{wt} \%$ nitric acid. The vertical lines identify the $225 \mathrm{mEq}$ of free hydroxide and the total $375 \mathrm{mEq}$ of hydroxide (includes $150 \mathrm{mEq}$ of bound hydroxide) in $50 \mathrm{~mL}$ of this simulant. ............................................20

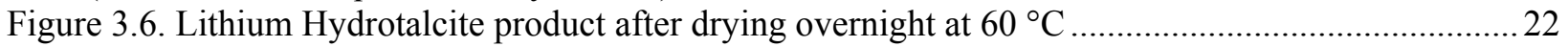

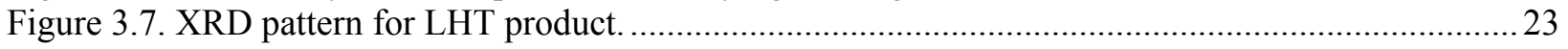

Figure 4.1. Images of the VHT samples for (a) quenched MS-HAL-5, (b) ccc MS-HAL-5, (c) quenched

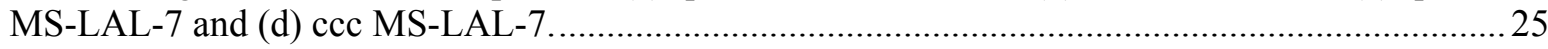

Figure 4.2. XRD data for quenched MS-LAL-7 glass typical of an amorphous glass. ..........................26

Figure 4.3. XRD data for ccc MS-LAL-7 glass showing at least two crystallites within the glass matrix. .

Figure 4.4. XRD data for quenched MS-HAL-5 glass typical of an amorphous glass........................... 27

Figure 4.5. XRD data for ccc MS-HAL-5 glass showing approximately four crystalline phases within the

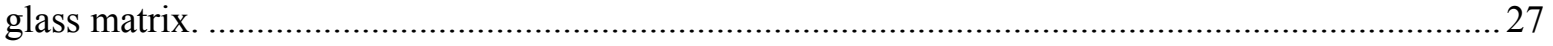

Figure 4.6. Images of the VHT samples for (a) quenched FCJHAL-1, (b) ccc FCJHAL-1, (c) quenched FCJLAL-3 and (d) ccc FCJLAL-3 ............................................................................................ 30

Figure 4.7. XRD spectra of the (a) quenched FCJLAL-3 glass, (b) FCJLAL-3ccc glass, (c) quenched

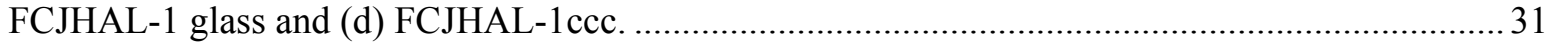

Figure 4.8. Images of the VHT samples for (a) quenched FCJHAL-1D, (b) ccc FCJHAL-1D, (c)

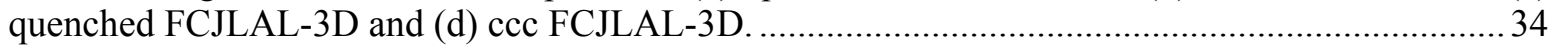

Figure 4.9. $\mathrm{Na}_{2} \mathrm{O}-\mathrm{SiO}_{2}-\mathrm{Al}_{2} \mathrm{O}_{3}$ ternary diagram showing the projected steam reformed waste form composition (blue square) for high and low aluminate waste streams..........................................36

Figure 4.10.Schematic of the Bench-Scale Steam Reformer............................................................... 37

Figure 4.11. DMR chamber showing the 2.5 inch reaction zone. ${ }^{27}$.................................................... 38

Figure 4.12. XRD plot of BSR product formulated with low aluminate simulant. Phases present are

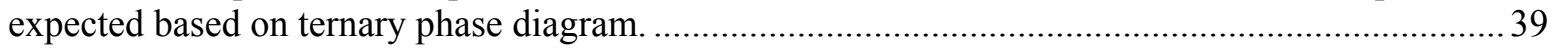

Figure 4.13. XRD plot of BSR product formulated with high aluminate simulant. Phases present are

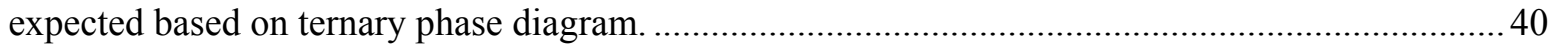

Figure 4.14. Low aluminate simulant and Big Brown Raw fly ash geopolymer paste after 14 days of

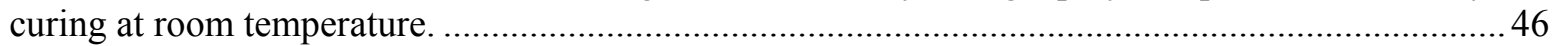

Figure 4.15. Low aluminate simulant mixed with big brown raw and slag geopolymer pastes after 14 days

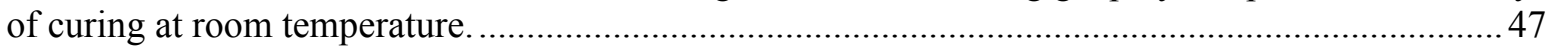

Figure 4.16. Low aluminate simulant mixed with Class C fly ash and slag geopolymer after 14 days of

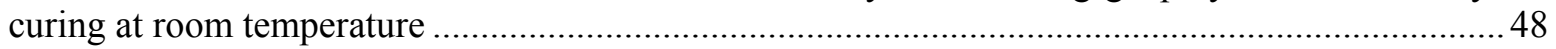

Figure 4.17. Low aluminate simulant mixed with Belews Creek fly ash and slag, geopolymer paste after

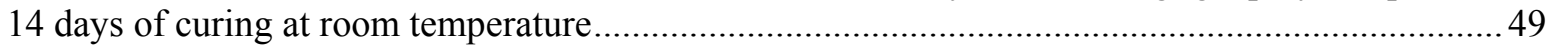

Figure 4.18. Isothermal calorimetry output for a mix of low aluminate waste stream \# 1 with a premix composed of 85 wt \% Big Brown Raw Class F fly ash and 15 wt \% slag. ...................................... 50

Figure 4.19. Isothermal calorimetry output for a mix of the low aluminate waste stream \# 1 with a premix composed of $85 \mathrm{wt} \%$ Class $\mathrm{C}$ fly ash and $15 \mathrm{wt} \%$ slag...............................................................51 
Figure 4.20. Normalized heat production $(\mathrm{J} / \mathrm{g}$ of $\mathrm{cm})$ for low and high aluminate mixes at $25^{\circ} \mathrm{C} \ldots \ldots \ldots . . . .53$

Figure 4.21. Dependence of Young's modulus on the curing temperature of the grouts. .......................55

Figure 4.22. The UFA centrifuge system for measuring permeability and capturing pore solution...........55

Figure 4.23. Total $\mathrm{Na}$ ion concentration $(\mathrm{ppm})$ for each sample taken as a function of the total amount of solution collected.

\section{LIST OF TABLES}

Table 3.1. Compositions of Precursors to the Low and High Aluminate Simulants .............................. 18

Table 3.2. Composition, Density and wt \% Solids of the Low and High Aluminate Simulants. .............. 21

Table 3.3. Solutions Used for Generating Lithium Hydrotalcite .......................................................... 22

Table 4.1. Target and Measured Glass Compositions for the HAL and LAL Iron Phosphate Glasses

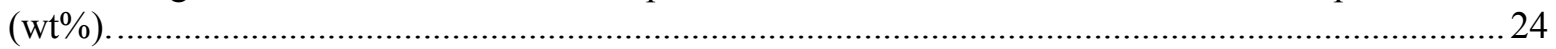

Table 4.2. Normalized Concentrations for the HAL and LAL Phosphate Glasses...................................25

Table 4.3. Volume and Mass of Waste Form Produced per Liter of LAW with Phosphate Glass........... 28

Table 4.4. Target and Measured Glass Compositions for the HAL and LAL Borosilicate Glasses (wt\%)29

Table 4.5. Normalized Concentrations for the HAL and LAL Borosilicate Glasses ..............................29

Table 4.6. Summary of VHT Results for HAL and LAL Borosilicate Glasses ........................................ 30

Table 4.7. Volume and Mass of Waste Form Produced per Liter of LAW with Borosilicate Glass ......... 32

Table 4.8. Target and Measured Compositions for the Doped HAL and LAL Borosilicate Glasses (wt\%)

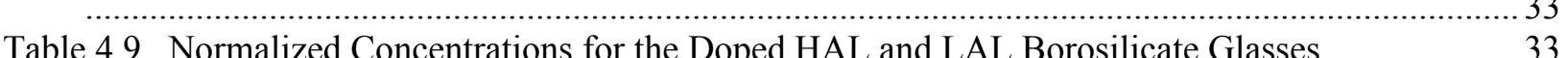

Table 4.9. Normalized Concentrations for the Doped HAL and LAL Borosilicate Glasses .................... 33

Table 4.10. Re and I Leachate Results ..................................................................................... 34

Table 4.11. Summary of Corrosion Results for the Doped HAL and LAL Borosilicate Glasses............. 34

Table 4.12. Relative Scaling of Process Operating Parameters of the BSR Compared to the FBSR for the

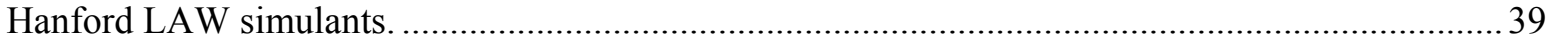

Table 4.13. Projected Waste Loadings for BSR Monolith Product. ........................................................ 40

Table 4.14. Oxide compositions of aluminosilicate powders based on Inductively Coupled Plasma-

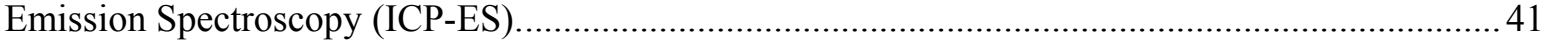

Table 4.15. Chemical Constituents and Concentrations of Simulants.................................................. 42

Table 4.16. Test Matrix for Geopolymer Mixtures with the Low Aluminate Waste Stream 1. ................. 43

Table 4.17. Gel time, normalized bleed water and compressive strength for all geopolymer mixtures

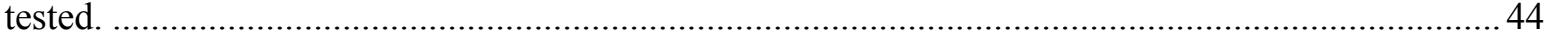

Table 4.18. Volume and mass fractions of geopolymer waste form....................................................5 51

Table 4.19 Cementitious Materials Used in Saltstone/Cast Stone Waste Form. .....................................5 52

Table 4.20. Processing properties for simulated low and high aluminate waste streams. ........................53

Table 4.21. Re Retention in the Low and High Aluminate Mixes.........................................................56

Table 4.22. Waste Loadings and Associated Volume and Mass Factors for the Mixes............................56 


\section{LIST OF ACRONYMS}

\begin{tabular}{ll} 
ACTL & Aiken County Technology Laboratory \\
ASTM & American Society for Testing and Materials \\
BFS & Blast Furnace Slag \\
CBO & Carbon Burn-Out \\
CCC & Canister Center-Line Cooled \\
CM & Cementitious Materials \\
CSH & Calcium Silicate Hydrate \\
CSL & Continuous Sludge Leaching \\
DMR & De-nitration Mineralization Reactor \\
DOE & Department of Energy \\
BSR & Bench Scale Steam Reformer \\
DSS & Decontaminated Salt Solution \\
E & Dynamic Young's Modulus \\
EM & Environmental Management \\
FA & Class F Fly Ash \\
FBSR & Fluidized Bed Steam Reforming \\
HAL & High Aluminate \\
HLW & High Level Waste \\
ICP & Inductively Coupled Plasma \\
IDF & Integrated Disposal Facility \\
LAW & Low Activity Waste \\
LAL & Low Aluminate \\
LHT & Lithium Hydrotalcite \\
MCU & Modular Caustic Side Solvent Extraction \\
NaSICON & Sodium (Na) Super Ion Conductor \\
NRC & Nuclear Regulatory Commission \\
NTTS & Near-Tank Treatment System \\
ORP & Office of River Protection \\
PA & Performance Assessment \\
PC & Portland Cement \\
PCT & Product Consistency Test \\
PEP & Pretreatment Engineering Platform \\
PNNL & Pacific Northwest National Laboratory \\
SEM & Scanning Electron Microscopy \\
SPF & Saltstone Production Facility \\
SRNL & Savannah River National Laboratory \\
SRNS & Savannah River Nuclear Solutions \\
SRS & Savannah River Site \\
UFA & Unsaturated Flow Apparatus \\
VHT & Vapor Hydration Test \\
w/cm & Water to Cementitious Material Ratio \\
WTP & Waste Treatment and Immobilization Plant \\
XRD & X-ray Diffraction \\
\hline &
\end{tabular}




\subsection{Introduction and Background}

The U.S. Department of Energy (DOE), Office of River Protection (ORP), is responsible for the remediation and stabilization of the Hanford Site tank farms, including 53 million gallons of highly radioactive mixed wasted waste contained in 177 underground tanks. ${ }^{1,2}$ The plan calls for all waste retrieved from the tanks to be transferred to the Waste Treatment Plant (WTP). The WTP will consist of three primary facilities: a pretreatment facility and two facilities for Low Activity Waste (LAW) and HLW vitrification (Figure 1.1). The pretreatment facility will receive waste feed from the Hanford tank farms and separate it into two treated process streams: a high-volume, low-activity, liquid process stream stripped of most solids and high-activity radioisotopes and a much smaller volume HLW slurry containing most of the solids, high-activity radioisotopes, and long-lived isotopes. In the pretreatment facility, solids and radioisotopes will be removed from the tank waste by precipitation, filtrations, and ion exchange processes to produce the LAW streams. The slurry of filtered solids will be blended with two ion exchange streams containing soluble radioisotopes to produce the HLW streams. The primary constituents that will be removed from the HLW prior to receipt at the WTP are aluminum (boehmite) and phosphate wastes. Treatment of boehmite will dramatically reduce the process cycle time for the WTP pretreatment facility while treatment of the phosphate will significantly reduce the volume of material processed by the ion exchange columns in WTP. The pretreated HLW mixture will route to the HLW Vitrification Facility and the pretreated LAW stream will route to the LAW Vitrification Facility. These two vitrification facilities will convert these process streams into glass, which is poured directly into stainless steel canisters.

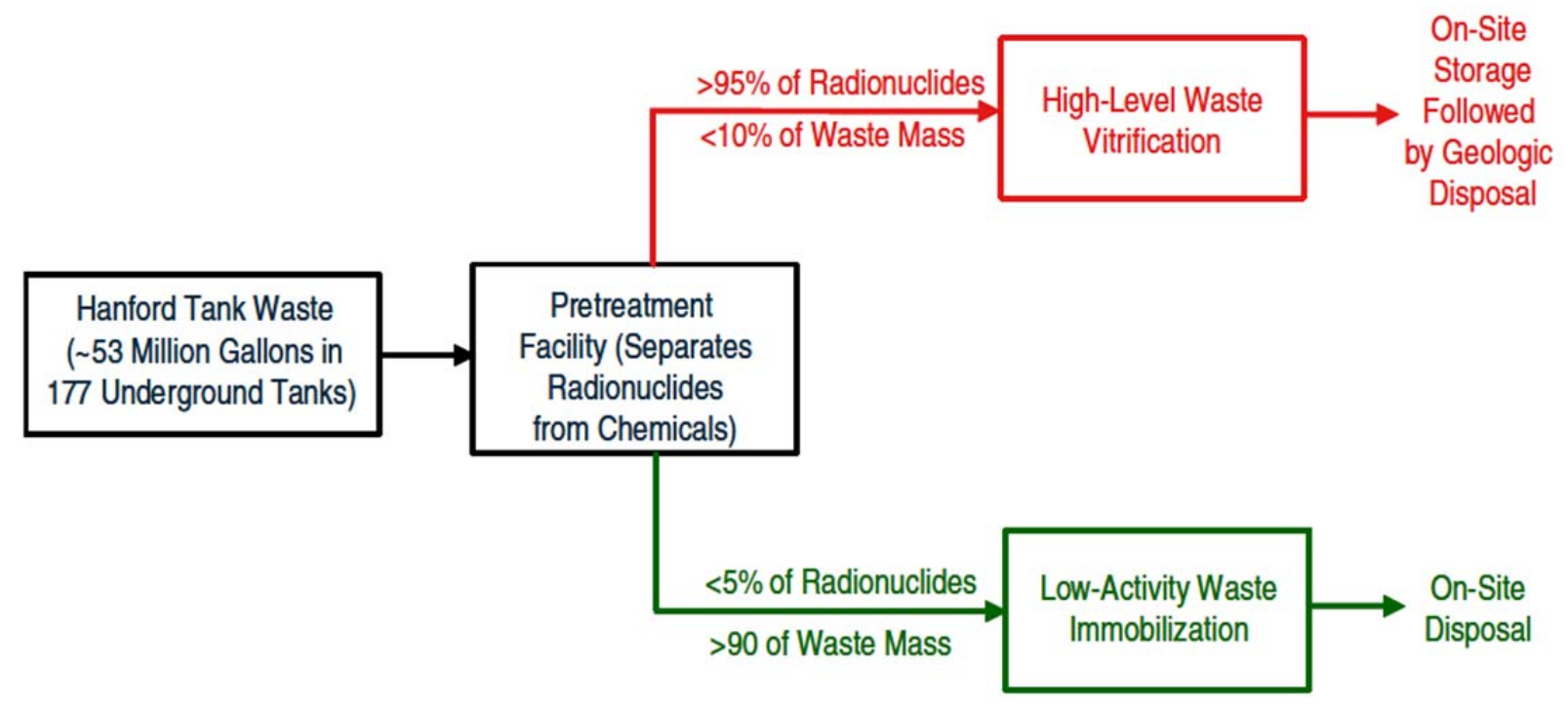

Figure 1.1. Simplified Hanford Tank Waste Treatment and Immobilization Flow Diagram²

Removal of aluminum from High Level Waste (HLW) sludge can be accomplished through caustic $(\mathrm{NaOH})$ leaching of the aluminum from the HLW sludge as sodium aluminate, $\mathrm{Na}^{+} \mathrm{Al}(\mathrm{OH})_{4}{ }^{-}$. A continuous process has been developed to perform this aluminum leaching step for near tank applications at the Hanford Site. However, this process will introduce a significant amount of sodium hydroxide into the waste stream and consequently will increase the volume of waste to be dispositioned. In order to reduce this sodium load, a second process was introduced to remove the sodium hydroxide and recycle it back to the aluminum dissolution process. ${ }^{3}$ 
The rationale for this at or near tank waste treatment approach is to (1) reduce the volume of vitrified HLW produced over the lifetime of WTP and (2) facilitate the early treatment of some of the HLW waste prior to the startup of the WTP. This will generate a waste stream prior to startup of WTP that will be immobilized for disposal as LAW at the Integrated Disposal Facility (IDF) at Hanford. This report will consider various methods of immobilization for the LAW waste stream to produce a waste form that meets the requirements of the IDF, produces an acceptable waste volume, and can be implemented at or near tank. Near Tank Cesium Removal (NTCR) will also be integrated into this system as necessary to ensure the reduction of the LAW to a Nuclear Regulatory Commission (NRC) Class C limits as defined by CFR $61.55 .^{3}$

One of the sodium recovery processes considered was developed by Ceramatec and involves an electrochemical driven transfer of sodium through a ceramic membrane. The overall result of this process is transfer of $\mathrm{NaOH}$ from the caustic, aluminum-rich waste stream in the anode cell to an aqueous solution in the cathode cell. This sodium recovery process can concentrate $\mathrm{NaOH}$ to $19 \mathrm{M}$ in the cathodic stream. It is this concentrated $\mathrm{NaOH}$ solution that will be recycled to the continuous sludge leaching process. An important issue with this process is the formation of a waste stream either close to saturation or at a state of super-saturation in aluminate. Consequently, alumina can precipitate out of solution and generate a slurry of alumina in salt solution as the LAW stream to be treated. The formation of this precipitate in the waste stream depends on the chemistry of the initial stream and the degree to which the $\mathrm{NaOH}$ removal is performed. Therefore, a wastes immobilization option must consider the physical and chemical nature of the slurry for both processing and immobilization. ${ }^{3}$

A second process being considered for sodium recovery uses lithium hydroxide to precipitate out crystalline lithium hydrotalcite (LHT) particles (as well as other mineral hydrotalcites). The particle size of the LHT is typically on the order of 50 microns. These particles can then be filtered leaving a $\mathrm{NaOH}$ supernate that will be recycled to continuous aluminum dissolution process. The filtered LHT particles may be washed to reduce the amount of radionuclides in the waste stream to an acceptable level. This process therefore, produces a slurry of LHT particles in a salt solution. As with the Ceramatec process, this LHT waste immobilization option must consider the physical and chemical nature of the slurry for both processing and ultimate immobilization. ${ }^{3}$

Methods of immobilization that will be considered for these two waste streams include low temperature processes (Saltstone/Cast stone and geopolymers), intermediate temperature processes (steam reforming and phosphate glasses) and high temperature processes (vitrification). These immobilization methods and the waste forms they produce will be evaluated for (1) compliance with the Performance Assessment (PA) requirements for disposal at the IDF, (2) waste form volume (waste loading), and (3) compatibility with the tank farms and systems. ${ }^{3}$

\subsection{Continuous Sludge Leaching}

The Continuous Sludge Leaching (CSL) Process is being developed under EM's Advanced Remediation Technology (ART) Program by Parsons Infrastructure \& Technology Group and the Pacific Northwest National Laboratory (PNNL) to remove aluminum and other undesirable compounds, such as chromium, from Hanford HLW. The WTP has a processing target to remove significant aluminum such that it is no longer the waste-limiting component in the final HLW glass waste form. ${ }^{4}$ The chromium must also be removed before producing the glass waste forms because there is low tolerance for it in the immobilization process due to chromium's low solubility in borosilicate waste glass. 


\subsection{Aluminum in Hanford Tanks}

Aluminum present in the HLW tanks at Hanford, if not removed, would substantially increase the number of vitrified HLW waste canisters sent to a geologic waste repository since it is a waste-limiting component in the HLW glass form. ${ }^{2,4}$ The most abundant elements in the tanks include iron, phosphorous, calcium, silicon, bismuth and aluminum, which is one of the most prevalent, accounting for nearly $70 \%$ of the sludge. ${ }^{5}$ Aluminum is primarily found in the forms of gibbsite, $\mathrm{Al}(\mathrm{OH})_{3}$, as micrometer sized colloidal particles or boehmite, $\mathrm{AlO}(\mathrm{OH})$, as agglomerated nanoparticles ${ }^{5}$; however, there are a large number of other aluminum compounds present (sodium aluminate), including some compounds (e.g., refractory aluminosilicates) that are resistant to leaching. ${ }^{2}$ The fundamental problem, from a chemistry perspective, is the wastes largely begin as gibbsite, but gradually convert to boehmite or other mineral forms as the wastes age.

\subsection{Aluminum Solubility}

Many studies have been performed that demonstrate the aluminum solubility in sodium hydroxide solutions depends on the mineral form of aluminum. ${ }^{7}$ As mentioned in the previous section, the most prevalent aluminum-containing minerals in Hanford tanks are gibbsite and boehmite; ${ }^{8}$ however, the dominant aluminum species in high-pH liquids is thought to be the aluminate ion $\mathrm{Al}(\mathrm{OH})_{4}{ }^{-}$. Gibbsite and sodium aluminate are easily dissolved by heating under caustic conditions (i.e. 8 hours at $50{ }^{\circ} \mathrm{C}$ with $3 \mathrm{M}$ $\mathrm{NaOH}){ }^{8}$ The reaction between free hydroxide, aluminate and gibbsite is shown in Equation 1. Sodium aluminate forms according to Equation 2.

$$
\begin{aligned}
& \mathrm{Al}(\mathrm{OH})_{3(s)}+\mathrm{OH}_{(a q)}^{-} \leftrightarrow \mathrm{Al}(\mathrm{OH})_{4(a q)}^{-} \\
& \mathrm{Na}_{(a q)}^{+}+\mathrm{Al}(\mathrm{OH})_{4(a q)}^{-} \leftrightarrow \mathrm{NaAl}(\mathrm{OH})_{4(s)}
\end{aligned}
$$

According to Equations 2.1 and 2.2, adding free hydroxide dissolves gibbsite and adding sodium allows sodium aluminate to precipitate. Thus, when sodium hydroxide is added to a solution with solid gibbsite, the gibbsite dissolves. If enough sodium hydroxide is added, sodium aluminate will re-precipitate. Therefore, there is an optimal sodium hydroxide concentration where the maximum quantity of aluminum (gibbsite) is dissolved while avoiding sodium aluminate precipitation. ${ }^{8}$

Multiple studies have been conducted on the dissolution kinetics of boehmite in caustic solutions. ${ }^{4,6,8}$ These studies have shown that the dissolution rate of boehmite is the rate-limiting step in aluminum dissolution and sensitive to temperature changes. One study showed the dissolution rate approximately doubles with every $20{ }^{\circ} \mathrm{C}$ temperature increase. ${ }^{8}$ Boehmite dissolution (Equation 2.3) requires more aggressive conditions of higher temperatures and longer time than to dissolve gibbsite. ${ }^{4}$ Both the precipitation and dissolution kinetics of boehmite are extremely slow at current tank temperatures. ${ }^{8,9}$

$$
\mathrm{AlO}(\mathrm{OH})+\mathrm{OH}_{(a q)}^{-}+\mathrm{H}_{2} \mathrm{O} \leftrightarrow \mathrm{Al}(\mathrm{OH})_{4(a q)}^{-}
$$

According to waste dissolution studies on batch processes, ${ }^{4,6,8}$ the adequate dissolution of boehmite from Hanford tank waste can be achieved in approximately 24 hours using a $3-5 \mathrm{M} \mathrm{NaOH}$ solution at $100{ }^{\circ} \mathrm{C}$.

\subsection{CSL Process}

The process uses a continuously stirred reactor vessel operating with caustic at 90 to $100{ }^{\circ} \mathrm{C}$ to remove aluminum and chromium by leaching with $\mathrm{NaOH}$ (Figure 2.1). The potential advantages of this approach are that it uses a longer residence time with a smaller footprint than the current semi-batch WTP pretreatment process based on reactor configuration to facilitate more complete aluminum extraction and may be applied in a near-tank configuration. ${ }^{2}$ The extended residence time and higher temperature allow 
for an increase in boehmite dissolution and reduced HLW canister production. Implementation of CSL could reduce the amount of $\mathrm{Al}$ and $\mathrm{Cr}$ in HLW by more than a factor of 2 by removing $90 \%$ of the boehmite. Currently, the WTP flow sheet targets less than $50 \%$ of the boehmite for dissolution. ${ }^{10}$ Deployment of the CSL process could result in approximately one third to one half reduction in the quantity of HLW canisters produced at Hanford, which results in up to $\$ 10$ billion in life cycle savings. ${ }^{11}$

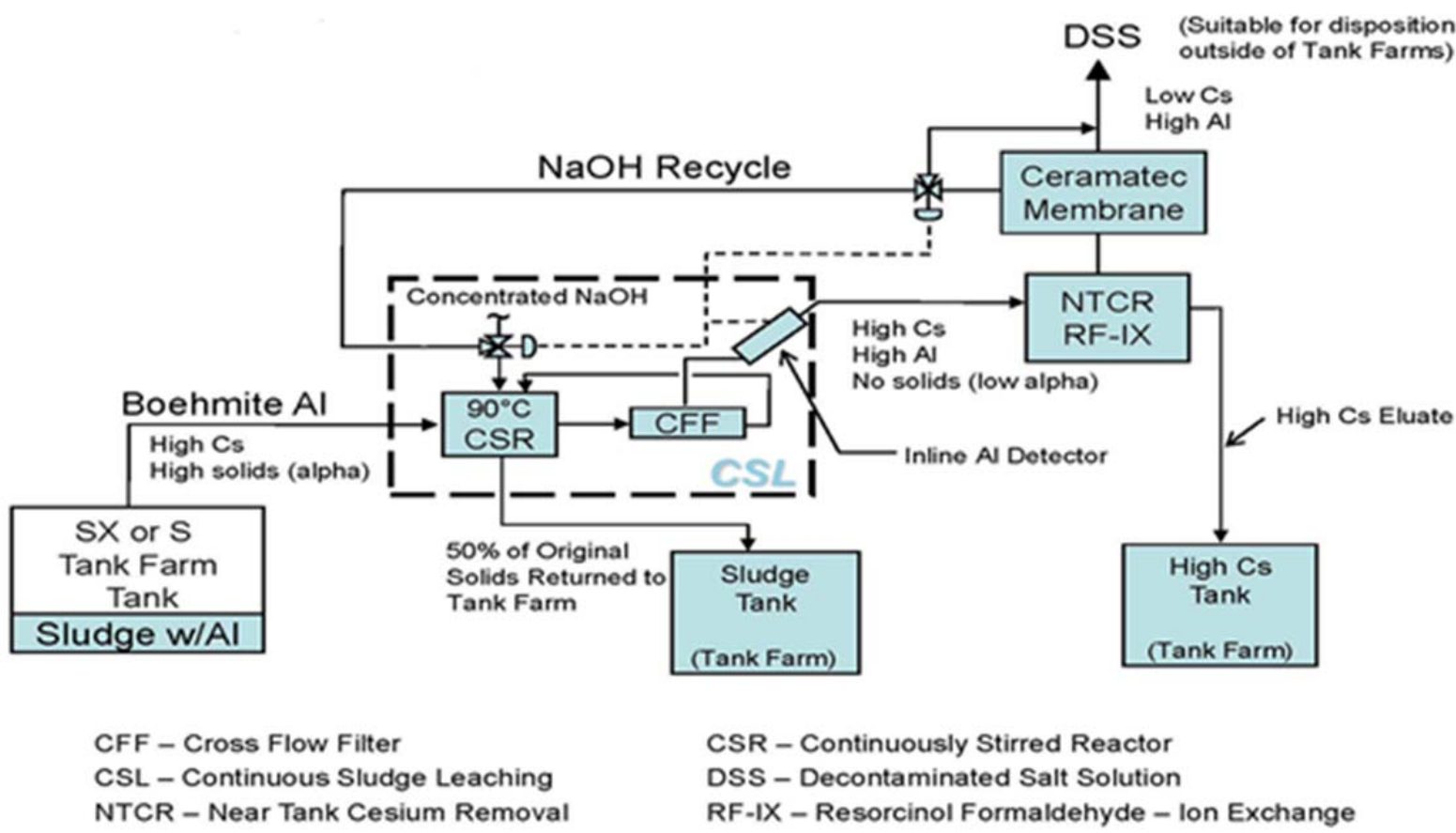

Figure 2.1. Near Tank Treatment System Process Flow Diagram. ${ }^{12}$

The full scale process will include a 3000 gallon reactor vessel and approximately 100 square feet of filter area (100 tube bundle). ${ }^{10}$ The CSL process will be designed to process $200 \mathrm{~kg} / \mathrm{hr}$ of waste, produce 150 $\mathrm{kg} / \mathrm{hr}$ of leached slurry, remove $90 \%$ of aluminum and reduce the mass of insoluble solids by $60 \%{ }^{10} \mathrm{~A}$ benefit of CSL implementation at Hanford is that does not introduce any new hazards to the site since it utilizes exiting chemicals, reduces the quantity of material at risk relative to the process baseline and the small reactor size reduces potential doses to workers. ${ }^{11}$ However, removal of aluminum from HLW results in a substantial increase in the amount of sodium to be processed in LAW because of the addition of sodium hydroxide to increase aluminum solubility and prevent corrosion. ${ }^{2}$

\subsection{Sodium Recovery Processes}

Dissolving or leaching aluminum from Hanford tank sludges and maintaining its solubility during pretreatment requires the addition of large amounts of sodium hydroxide. ${ }^{9}$ Recent projections at Hanford indicate that up to 40,000 metric tons of sodium would be needed to dissolve the aluminum and maintain it in solutions, which nearly doubles the amount of sodium in the entire current waste tank inventory. ${ }^{6}$ Therefore, a sodium recovery process must be implemented that allows the caustic to be recycled through the CSL process to minimize the amount of required caustic. 


\subsubsection{Ceramatec Process}

The first option for sodium recovery after CSL, developed by Ceramatec, electrochemically transfers sodium ions through a Sodium (Na) Super Ion Conductor (NaSICON) ceramic membrane while generating free hydroxide ions and hydrogen at the cathode and oxygen and hydrogen ions at the anode. ${ }^{13-}$

${ }^{15}$ This process shows promise as a means to mitigate the impact of $\mathrm{Na}$ by enabling the separation and recycling of $\mathrm{Na}$ from the radioactive wastes. In this process, the waste is added to the anode compartment, and an electrical potential is applied to the cell. The ceramic membrane allows the selective transport of $\mathrm{Na}+$ ions to the cathode compartment while most other cations (e.g., $\mathrm{K}^{+}, \mathrm{Cs}^{+}$) and anions are left behind (i.e., rejected) in the anode compartment. The charge balance in the anode compartment is maintained by generating $\mathrm{H}^{+}$from the electrolysis of water. The charge balance in the cathode is maintained by generating $\mathrm{OH}^{-}$, either from the electrolysis of water or from oxygen and water using an oxygen gas diffusion cathode. ${ }^{13}$ The normal gaseous products of the electrolysis of water are oxygen at the anode and hydrogen at the cathode. Potentially flammable gas mixtures can be prevented by providing adequate volumes of a sweep gas, using an alternative reductant, or destroying the hydrogen as it is generated. As $\mathrm{H}^{+}$is generated in the anode compartment the $\mathrm{pH}$ drops and the waste stream becomes less alkaline. ${ }^{13,15}$ Producing $\mathrm{OH}^{-}$in the cathode compartment results in a rise in $\mathrm{pH}$ as the $\mathrm{Na}$ hydroxide product is produced. ${ }^{13}$ Figure 3.1 is a schematic of the electrochemical process using the NaSICON membrane.
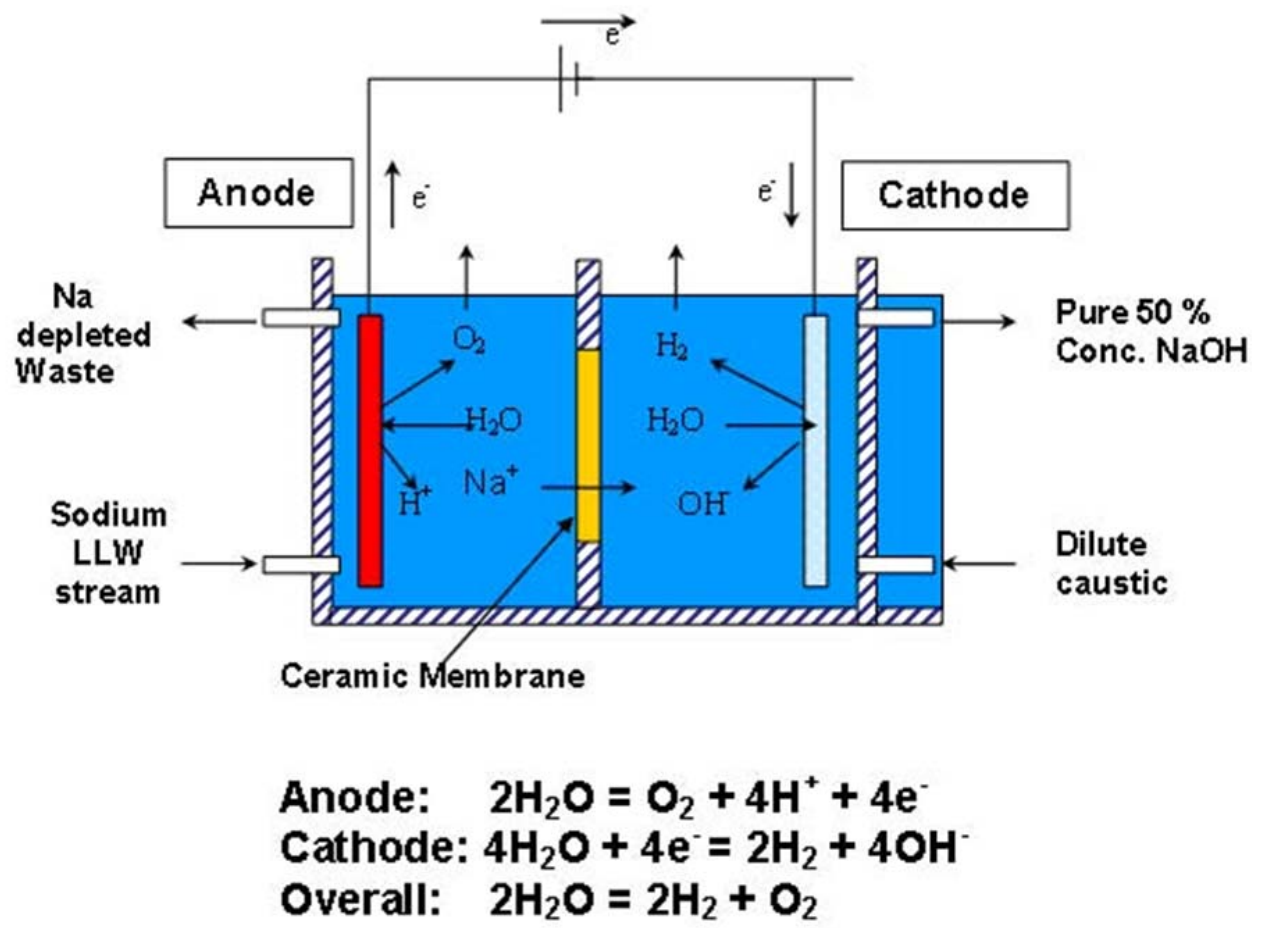

Figure 3.1. Schematic of an Electrochemical Process Using the NaSICON Membrane. ${ }^{13}$

The overall result of this process is transfer of $\mathrm{NaOH}$ from the caustic, aluminum-rich waste stream in the anode cell to an aqueous solution in the cathode cell. This sodium recovery process can concentrate $\mathrm{NaOH}$ to $19 \mathrm{M}$ in the cathodic stream. It is this concentrated $\mathrm{NaOH}$ solution that will be recycled to the continuous sludge leaching process. An important issue with this process is the formation of a waste stream either close to saturation or at a state of super-saturation in aluminate. Consequently, alumina can precipitate out of solution and generate a slurry of alumina in salt solution as the LAW stream to be treated. The formation of this precipitate in the waste stream depends on the chemistry of the initial stream and the degree to which the $\mathrm{NaOH}$ removal is performed. Therefore, a waste immobilization 
option must consider the physical and chemical nature of the slurry for both processing and immobilization. ${ }^{3}$

There are multiple benefits to this technology including a reduction in handling and processing of waste and potential cost savings for waste cleanup by lowering the volume of waste processed. ${ }^{16}$ The concentrated $\mathrm{NaOH}$ solution generated at the anode is recycled for continued aluminum leaching of the HLW sludge. The NaSICON ceramic membrane technology will directly make sodium hydroxide up to $50 \mathrm{wt} \%$ and prevents migration of cesium and other radionuclides to the sodium hydroxide stream. ${ }^{16}$

\subsubsection{Areva Process}

The second option for sodium recovery, developed by AREVA, adds lithium hydroxide to the waste stream to precipitate the leached aluminum as a lithium hydrotalcite (LHT) (Figure 3.2). ${ }^{14,17}$ The proposed LHT process theoretically eliminates the large volume of additional sodium hydroxide required to leach and maintain alumina solubility through Hanford Waste Treatment Plant (WTP) operations. ${ }^{18}$

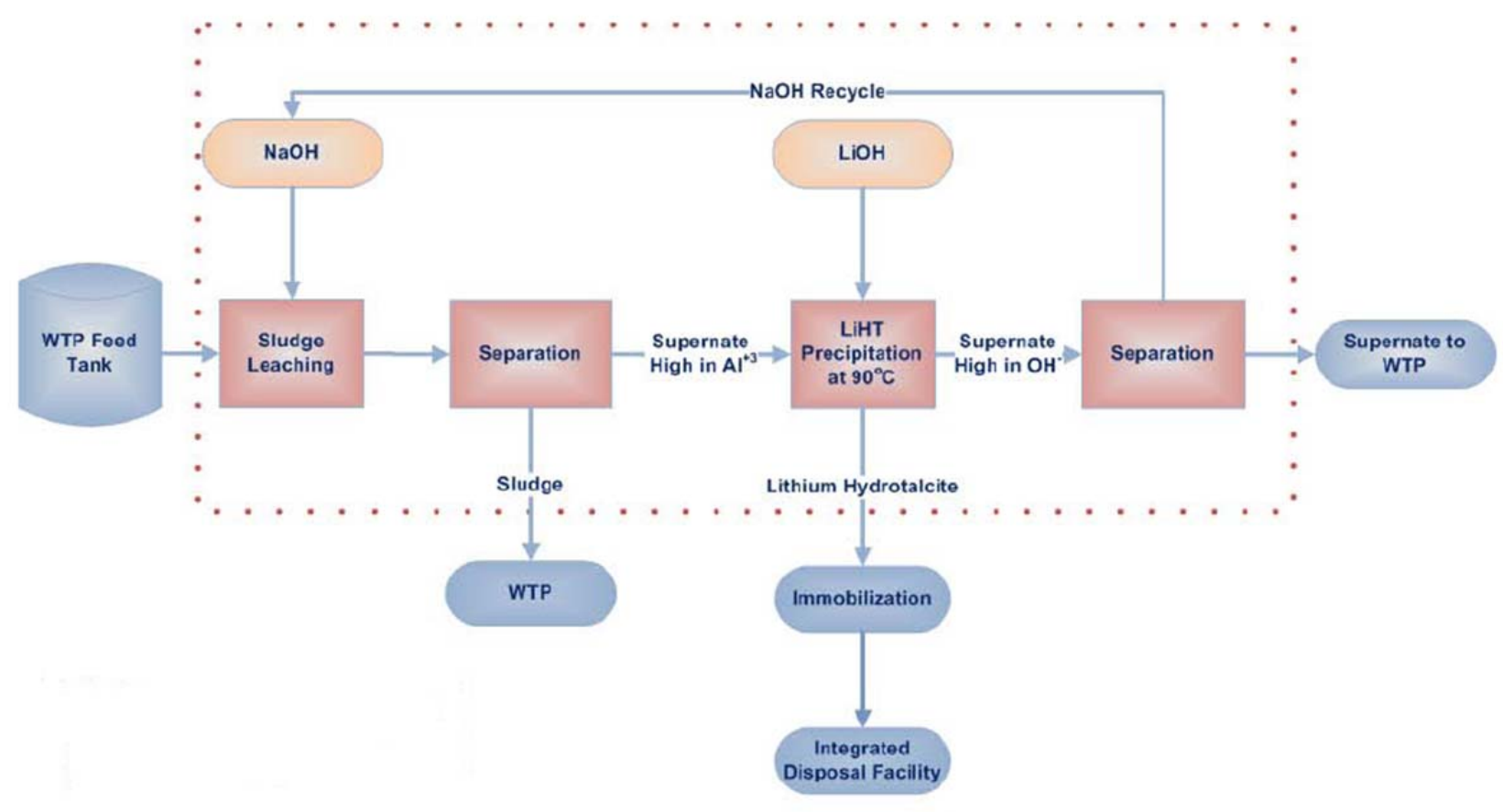

Figure 3.2. Schematic of WTP Process with the Areva LHT Process for Sodium Recovery. ${ }^{19}$

The key reaction in Equation 3.1. ${ }^{18}$ A $10 \%$ aqueous solution of lithium hydroxide ( $\left.\mathrm{LiOH}\right)$ is reacted with soluble sodium aluminate $\left(\mathrm{NaAl}(\mathrm{OH})_{4}\right)$ and sodium carbonate ${ }^{*}\left(\mathrm{Na}_{2} \mathrm{CO}_{3}\right)$ present in the waste to produce lithium hydrotalcite $\left(\mathrm{Li}_{2} \mathrm{CO}_{3} \cdot 4 \mathrm{Al}(\mathrm{OH})_{3} \cdot 3 \mathrm{H}_{2} \mathrm{O}\right)$ and sodium hydroxide $(\mathrm{NaOH})$. The solid lithium hydrotalcite is separated from solution; the aqueous sodium hydroxide is recycled to further leach alumina sludge as shown in Equation 3.2. ${ }^{18}$

\footnotetext{
* Aqueous sodium carbonate $\left(\mathrm{Na}_{2} \mathrm{CO}_{3(\mathrm{AQ})}\right)$ is abundant in Hanford waste. In the absence of sodium carbonate, another abundant sodium salt (e.g. $\mathrm{NaNO}_{3(\mathrm{AQ})}$ ) may substitute.
} 


$$
\mathrm{NaOH}+\mathrm{Al}(\mathrm{OH})_{3(s)} \rightarrow \mathrm{NaAl}(\mathrm{OH})_{4(a q)}
$$

The combination of alumina sludge leaching (3.1) and lithium hydrotalcite precipitation (3.2) continuously liberates sodium hydroxide that can be recycled to the waste while removing alumina as a filterable solid (Equation 3.3). ${ }^{18}$

$$
\begin{aligned}
& 2 \mathrm{LiOH}_{(a q)}+\mathrm{Na}_{2} \mathrm{CO}_{3(a q)}+4 \mathrm{Al}(\mathrm{OH})_{3(s)}+3 \mathrm{H}_{2} \mathrm{O} \rightarrow \mathrm{Li}_{2} \mathrm{CO}_{3} \cdot 4 \mathrm{Al}(\mathrm{OH})_{3} \cdot 3 \mathrm{H}_{2} \mathrm{O}_{(s)}+ \\
& 2 \mathrm{NaOH}_{(a q)}
\end{aligned}
$$

Analytical results of the experiments concur with literature reports and thermodynamic models of the method. The hydrotalcite reaction (3.1) occurs rapidly at $90^{\circ} \mathrm{C}$. Thermodynamic studies indicate that reaction yield is maximized at low temperature $\left(25^{\circ} \mathrm{C}\right)$. However, at this temperature the kinetic rate of reaction is slow and will require a large vessel to provide long residence time. Work is being performed to determine the optimum reaction temperature to achieve a balance between product yield and reaction rate. $^{18}$

To improve the efficiency of LHT alumina removal, the leachate should be saturated or near-saturated in alumina. By this method, the maximum amount of alumina is leached and precipitated per gallon of solution. However, leaching rate decreases asymptotically as saturation is reached, and the required residence time to reach full saturation increases exponentially. Thus, a practical limit to the approach to alumina saturation will be determined. ${ }^{18}$ The product forms large $(50 \mu \mathrm{m})$ particles with narrow size distribution, and can be separated and decontaminated from simulated waste solution easier than other precipitated alumina phases. ${ }^{18}$ A non-radioactive cesium decontamination factor $\left({ }^{134} \mathrm{Cs} \mathrm{DF}\right)$ of $>2,000$ was obtained by water washing of the filter cake. Product purity was $>99.9 \%$. Theoretical yield (95\%) was obtained in less than one-half hour of reaction time. Sodium hydroxide was regenerated by the reaction and recycled for alumina leaching. ${ }^{18}$ The filtered and washed LHT particles will then be immobilized for disposal at IDF. The concentrated filtrate, high in $\mathrm{NaOH}$ concentration, will be recycled for continued HLW sludge leaching.

Theoretically, this method can eliminate the large sodium hydroxide demand to leach alumina sludge and reduce two-thirds ${ }^{4}$ of the total sludge mass to be treated by the WTP. The actual amount of sodium hydroxide savings and alumina sludge reduction will depend upon the success of the development, the extent of implementation of the technology, and the amount of waste treated by this method. ${ }^{18}$

\subsection{Simulant Development}

Since the CSL and sodium hydroxide recovery processes are developmental, the first step in the task of waste form development is to produce model simulants to initiate evaluation of various immobilization methods. The simulants are based on the potential implementation of a Near-Tank Treatment System (NTTS) consisting of CSL of HLW followed by cesium-137 removal through ion exchange and sodium hydroxide recovery. ${ }^{14}$ It is assumed that cesium removal through ion exchange will not significantly change the chemical composition of the waste stream solution. As additional results are obtained from the CSL and sodium recovery processes, the simulant compositions will be refined. In addition, simulants will also be developed that bracket the compositional ranges due to projected variations in these processes. ${ }^{14}$ Although the Areva simulant was developed for testing with the candidate waste forms, the scope of the project was altered during the testing phase of this project and therefore the waste forms were formulated using the high and low aluminate solution simulants from the Ceramatec process only.

\subsubsection{Ceramatec Simulant}

Two simulants were prepared for the processes involving CSL followed by the Ceramatec sodium recovery process. The low aluminate simulant is based on a demonstration of the CSL process. ${ }^{20}$ The 
high aluminate simulant was based on the PEP simulant and analytical results during PEP pilot scale testing. Ceramatec tested both of these aluminum-leached simulants at their Salt Lake City facility using this sodium recovery process. The measured $\mathrm{NaOH}$ and aluminate concentrations prior to and after sodium recovery were used in this simulant development. ${ }^{14}$ The goal of this sodium recovery process is to recover as much $\mathrm{NaOH}$ as possible for recycle without producing an aluminum hydroxide precipitate in the waste stream. The presence of aluminum precipitates would produce a stream that could easily foul the downstream processes. Secondly, the recycling of $\mathrm{NaOH}$ reduces the amount of sodium in the LAW stream and consequently the volume of LAW waste form produced. ${ }^{14}$

In order to produce simulants that remain in solution, precursor simulants were batched with compositions based on the waste streams after aluminum dissolution but before sodium recovery. These precursor simulants were then titrated with nitric acid to determine the point where irreversible precipitation of aluminum hydroxide occurs. This titration simulates the removal of $\mathrm{NaOH}$ by the Ceramatec electrochemical process. Once this point is determined, the next step was to provide a safety margin in hydroxide ion concentration to prevent precipitation. The compositions of the precursors to the low and high aluminate simulants (prior to sodium recovery) are provided in Table 3.1. The titration system is shown in Figure 3.3. This photograph shows an injection of the nitric acid and formation of the alumina precipitate after all of the free hydroxide ions had been neutralized. ${ }^{14}$

Table 3.1. Compositions of Precursors to the Low and High Aluminate Simulants

\begin{tabular}{||c|c|c||}
\hline \multirow{2}{*}{ Compound } & \multicolumn{2}{|c||}{ Precursor Simulants } \\
\cline { 2 - 3 } & Low Aluminate (M) & High Aluminate (M) \\
\hline \hline $\mathrm{NaOH}$ & 5.000 & 7.500 \\
\hline $\mathrm{NaNO}_{3}$ & 0.147 & 0.160 \\
\hline $\mathrm{NaNO}_{2}$ & 0.054 & 0.005 \\
\hline $\mathrm{Na}_{2} \mathrm{CO}_{3}$ & 0.055 & 0.055 \\
\hline $\mathrm{Na}_{2} \mathrm{C}_{2} \mathrm{O}_{4}$ & 0.001 & 0.001 \\
\hline $\mathrm{Na}_{2} \mathrm{SO}_{4}$ & 0.001 & 0.018 \\
\hline $\mathrm{Al}\left(\mathrm{NO}_{3}\right)_{3}$ & 0.250 & 0.750 \\
\hline $\mathrm{Na}_{3}\left(\mathrm{PO}_{4}\right)$ & 0.002 & 0.000 \\
\hline Total $\mathrm{Na} \mathrm{Molarity}^{\mid}$ & 5.32 & 7.81 \\
\hline
\end{tabular}

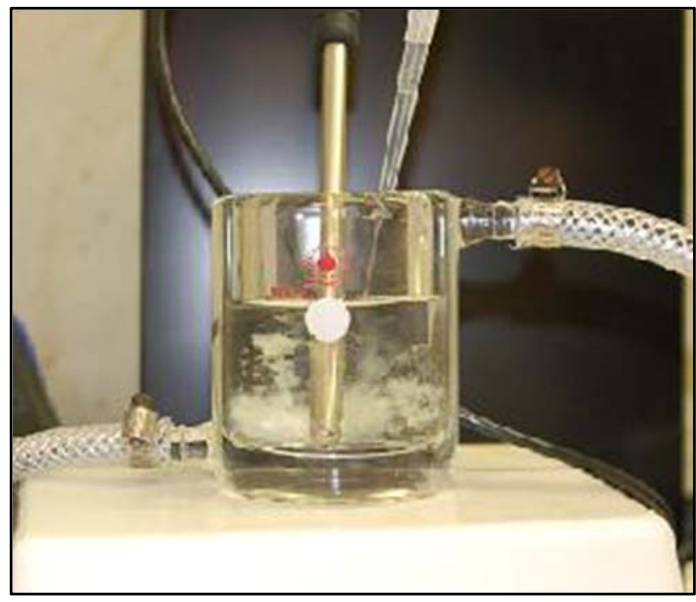


SRNL-STI-2011-00525

Revision 0

Figure 3.3. Titration system showing alumina precipitation after all of the free hydroxide has been neutralized.

Titration results for the low aluminate simulant precursor are provided in Figure 3.4. In this test, $50 \mathrm{~mL}$ of the simulant were titrated with a $10 \mathrm{wt} \%$ nitric acid solution. There are $200 \mathrm{mEq}$ of free hydroxide ions and $50 \mathrm{mEq}$ of bound hydroxide ions associated with $\mathrm{Al}(\mathrm{OH})_{4}$ (and $2.8 \mathrm{mEq}$ from the carbonate and oxalate) in $50 \mathrm{~mL}$ of this simulant precursor.

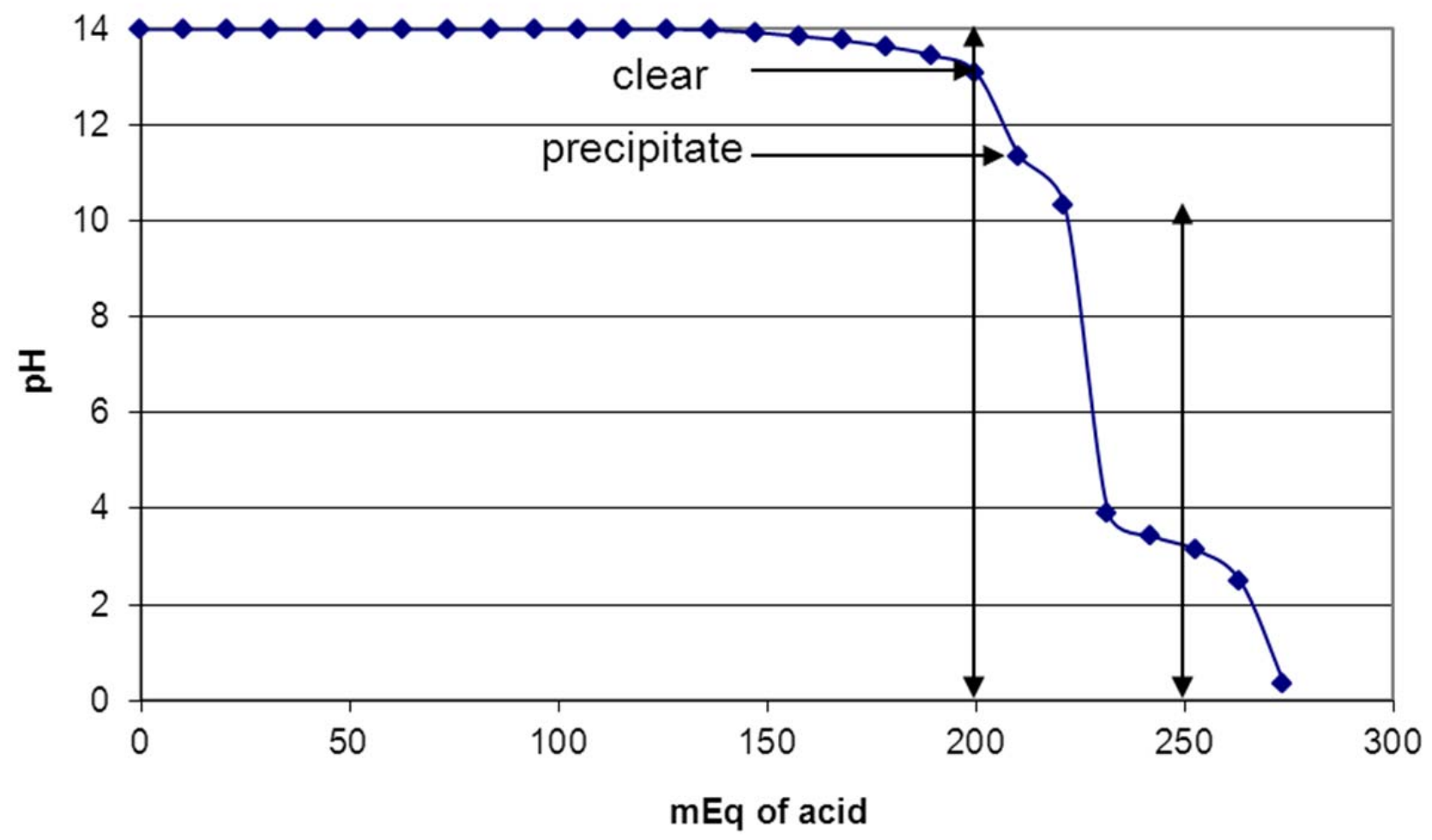

Figure 3.4. Results of titration of $50 \mathrm{~mL}$ of the low aluminate simulant precursor with $10 \mathrm{wt} \%$ nitric acid. The vertical lines identify the $200 \mathrm{mEq}$ of free hydroxide and the total $250 \mathrm{mEq}$ of hydroxide (includes $50 \mathrm{mEq}$ of bound hydroxide) in the $50 \mathrm{~mL}$ of this simulant.

Titration results for the high aluminate simulant precursor are provided in Figure 3.5. In this test, $50 \mathrm{~mL}$ of the simulant were titrated with $10 \mathrm{wt} \%$ nitric acid. There are $225 \mathrm{mEq}$ of free hydroxide ions and 150 $\mathrm{mEq}$ of bound hydroxide ions associated with $\mathrm{Al}(\mathrm{OH})_{4}{ }^{-}$(and $2.8 \mathrm{mEq}$ from carbonate and oxalate) in 50 $\mathrm{mL}$ of this simulant precursor. 
SRNL-STI-2011-00525

Revision 0

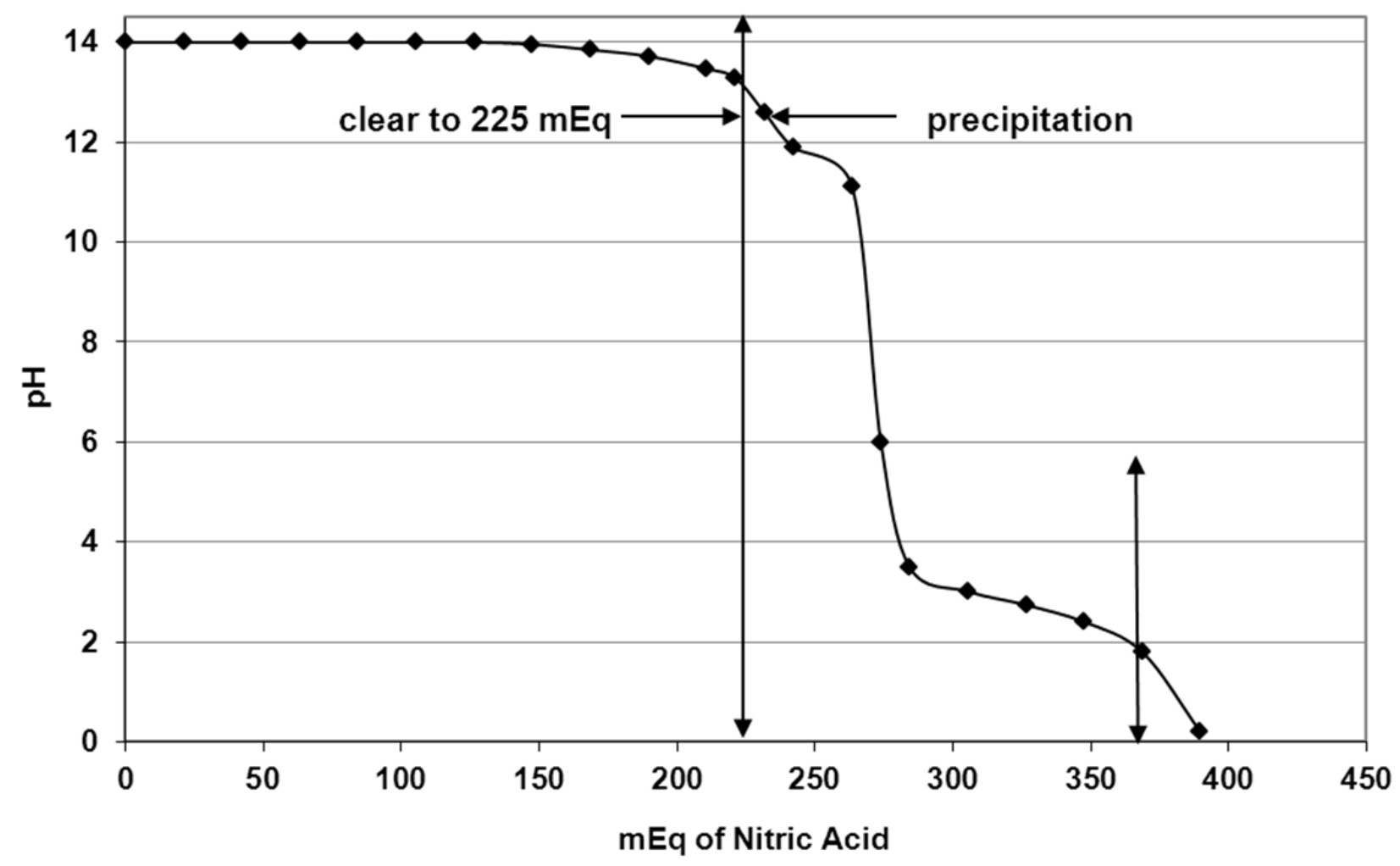

Figure 3.5. Results of titration of $50 \mathrm{~mL}$ of the high aluminate simulant precursor with 10 wt \% nitric acid. The vertical lines identify the $225 \mathrm{mEq}$ of free hydroxide and the total $375 \mathrm{mEq}$ of hydroxide (includes $150 \mathrm{mEq}$ of bound hydroxide) in $50 \mathrm{~mL}$ of this simulant.

The results of the titrations for both precursor simulants demonstrate that precipitation occurs immediately after all of the free hydroxide is neutralized. Additional acid added after this point results in the neutralization of the hydroxides bound to the aluminate, $\mathrm{Al}(\mathrm{OH})_{4}{ }_{4}^{-}$. The precipitation which accompanies this neutralization of the bound hydroxides is a result of $\mathrm{Al}(\mathrm{OH})_{3}$ formation. In order to provide a safety factor to prevent this precipitation, it is necessary to reduce the amount of acid added to the system (equivalent to the amount of free hydroxide in solution). A value of $1.0 \mathrm{M}$ free hydroxide ion was selected as a value for the simulants after sodium recovery which provides sufficient safety from precipitation. This corresponds to $150 \mathrm{mEq}$ of acid added to the low aluminate precursor simulant and $175 \mathrm{mEq}$ of acid added to the high aluminate precursor simulant.

In terms of sodium hydroxide recovery using the Ceramatec process, these final states of the two simulants correspond to sodium hydroxide recovery of $56 \%$ for the low aluminate simulant and $44 \%$ for the high aluminate simulant. For comparison, the maximum recovery of sodium hydroxide prior to alumina formation is $75 \%$ for the low aluminate simulant and $57 \%$ for the high aluminate simulant. In this discussion, the sodium hydroxide recovery is based on the initial sodium concentration in the waste stream after aluminum dissolution and the final concentration of sodium after sodium recovery. That is, the percent efficiency, $\eta$, for sodium hydroxide recovery, is given by Equation 3.4.

The compositions of the low and high aluminate simulants, reflective of the compositions of the LAW waste streams after both aluminum dissolution and sodium hydroxide recovery with inclusion of a safety 
margin to prevent alumina formation are provided in Table 3.2. The densities and wt $\%$ solids for the two simulants are also provided in Table 3.2. These simulants did not show any precipitation even after storage at $5{ }^{\circ} \mathrm{C}$.

Table 3.2. Composition, Density and wt \% Solids of the Low and High Aluminate Simulants.

\begin{tabular}{|c|c|c|}
\hline \multirow{2}{*}{ Compound } & \multicolumn{2}{|c|}{ Simulants } \\
\cline { 2 - 3 } & Low Aluminate (M) & High Aluminate (M) \\
\hline \hline $\mathrm{NaOH}$ & 2.000 & 4.000 \\
\hline $\mathrm{NaNO}_{3}$ & 0.147 & 0.160 \\
\hline $\mathrm{NaNO}_{2}$ & 0.054 & 0.050 \\
\hline $\mathrm{Na}_{2} \mathrm{CO}_{3}$ & 0.055 & 0.055 \\
\hline $\mathrm{Na}_{2} \mathrm{C}_{2} \mathrm{O}_{4}$ & 0.001 & 0.001 \\
\hline $\mathrm{Na}_{2} \mathrm{SO}_{4}$ & 0.001 & 0.018 \\
\hline $\mathrm{Al}_{(}\left(\mathrm{NO}_{3}\right)_{3}$ & 0.250 & 0.750 \\
\hline $\mathrm{Na}_{3}\left(\mathrm{PO}_{4}\right)$ & 0.002 & 0.006 \\
\hline Total Na Molarity & 2.32 & 4.38 \\
\hline Density (g/mL) & 1.113 & 1.224 \\
\hline Wt \% Solids & 13.77 & 27.33 \\
\hline
\end{tabular}

\subsubsection{Areva Simulant}

A second method of sodium recovery, developed by AREVA, precipitates the aluminate in the supernate waste stream as a lithium hydrotalcite $(\mathrm{LHT}), \mathrm{Li}_{2} \mathrm{CO}_{3} \bullet 4 \mathrm{Al}(\mathrm{OH})_{3} \bullet 3 \mathrm{H}_{2} \mathrm{O}$, by addition of lithium hydroxide. The LHT crystalline powder is then filtered and washed. The filtrate (containing the sodium hydroxide and other salts) and spent washes are combined, concentrated and then recycled for aluminum leaching of HLW. The LHT powder is an aluminum rich crystalline material that is part of the layered double hydroxide family of materials. These crystals consist of positively charged aluminate layers separated by layers containing water and anions (carbonate, nitrate, hydroxide etc). The washed LHT is the LAW stream that will be immobilized. There is also the possibility to use LHT, at least in part, as glass formers in WTP. ${ }^{14}$

The number of washes of the LHT will depend on operational and regulatory limits, but it could be as high as five. The resultant LHT powder will therefore have relatively small amounts of salts present in the interstitial water. Consequently, the approach taken for this task was to generate the carbonate form of LHT without addition of any of the other common anions (exclusive of $\mathrm{OH}^{-}$). To accomplish this, a solution was made to which a 4.6 M LiOH solution was introduced (Table 3.3). ${ }^{14}$ 
SRNL-STI-2011-00525

Revision 0

Table 3.3. Solutions Used for Generating Lithium Hydrotalcite

\begin{tabular}{|c|c|c|}
\hline \multirow{2}{*}{ Compound } & \multicolumn{2}{|c|}{ LHT Generation } \\
\cline { 2 - 3 } & Initial Solution (M) & Added Solution (M) \\
\hline \hline $\mathrm{NaOH}$ & 4.50 & 0.00 \\
\hline $\mathrm{NaNO}_{3}$ & 0.00 & 0.00 \\
\hline $\mathrm{NaNO}_{2}$ & 0.00 & 0.00 \\
\hline $\mathrm{Na}_{2} \mathrm{CO}_{3}$ & 0.30 & 0.00 \\
\hline $\mathrm{Na}_{2} \mathrm{C}_{2} \mathrm{O}_{4}$ & 0.00 & 0.00 \\
\hline $\mathrm{Na}_{2} \mathrm{SO}_{4}$ & 0.00 & 0.00 \\
\hline $\mathrm{Al}_{2}\left(\mathrm{NO}_{3}\right)_{3}$ & 0.80 & 0.00 \\
\hline $\mathrm{Na}_{3}\left(\mathrm{PO}_{4}\right)$ & 0.00 & 0.00 \\
\hline $\mathrm{LiOH}^{2}$ & 0.00 & 4.60 \\
\hline
\end{tabular}

In this process, the initial solution $(1000 \mathrm{~g})$ was heated to $90{ }^{\circ} \mathrm{C}$ and then $\mathrm{LiOH}$ solution $(70 \mathrm{~mL})$ was added at a constant rate over a period of $\sim 1$ hour. A white precipitate was evident and the slurry was maintained at $90{ }^{\circ} \mathrm{C}$ for 3 additional hours. After cooling, the slurry was filtered using a Buchner funnel and the product was collected on a cellulose filter (1452-110, \#52) with a particle size cutoff of $\sim 7$ microns. For this initial test, the product was washed only once, transferred to a drying pan and placed in a $60{ }^{\circ} \mathrm{C}$ oven for drying overnight. The powdered product is shown in Figure 3.6. The yield was $46 \mathrm{~g}$ of LHT, $65 \%$ of the potential product based on $\mathrm{Al}$ and Li concentrations. ${ }^{14,19}$

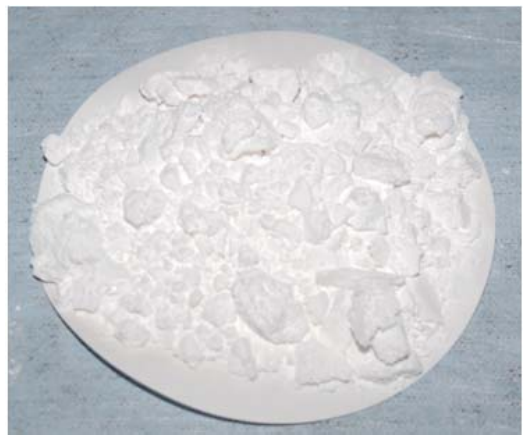

Figure 3.6. Lithium Hydrotalcite product after drying overnight at $60^{\circ} \mathrm{C}$

A small sample of LHT was dissolved in acid at elevated temperatures for determination of the lithium and aluminum concentrations by Inductively Coupled Plasma (ICP) spectroscopy. The molar ratio of $\mathrm{Li} / \mathrm{Al}$ determined by ICP was 0.54 , which can be compared to the expected value of 0.50 . An XRay Diffraction (XRD) measurement revealed a pattern consistent with LHT (Figure 3.7). 
SRNL-STI-2011-00525

Revision 0

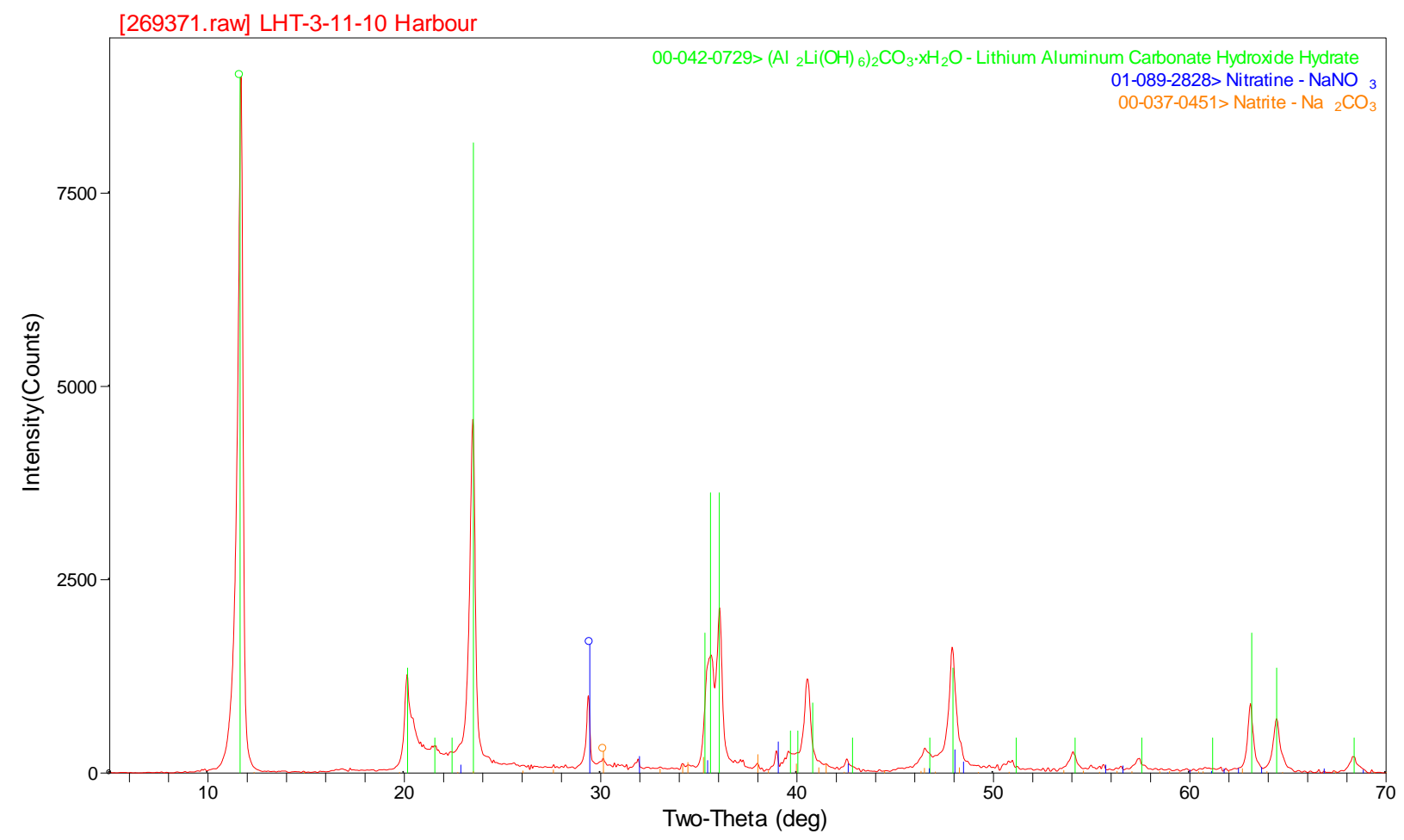

Figure 3.7. XRD pattern for LHT product.

\subsection{Immobilization Waste Forms}

Methods of immobilization that were considered for the two waste streams include low temperature processes (Saltstone/Cast stone and geopolymers), intermediate temperature processes (steam reforming and phosphate glasses) and high temperature processes (borosilicate glass). These immobilization methods and the waste forms they produce will be evaluated for (1) compliance with the Performance Assessment (PA) requirements for disposal at the IDF, (2) waste form volume (waste loading), (3) compatibility with the tank farms and systems, and (4) feasibility of implementation. ${ }^{3}$

\subsection{Iron phosphate Glass Waste Forms}

Immobilization of LAW and HLW waste streams by incorporation into iron phosphate glass waste forms has been considered in general within the DOE Complex and in particular for Hanford. ${ }^{21}$ For this task, an iron phosphate waste form was selected as one of the intermediate temperature waste forms for the LAW streams resulting after CSL and sodium recovery at Hanford.

\subsubsection{Formulation}

The iron phosphate glass formulations were developed by the MO-SCI Corporation. A number of glasses were fabricated and subsequently evaluated using the ASTM C1285 Product Consistency Test (PCT) ${ }^{22}$ for both the quenched and canister-center-line cooled (CCC) glasses. ${ }^{\dagger}$ Candidate glass waste forms for the high aluminate (HAL) and low aluminate (LAL) were selected based on the sodium normalized release

\footnotetext{
${ }^{\dagger}$ As there was no previous basis for the cooling curve profile, the WTP LAW ccc profile was adapted from its original form (WSRC-TR-2003-00536). Instead of starting at $1114^{\circ} \mathrm{C}$, the profile was started at $1000^{\circ} \mathrm{C}$ to account for the lower melting temperature of the phosphate glasses.
} 
rates from the PCT. Compositions of these glasses are provided in Table 4.1. Note that $\mathrm{Al}_{2} \mathrm{O}_{3}, \mathrm{Na}_{2} \mathrm{O}$, $\mathrm{P}_{2} \mathrm{O}_{5}$ and $\mathrm{SO}_{3}$ are solely waste components and the remaining oxides are additives. Although the initial formulations of HAL and LAL were quite different, the resulting candidate compositions are coincidentally very similar for both wastes.

Table 4.1. Target and Measured Glass Compositions for the HAL and LAL Iron Phosphate Glasses (wt\%).

\begin{tabular}{|c|c|c|c|c||}
\hline \multirow{2}{*}{ Oxide } & \multicolumn{2}{|c|}{ MS-HAL-5 } & \multicolumn{2}{c|}{ MS-LAL-7 } \\
\cline { 2 - 5 } & $\begin{array}{c}\text { Target } \\
\text { Composition }\end{array}$ & $\begin{array}{c}\text { Measured } \\
\text { Composition }\end{array}$ & $\begin{array}{c}\text { Target } \\
\text { Composition }\end{array}$ & $\begin{array}{c}\text { Measured } \\
\text { Composition }\end{array}$ \\
\hline \hline $\mathbf{A l}_{2} \mathbf{O}_{3}$ & 13.60 & 13.58 & 13.60 & 13.47 \\
\hline $\mathbf{N a}_{2} \mathbf{O}$ & 20.30 & 19.85 & 20.34 & 19.64 \\
\hline $\mathbf{P}_{\mathbf{2}} \mathbf{O}_{5}$ & 40.04 & 40.19 & 40.04 & 39.62 \\
\hline $\mathbf{S O}_{3}$ & 0.21 & 0.00 & 0.02 & 0.00 \\
\hline $\mathbf{B}_{\mathbf{2}} \mathbf{O}_{3}$ & 2.00 & 2.05 & 2.00 & 5.04 \\
\hline $\mathbf{C a O}$ & 1.50 & 1.48 & 1.50 & 1.42 \\
\hline $\mathbf{F e}_{\mathbf{2}} \mathbf{O}_{3}$ & 10.99 & 10.90 & 11.14 & 11.01 \\
\hline $\mathbf{L a} \mathbf{O}_{3}$ & 1.00 & 0.94 & 1.00 & 0.93 \\
\hline $\mathbf{S i O}_{2}$ & 5.00 & 5.18 & 5.00 & 5.05 \\
\hline $\mathbf{Z n O}$ & 4.36 & 4.59 & 4.36 & 4.58 \\
\hline $\mathbf{Z r O} \mathbf{O}_{2}$ & 1.00 & 0.91 & 1.00 & 0.91 \\
\hline \hline
\end{tabular}

\subsection{2 $\underline{\mathrm{PCT}}$}

The normalized leachate concentrations ${ }^{22}(\mathrm{~g} / \mathrm{L}$ ) for $\mathrm{Na}, \mathrm{Si}$, and $\mathrm{Al}$ for the selected glasses are provided in Table 4.2. The ccc glasses exhibit higher release rates than the quenched glasses, but still meet the acceptance criterion of less than $4 \mathrm{~g} / \mathrm{L}$. A value of $4 \mathrm{~g} / \mathrm{L}$ is equivalent to the specification in the WTP contract, which is expressed in terms of surface area $\left(2 \mathrm{~g} / \mathrm{m}^{2}\right){ }^{21}$ 
SRNL-STI-2011-00525

Revision 0

Table 4.2. Normalized Concentrations for the HAL and LAL Phosphate Glasses

\begin{tabular}{|c|c|c|c|c|c|c|}
\hline \multicolumn{3}{|c|}{ Sample ID } & MS-HAL-5 & $\begin{array}{c}\text { MS-HAL- } \\
\text { 5ссс }\end{array}$ & MS-LAL-7 & $\begin{array}{c}\text { MS-LAL- } \\
\text { 7cсc }\end{array}$ \\
\hline \multirow{8}{*}{ 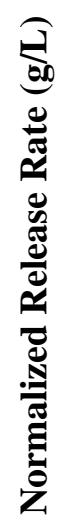 } & Target & \multirow{2}{*}{$\mathrm{Al}$} & 0.63 & 1.24 & 0.62 & 1.24 \\
\hline & Measured & & 0.63 & 1.24 & 0.62 & 1.25 \\
\hline & Target & \multirow{2}{*}{$\mathrm{Na}$} & 1.67 & 1.83 & 1.61 & 1.74 \\
\hline & Measured & & 1.70 & 1.87 & 1.67 & 1.80 \\
\hline & Target & \multirow{2}{*}{$\mathrm{P}$} & 0.89 & 0.82 & 0.88 & 0.81 \\
\hline & Measured & & 0.88 & 0.82 & 0.89 & 0.82 \\
\hline & Target & \multirow{2}{*}{$\mathrm{Si}$} & 0.70 & 1.19 & 0.68 & 1.23 \\
\hline & Measured & & 0.68 & 1.14 & 0.67 & 1.22 \\
\hline
\end{tabular}

Release rates are normalized to both the target and measured compositions.

\subsubsection{Vapor Hydration Test (VHT)}

The corrosion rates of MS-HAL-5ccc and MS-LAL-7ccc were calculated to be $715 \mathrm{~g} / \mathrm{m}^{2}$ and $635 \mathrm{~g} / \mathrm{m}^{2}$, respectively. ${ }^{23}$ Corrosion rates for the quenched versions of these glasses were not performed. Neither of these glasses are acceptable in terms of the $50 \mathrm{~g} / \mathrm{m}^{2}$ limit. ${ }^{21}$ Photos of the tested materials are shown in Figure 4.1.

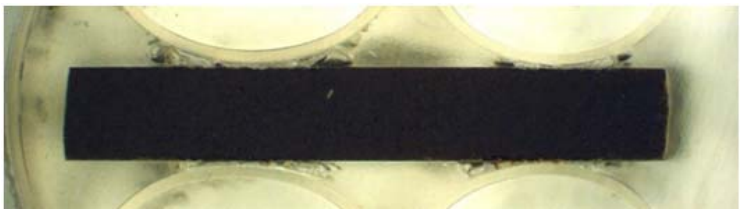

(a) Quenched MS-HAL-5

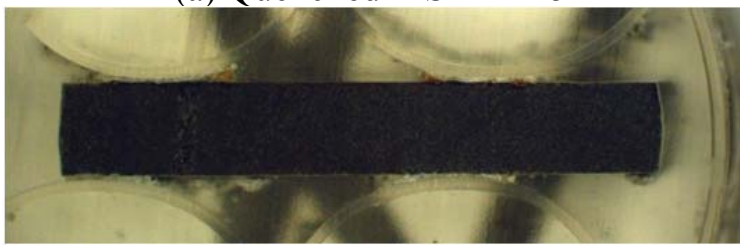

(c) Quenched MS-LAL-7

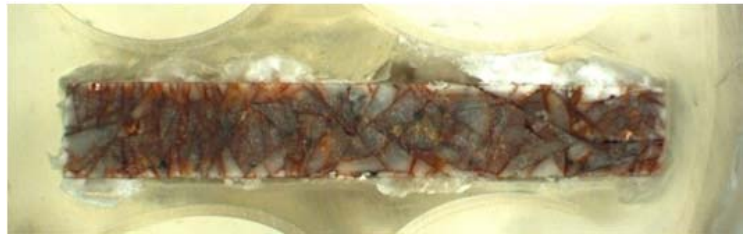

(b) ccc MS-HAL-5

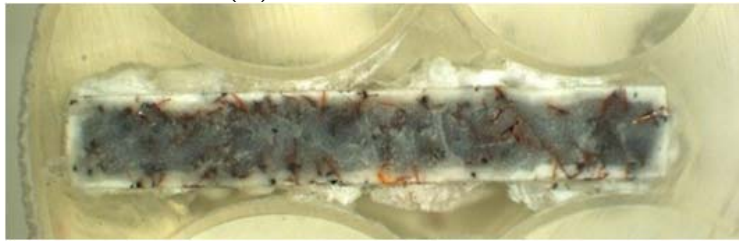

(d) ccc MS-LAL-7

Figure 4.1. Images of the VHT samples for (a) quenched MS-HAL-5, (b) ccc MS-HAL-5, (c) quenched MS-LAL-7 and (d) ccc MS-LAL-7.

\subsection{4 $\underline{\mathrm{XRD}}$}

X-ray Diffraction (XRD) data for these glasses are provided in Figure 4.2 through Figure 4.5. Both of the quenched glasses are amorphous; however, the ccc versions of these glasses do contain various crystalline phases. ${ }^{\ddagger}$ The best matches for the ccc sample of MS-LAL-7 include sodium iron phosphate and a phase

¿ Difficulties were encountered during analysis of the XRD spectra. Many of the crystals listed are best matches; however, they are not exact matches to the peaks of the LAL and HAL samples. In some cases, not all of the peaks could be identified. 
SRNL-STI-2011-00525

Revision 0

similar to sodium praseodymium phosphate ${ }^{\S}$, while MS-HAL-5ccc may contain sodium iron phosphate, hematite and a phase similar to sodium lanthanum phosphate.

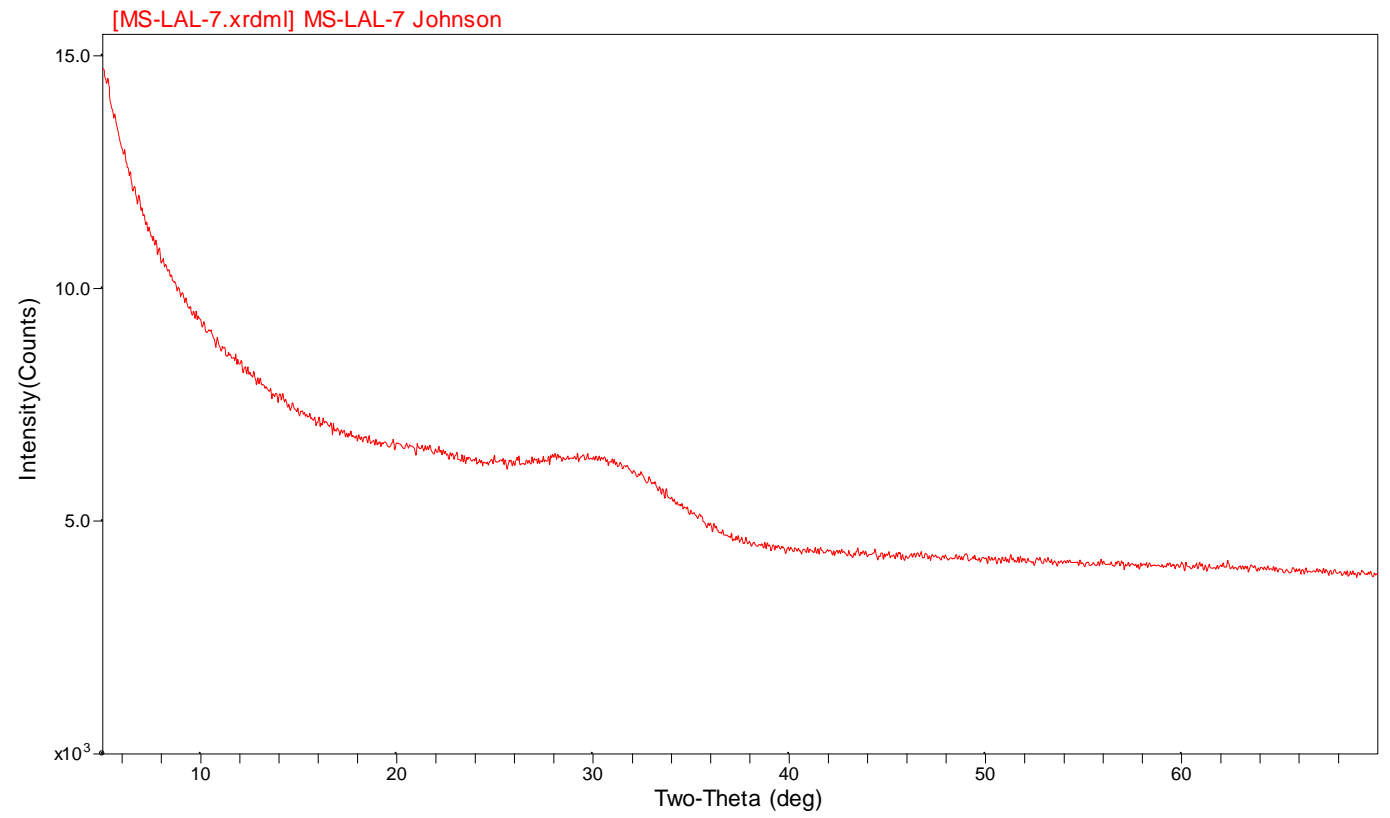

Figure 4.2. XRD data for quenched MS-LAL-7 glass typical of an amorphous glass.

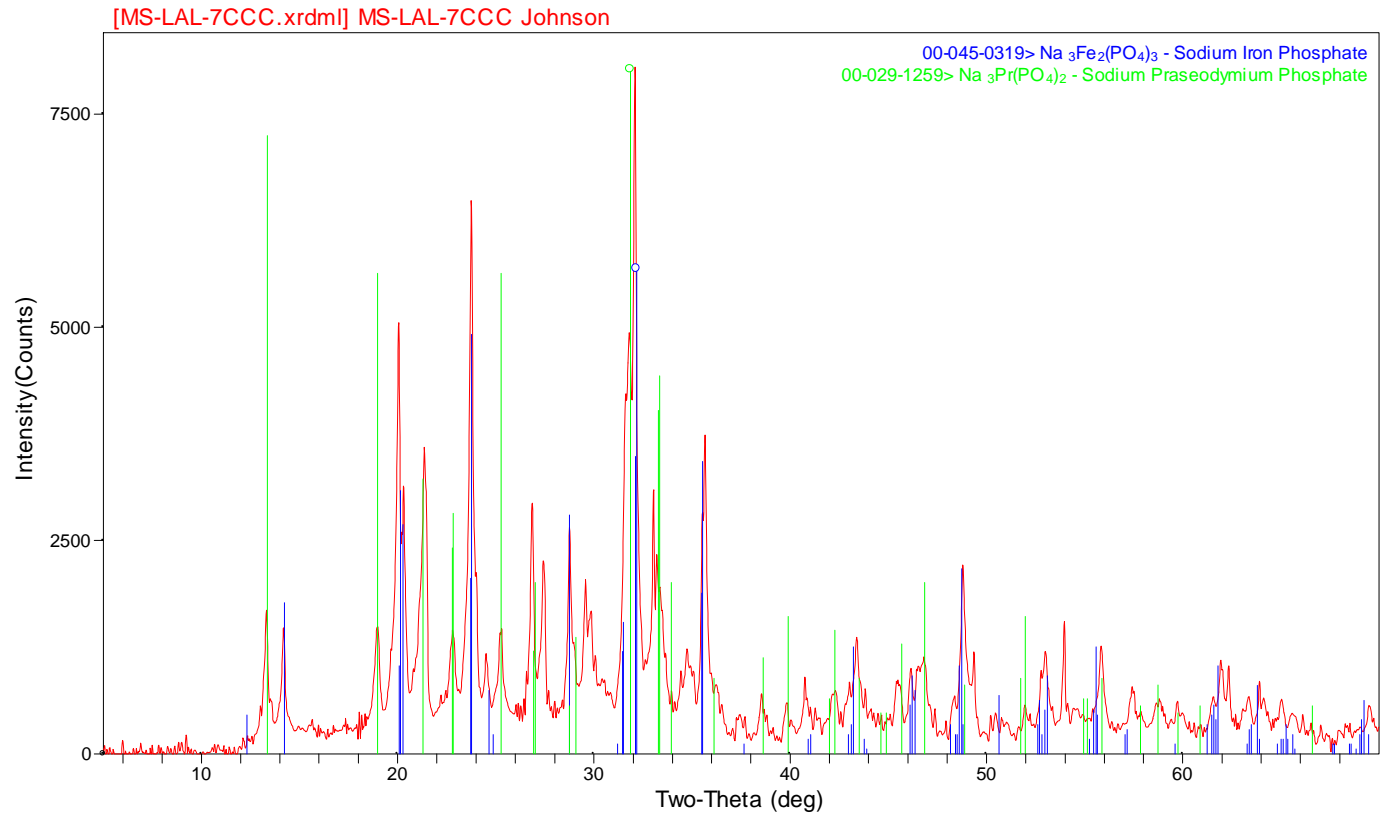

Figure 4.3. XRD data for ccc MS-LAL-7 glass showing at least two crystallites within the glass matrix.

\footnotetext{
${ }^{\S}$ Praseodymium is not present in these glasses, but it is likely that there is some type of substitution occurring for a
} similar element. 
SRNL-STI-2011-00525

Revision 0

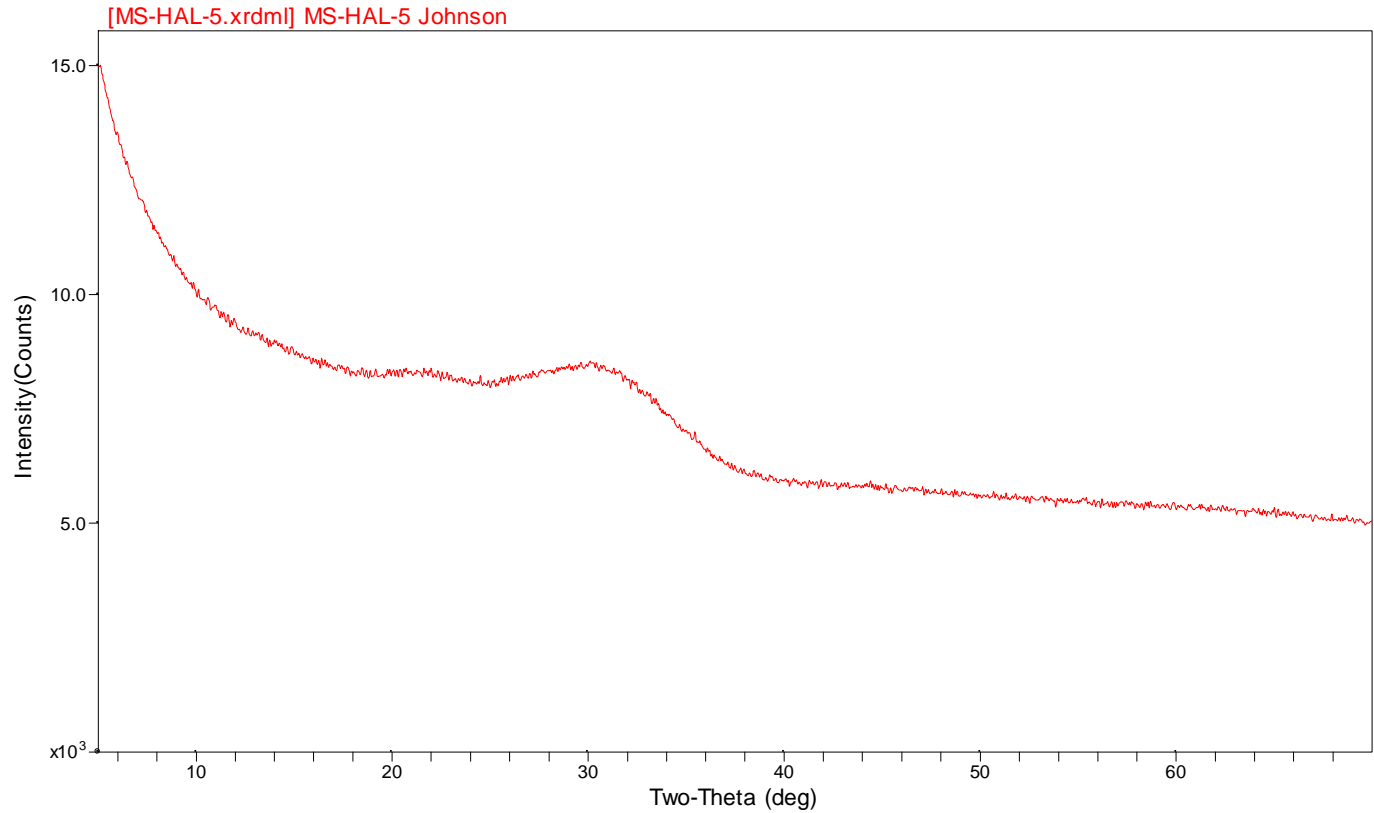

Figure 4.4. XRD data for quenched MS-HAL-5 glass typical of an amorphous glass.

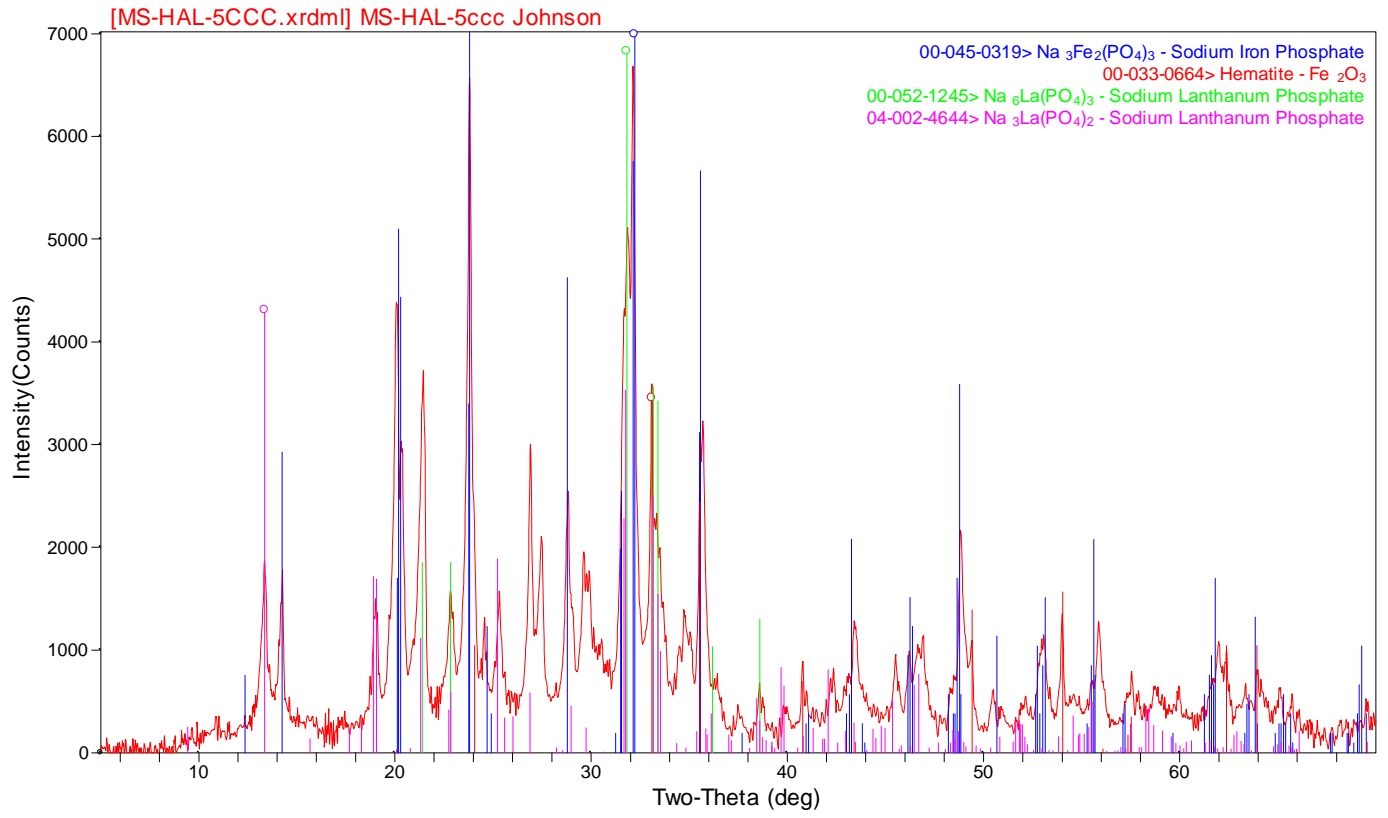

Figure 4.5. XRD data for ccc MS-HAL-5 glass showing approximately four crystalline phases within the glass matrix. 


\subsubsection{Volume and Mass Factors}

The volume and mass of the waste form produced for each liter of LAW waste stream is provided in Table 4.3. The volume of waste is reduced by a factor of 0.12 . The total mass is reduced by a factor of 0.32 . All of the sodium was introduced in the waste streams such that the waste loading of $\mathrm{Na}_{2} \mathrm{O}$ on a mass basis was $20.3 \%$.

These initial formulations did not include Re and I. Additional experimental work will be required to include Re and I into the glass formulations with these elements to simulate I-129 and Tc-99 in the waste stream. The glasses prepared with the surrogates will then be subjected to the same analysis and leach testing performed in this study.

Table 4.3. Volume and Mass of Waste Form Produced per Liter of LAW with Phosphate Glass

\begin{tabular}{|c|c|c|c|}
\hline Volume of Waste & Volume of Glass & \multirow{2}{*}{ Volume Factor } & \\
\hline \multicolumn{2}{|c|}{$(\mathrm{L})$} & & \\
\hline 1.0 & 0.12 & 0.12 & \\
\hline Mass of Waste & Mass of Glass & \multirow{2}{*}{ Mass Factor } & $\% \mathrm{Na}_{2} \mathrm{O}$ \\
\hline \multicolumn{2}{|c|}{ (g) } & & Mass Basis \\
\hline$\sim 1100$ & 354 & 0.32 & 20.3 \\
\hline
\end{tabular}

\subsection{Borosilicate Glass Waste Forms}

Another immobilization option is to vitrify Hanford LAW and HLW waste streams as borosilicate glass. The Hanford LAL composition is different from the compositions of the waste streams identified for this task and are therefore outside the envelope of current formulations for LAL. This also applies to the borosilicate glass formulations developed as part of the bulk vitrification option. Therefore, new formulations were developed for these waste streams that provide the baseline case through which to compare the results on the other waste forms tested in this program.

\subsubsection{Formulation}

In previous work, glasses were fabricated and subsequently tested and evaluated by PCT leaching for both the quenched and CCC glasses. ${ }^{* *}$ Glass compositions for the HAL and LAL wastes were selected based normalized release rates determined from the PCT. Target and measured compositions are provided in Table 4.4 .

\footnotetext{
${ }^{* *}$ As stated in the previous section, there was no previous basis for the cooling curve profile, so the WTP LAW ccc profile was adapted from its original form (WSRC-TR-2003-00536). Instead of starting at $1114{ }^{\circ} \mathrm{C}$, the profile was started at $1200{ }^{\circ} \mathrm{C}$ to account for the higher melting temperature of the borosilicate glasses. The samples were cooled at a rate of $10^{\circ} \mathrm{C} / \mathrm{min}$ to $1114^{\circ} \mathrm{C}$, at which point the original profile was followed.
} 
SRNL-STI-2011-00525

Revision 0

Table 4.4. Target and Measured Glass Compositions for the HAL and LAL Borosilicate Glasses (wt\%)

\begin{tabular}{|c|c|c|c|c||}
\hline \multirow{2}{*}{ Oxide } & \multicolumn{2}{|c|}{ FCJHAL1 } & \multicolumn{2}{c|}{ FCJLAL3 } \\
\cline { 2 - 5 } & $\begin{array}{c}\text { Target } \\
\text { Composition }\end{array}$ & $\begin{array}{c}\text { Measured } \\
\text { Composition }\end{array}$ & $\begin{array}{c}\text { Target } \\
\text { Composition }\end{array}$ & $\begin{array}{c}\text { Measured } \\
\text { Composition }\end{array}$ \\
\hline \hline $\mathbf{A l}_{2} \mathbf{O}_{3}$ & 6.53 & 6.45 & 6.60 & 6.51 \\
\hline $\mathbf{N a}_{2} \mathbf{O}$ & 23.16 & 22.07 & 25.33 & 24.23 \\
\hline $\mathbf{P}_{\mathbf{2}} \mathbf{O}_{5}$ & 0.08 & 0.00 & 0.05 & 0.00 \\
\hline $\mathbf{S O}_{3}$ & 0.24 & 0.25 & 0.02 & 0.00 \\
\hline $\mathbf{B}_{\mathbf{2}} \mathbf{O}_{3}$ & 9.00 & 9.19 & 8.00 & 8.45 \\
\hline $\mathbf{C a O}$ & 2.00 & 2.00 & 2.00 & 2.02 \\
\hline $\mathbf{F e}_{2} \mathbf{O}_{3}$ & 6.00 & 5.53 & 5.50 & 5.13 \\
\hline $\mathbf{M g O}$ & 1.60 & 1.42 & 1.60 & 1.43 \\
\hline $\mathbf{S i O}_{2}$ & 45.00 & 43.44 & 44.50 & 43.34 \\
\hline $\mathbf{T i O}_{2}$ & 1.01 & 0.95 & 1.01 & 0.96 \\
\hline $\mathbf{Z n O}$ & 2.00 & 1.80 & 2.00 & 1.85 \\
\hline $\mathbf{Z r O} \mathbf{O}_{2}$ & 3.38 & 3.06 & 3.39 & 3.15 \\
\hline \hline
\end{tabular}

\subsection{2 $\underline{\mathrm{PCT}}$}

The normalized leachate concentrations in $\mathrm{g} / \mathrm{L}$ for $\mathrm{Na}, \mathrm{Si}$, and $\mathrm{Al}$ for the selected glasses are provided in Table 4.5. The ccc glasses show lower release rates for $\mathrm{B}$ and $\mathrm{Na}$ than the quenched glasses and all glasses meet the acceptance criterion of $<4 \mathrm{~g} / \mathrm{L}$. A value of $<4 \mathrm{~g} / \mathrm{L}$ is equivalent to the specification in the Contract which is expressed in terms of surface area $\left(<2 \mathrm{~g} / \mathrm{m}^{2}\right){ }^{21}$

Table 4.5. Normalized Concentrations for the HAL and LAL Borosilicate Glasses

\begin{tabular}{|c|c|c|c|c|c|c|}
\hline \multicolumn{3}{|c|}{ Sample ID } & FCJHAL-1 & FCJHAL-1ccc & FCJLAL-3 & $\begin{array}{c}\text { FCJLAL- } \\
\text { Зccc }\end{array}$ \\
\hline \multirow{6}{*}{ 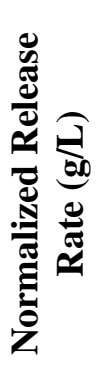 } & Target & \multirow{2}{*}{ B } & 0.94 & 0.78 & 1.07 & 0.95 \\
\hline & Measured & & 0.92 & 0.77 & 1.01 & 0.89 \\
\hline & Target & \multirow{2}{*}{$\mathrm{Na}$} & 0.95 & 0.87 & 1.19 & 1.08 \\
\hline & Measured & & 1.00 & 0.92 & 1.24 & 1.13 \\
\hline & Target & \multirow{2}{*}{$\mathrm{Si}$} & 0.39 & 0.37 & 0.48 & 0.45 \\
\hline & Measured & & 0.40 & 0.39 & 0.49 & 0.47 \\
\hline
\end{tabular}

Release rates are normalized to both the target and measured compositions. 


\subsubsection{Vapor Hydration Tests}

VHT $^{23}$ results are presented in Table 4.6. Because the samples cracked, there is no method for determining a corrosion rate. Only the ccc sample of FCJHAL-1 is acceptable with respect to the limit of $50 \mathrm{~g} / \mathrm{m}^{2} .{ }^{21}$ Photos of the tested materials are shown in Figure 4.6.

Table 4.6. Summary of VHT Results for HAL and LAL Borosilicate Glasses

\begin{tabular}{|c|c|c||}
\hline Sample ID & Corrosion & Notes \\
\hline \hline FCJHAL-1 & $65 \mathrm{~g} / \mathrm{m}^{2}$ & \multicolumn{2}{||}{ NA } \\
\cline { 1 - 2 } FCJHAL-1ccc & $27 \mathrm{~g} / \mathrm{m}^{2}$ & \\
\cline { 1 - 2 } FCJLAL-3 & $\sim 50 \%$ & Sample expanded. Some cracks go all the way through sample. \\
\hline FCJLAL-3ccc & $\sim 50 \%$ & Sample expanded. Some cracks go all the way through sample. \\
\hline
\end{tabular}

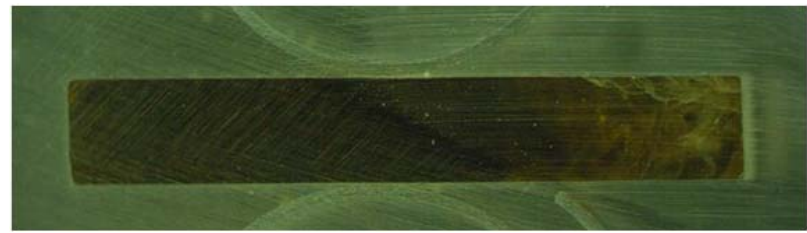

(a) Quenched FCJHAL-1

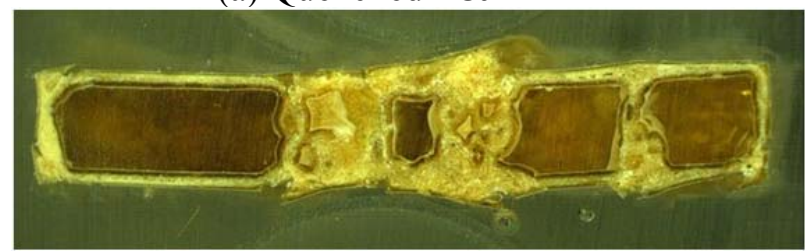

(c) Quenched FCJLAL-3

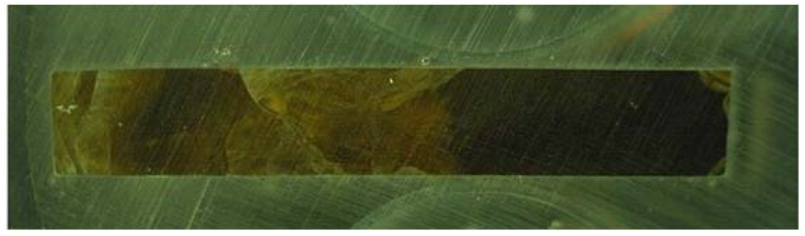

(b) ccc FCJHAL-1

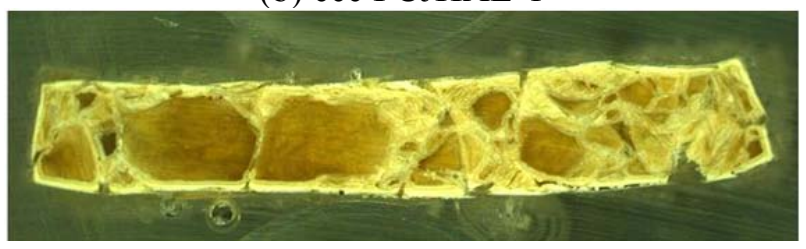

(d) $\operatorname{ccc}$ FCJLAL-3

Figure 4.6. Images of the VHT samples for (a) quenched FCJHAL-1, (b) ccc FCJHAL-1, (c) quenched FCJLAL-3 and (d) ccc FCJLAL-3.

\subsubsection{X-ray Diffraction}

XRD data for these glasses are provided in Figure 4.7. Both the quenched and ccc versions of the HAL and LAL glasses are amorphous. 
SRNL-STI-2011-00525

Revision 0

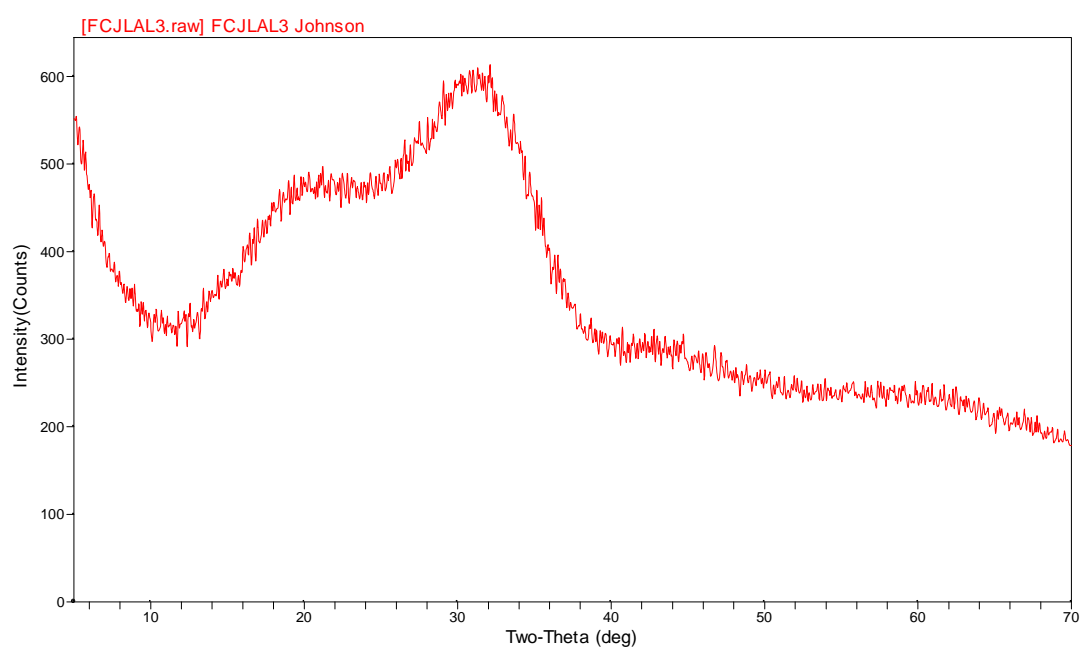

(a) Quenched FCJLAL-3

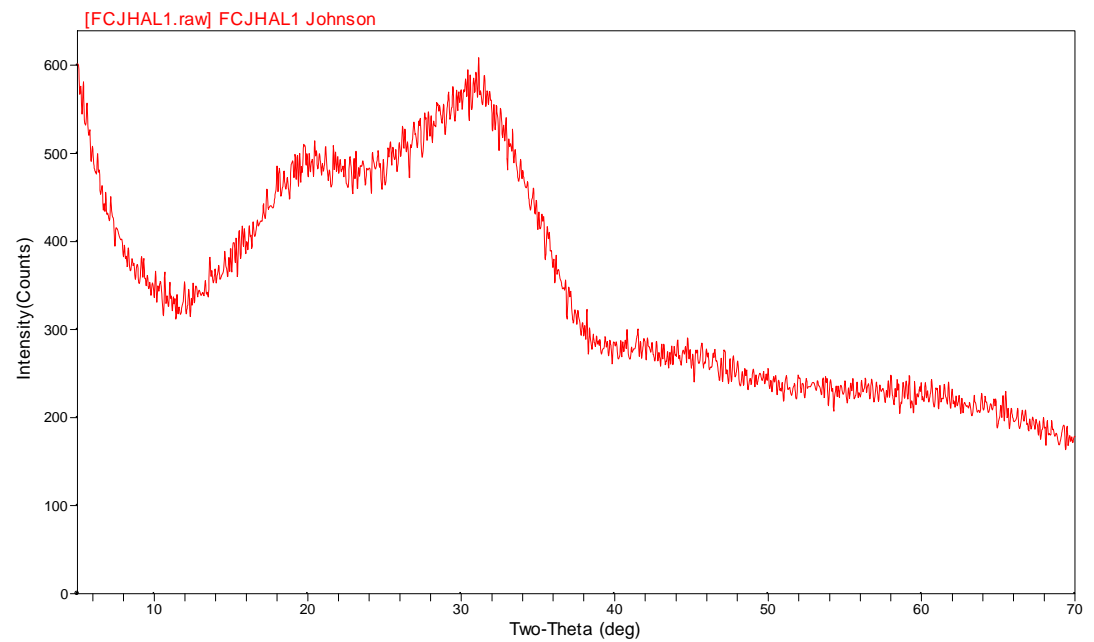

(c) Quenched FCJHAL-1

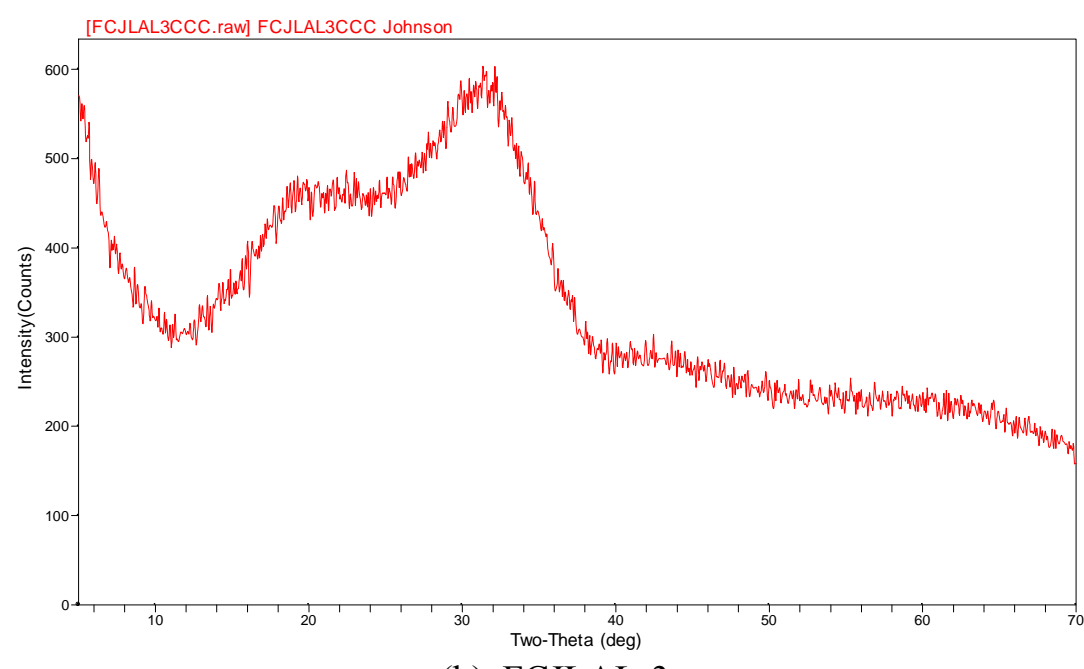

(b) FCJLAL-3ccc

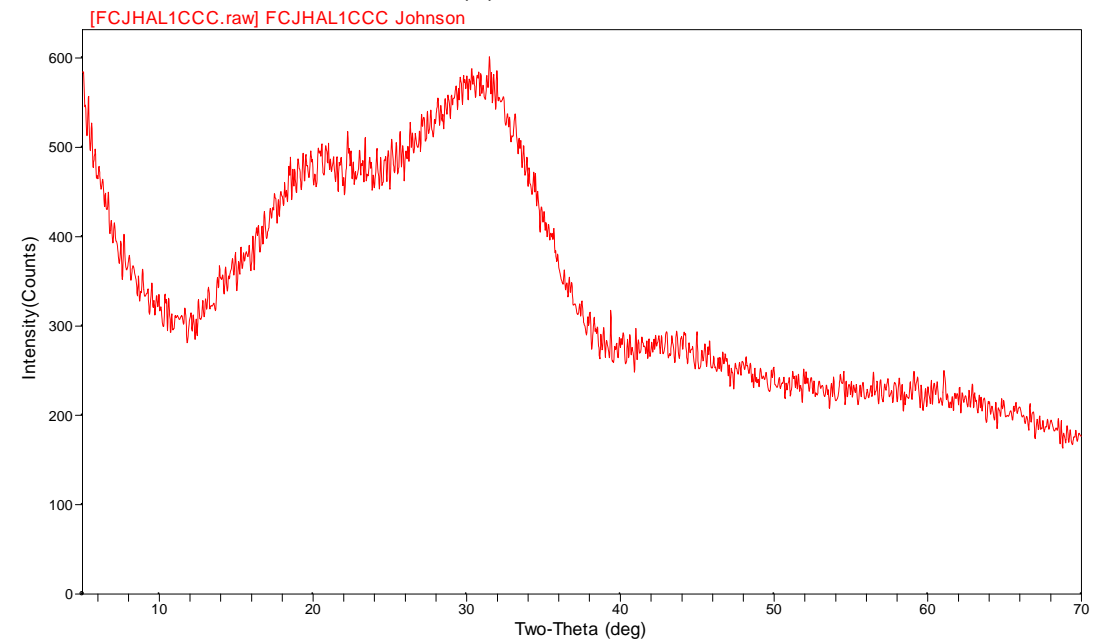

(d) FCJHAL- $1 \mathrm{ccc}$

Figure 4.7. XRD spectra of the (a) quenched FCJLAL-3 glass, (b) FCJLAL-3ccc glass, (c) quenched FCJHAL-1 glass and (d) FCJHAL-1ccc. 


\subsubsection{Volume and Mass Factors}

The volume and mass of the waste form produced for each liter of LAW is provided in Table 4.7. The volume of waste is reduced by a factor of 0.10 . The total mass is reduced by a factor of 0.26 . All of the sodium was introduced in the waste streams such that the waste loading of $\mathrm{Na}_{2} \mathrm{O}$ on a mass basis was 25.4 $\%$.

Table 4.7. Volume and Mass of Waste Form Produced per Liter of LAW with Borosilicate Glass

\begin{tabular}{|c|c|c|c|}
\hline Volume of Waste & Volume of Glass & \multirow{2}{*}{ Volume Factor } & \\
\hline \multicolumn{2}{|c|}{$(\mathrm{L})$} & & \\
\hline 1.0 & 0.10 & 0.10 & \\
\hline Mass of Waste & Mass of Glass & \multirow{2}{*}{ Mass Factor } & $\% \mathrm{Na}_{2} \mathrm{O}$ \\
\hline \multicolumn{2}{|c|}{ (g) } & & Mass Basis \\
\hline$\sim 1100$ & 282 & 0.26 & 25.4 \\
\hline
\end{tabular}

\subsubsection{Doped Glasses}

Glasses were also batched for FCJLAL-3 and FCJHAL-1 compositions with 0.57 wt \% I and 0.2 wt \% $\mathrm{Re}_{2} \mathrm{O}_{7}$ added to simulate I-129 and Tc-99 in the waste stream, which are denoted as FCJLAL-3D and FCJHAL1-D. These two radionuclides are important to the Performance Assessment (PA) for the IDF at Hanford. A comparison of the target and measured compositions are provided in Table 4.8. A batching error occurred for FCJHAL-1D and no $\mathrm{ZrO}_{2}$ was added to the glass. In general, the rest of the measured main components of the glass are consistent with the target values. The dopant concentrations are low; however, the analytical methods used for evaluating those constituents are being evaluated. It is possible that the dopants were vaporized during melting or during preparation of the samples for analysis.

The normalized PCT release rates are provided in Table 4.9. All of the values are acceptable with respect to the $4 \mathrm{~g} / \mathrm{L}$ limit specified in the WTP contract. Leaching results for I and Re for the LAL and HAL glasses are provided in Table 4.10 .

VHT results are presented in Table 4.11. There is no method for determining a corrosion rate since the samples were cracked. Thus, none of the samples exhibited corrosion rates that were less than the limit of $50 \mathrm{~g} / \mathrm{m}^{2}$ per day. Photos of the tested materials are shown in Figure 4.8. The anomalous behavior exhibited by the FCJHAL1D samples can be attributed to the lack of $\mathrm{ZrO}_{2}$ in the batched material. ${ }^{\dagger \dagger}$

\footnotetext{
${ }^{\dagger \dagger}$ Increased concentrations of $\mathrm{ZrO}_{2}$ have been shown to significantly improve the VHT corrosion rate.
} 
SRNL-STI-2011-00525

Revision 0

Table 4.8. Target and Measured Compositions for the Doped HAL and LAL Borosilicate Glasses (wt \%)

\begin{tabular}{|c|c|c|c|c|}
\hline \multirow[b]{2}{*}{ Oxide } & \multicolumn{2}{|c|}{ FCJHAL-1D } & \multicolumn{2}{|c|}{ FCJLAL-3D } \\
\hline & $\begin{array}{c}\text { Target } \\
\text { Composition }\end{array}$ & $\begin{array}{c}\text { Measured } \\
\text { Composition }\end{array}$ & $\begin{array}{c}\text { Target } \\
\text { Composition }\end{array}$ & $\begin{array}{c}\text { Measured } \\
\text { Composition }\end{array}$ \\
\hline $\mathbf{A l}_{2} \mathbf{O}_{3}$ & 6.53 & 6.76 & 6.60 & 6.70 \\
\hline $\mathrm{Na}_{2} \mathrm{O}$ & 23.16 & 23.15 & 25.33 & 25.31 \\
\hline $\mathbf{P}_{2} \mathbf{O}_{5}$ & 0.08 & 0.00 & 0.05 & 0.00 \\
\hline $\mathrm{SO}_{3}$ & 0.24 & 0.26 & 0.02 & 0.00 \\
\hline $\mathbf{B}_{2} \mathbf{O}_{3}$ & 8.90 & 9.26 & 7.91 & 7.79 \\
\hline $\mathrm{CaO}$ & 1.98 & 2.12 & 1.98 & 2.18 \\
\hline $\mathrm{Fe}_{2} \mathrm{O}_{3}$ & 5.93 & 6.03 & 5.44 & 5.23 \\
\hline MgO & 1.58 & 1.52 & 1.58 & 1.46 \\
\hline $\mathrm{SiO}_{2}$ & 44.50 & 46.12 & 44.00 & 45.05 \\
\hline $\mathrm{TiO}_{2}$ & 1.01 & 0.98 & 1.00 & 0.95 \\
\hline $\mathrm{ZnO}$ & 1.98 & 1.96 & 1.98 & 1.95 \\
\hline $\mathrm{ZrO}_{2}$ & 3.34 & 0.00 & 3.35 & 3.10 \\
\hline \multicolumn{5}{|c|}{ Dopants } \\
\hline $\mathbf{R e}_{2} \mathbf{O}_{7}$ & 0.20 & 0.14 & 0.20 & 0.14 \\
\hline I & 0.57 & 0.18 & 0.57 & 0.24 \\
\hline
\end{tabular}

Table 4.9. Normalized Concentrations for the Doped HAL and LAL Borosilicate Glasses

\begin{tabular}{|c|c|c|c|c|c|c|}
\hline \multicolumn{3}{|c|}{ Sample ID } & FCJHAL-1D & $\begin{array}{c}\text { FCJHAL- } \\
\text { 1Dccc }\end{array}$ & FCJLAL-3D & $\begin{array}{c}\text { FCJLAL- } \\
\text { 3Dccc }\end{array}$ \\
\hline \multirow{6}{*}{ 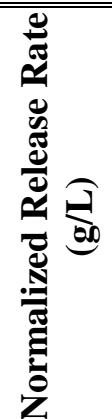 } & Target & \multirow{2}{*}{ B } & 1.81 & 1.31 & 1.29 & 1.21 \\
\hline & Measured & & 1.74 & 1.26 & 1.31 & 1.23 \\
\hline & Target & \multirow{2}{*}{$\mathrm{Na}$} & 1.59 & 1.25 & 1.44 & 1.33 \\
\hline & Measured & & 1.59 & 1.25 & 1.44 & 1.33 \\
\hline & Target & \multirow{2}{*}{$\mathrm{Si}$} & 0.66 & 0.58 & 0.51 & 0.53 \\
\hline & Measured & & 0.64 & 0.56 & 0.50 & 0.52 \\
\hline
\end{tabular}


Table 4.10. Re and I Leachate Results

\begin{tabular}{|c|c|c|}
\hline \multirow{2}{*}{ Sample ID } & Re & \multicolumn{1}{|c|}{ I } \\
\cline { 2 - 3 } & \multicolumn{2}{|c|}{ (ppm) } \\
\hline \hline FCJHAL1D & 1.19 & 0.65 \\
\hline FCJHAL1Dccc & 0.68 & 0.17 \\
\hline FCJLAL3D & 1.03 & 2.08 \\
\hline FCJLAL3Dccc & 0.88 & 0.99 \\
\hline
\end{tabular}

Table 4.11. Summary of Corrosion Results for the Doped HAL and LAL Borosilicate Glasses

\begin{tabular}{|c|c|c||}
\hline Sample ID & Corrosion & Notes \\
\hline \hline FCJHAL-1D & $100 \%$ & Center of sample is void. \\
\hline $\begin{array}{c}\text { FCJHAL- } \\
\text { 1Dcc }\end{array}$ & $100 \%$ & Center of sample is void. \\
\hline $\begin{array}{c}\text { FCJLAL-3D } \\
\text { FCJLAL- } \\
\text { 3Dccc }\end{array}$ & $\sim 90 \%$ & Sample expanded. Some cracks go all the way through sample. \\
\hline
\end{tabular}

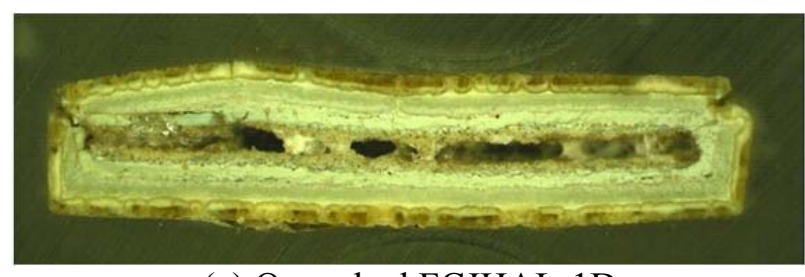

(a) Quenched FCJHAL-1D

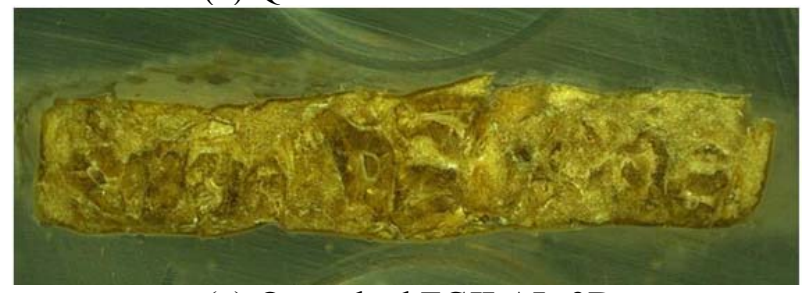

(c) Quenched FCJLAL-3D

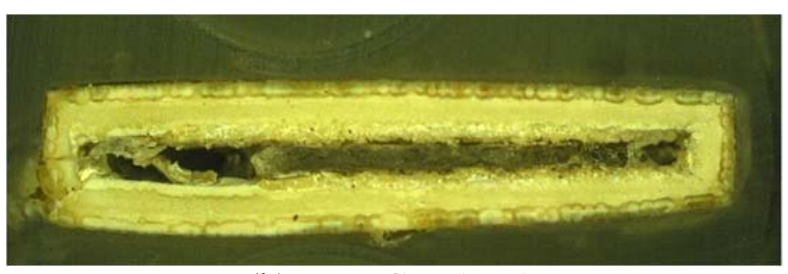

(b) ccc FCJHAL-1D

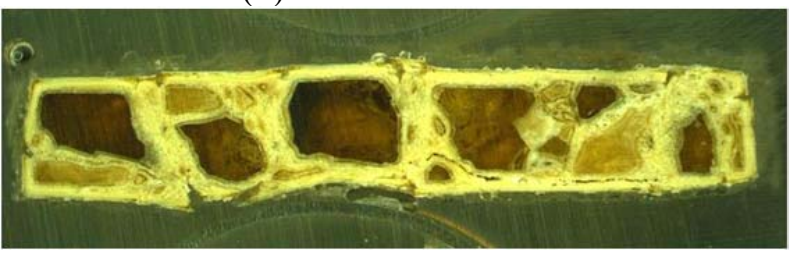

(d) ccc FCJLAL-3D

Figure 4.8. Images of the VHT samples for (a) quenched FCJHAL-1D, (b) ccc FCJHAL-1D, (c) quenched FCJLAL-3D and (d) cCC FCJLAL-3D.

\subsection{Steam Reformed Waste Form}

One immobilization option for the Hanford LAW waste stream after sodium recovery is Fluidized Bed Steam Reforming (FBSR). This method is already under evaluation for Hanford LAW through EM-31. Due to process scale, the steam reformed waste form was prepared using the SRNL Bench Scale Steam Reformer (BSR). 
FBSR is being considered as an alternative technology for the immobilization of a wide variety of aqueous high sodium containing radioactive wastes at various DOE facilities. ${ }^{24}$ The addition of clay, charcoal, and a catalyst as co-reactants converts aqueous LAW to a granular or "mineralized" waste form while converting organic components to $\mathrm{CO}_{2}$ and steam through pyrolysis, and nitrate/nitrite components to $\mathrm{N}_{2} \cdot{ }^{24}$ The waste form produced is a multiphase mineral assemblage of Na-Al-Si feldspathoid minerals with cage-like structures that immobilize radionuclides. ${ }^{24}$ If carbon is the only additive to the waste stream, then a solid carbonate product will be formed. This product is water soluble making it easy for further processing such as to a slurry fed glass melter. If sodium-aluminosilicates are added as well, then a final waste form can be produced for storage in drums. This form can also be captured in a cementitious monolith. $^{25}$

\subsubsection{Formulation}

Formulations for the steam reformed product utilized both the low and high aluminate waste streams. The projected BSR waste form composition ${ }^{26}$ for each waste stream is shown on the $\mathrm{Na}_{2} \mathrm{O}-\mathrm{SiO}_{2}-\mathrm{Al}_{2} \mathrm{O}_{3}$ ternary diagram (Figure 4.9). The projected formulation is the AN-107 FBSR product shown by the blue square on the ternary diagram. Optikast and Sagger mixed clays were used based on the amount and composition of the simulant used in the formulation according to the algorithm ${ }^{26}$ used to obtain the desired mineral product. Coal is added as a reductant to destroy the nitrates present in the salt solution waste stream. In addition, the coal serves as the energy source for the exothermic reaction. 
SRNL-STI-2011-00525

Revision 0

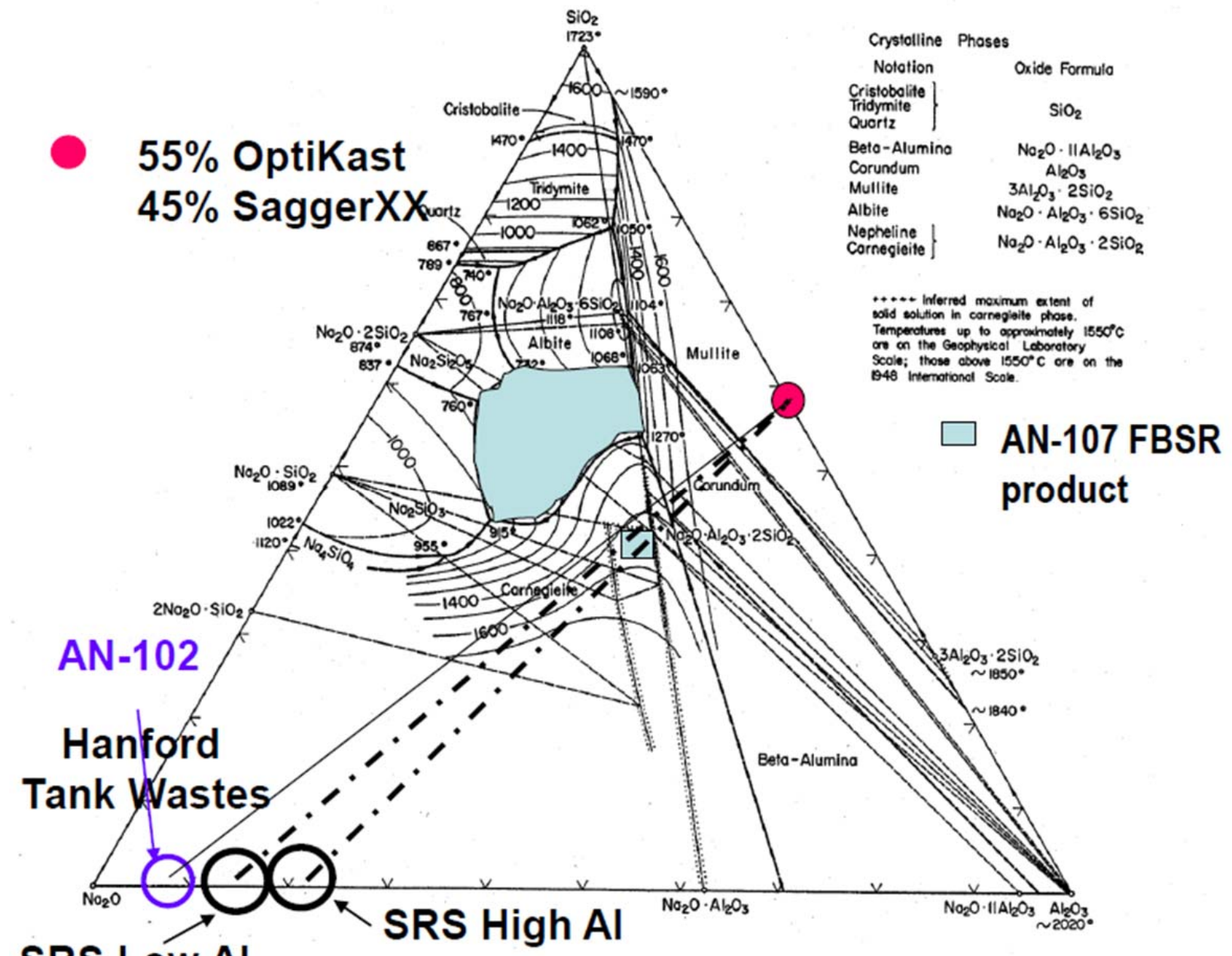

\section{SRS LoW Al}

Figure 4.9. $\mathrm{Na}_{2} \mathrm{O}-\mathrm{SiO}_{2}-\mathrm{Al}_{2} \mathrm{O}_{3}$ ternary diagram showing the projected steam reformed waste form composition (blue square) for high and low aluminate waste streams.

\subsubsection{BSR Equipment Setup}

The BSR designed at SRNL is a two-stage unit used to produce the same mineralized products and gases as the FBSR (Figure 4.10). Unlike the FBSR, the BSR is not fluidized since it was designed to fit in the shielded cells and there is not enough height in the cells to allow for product disengagement. Steam does flow though the product freely. Only the first stage or De-nitration Mineralization Reactor (DMR) was used for this study. ${ }^{27}$ 
SRNL-STI-2011-00525

Revision 0

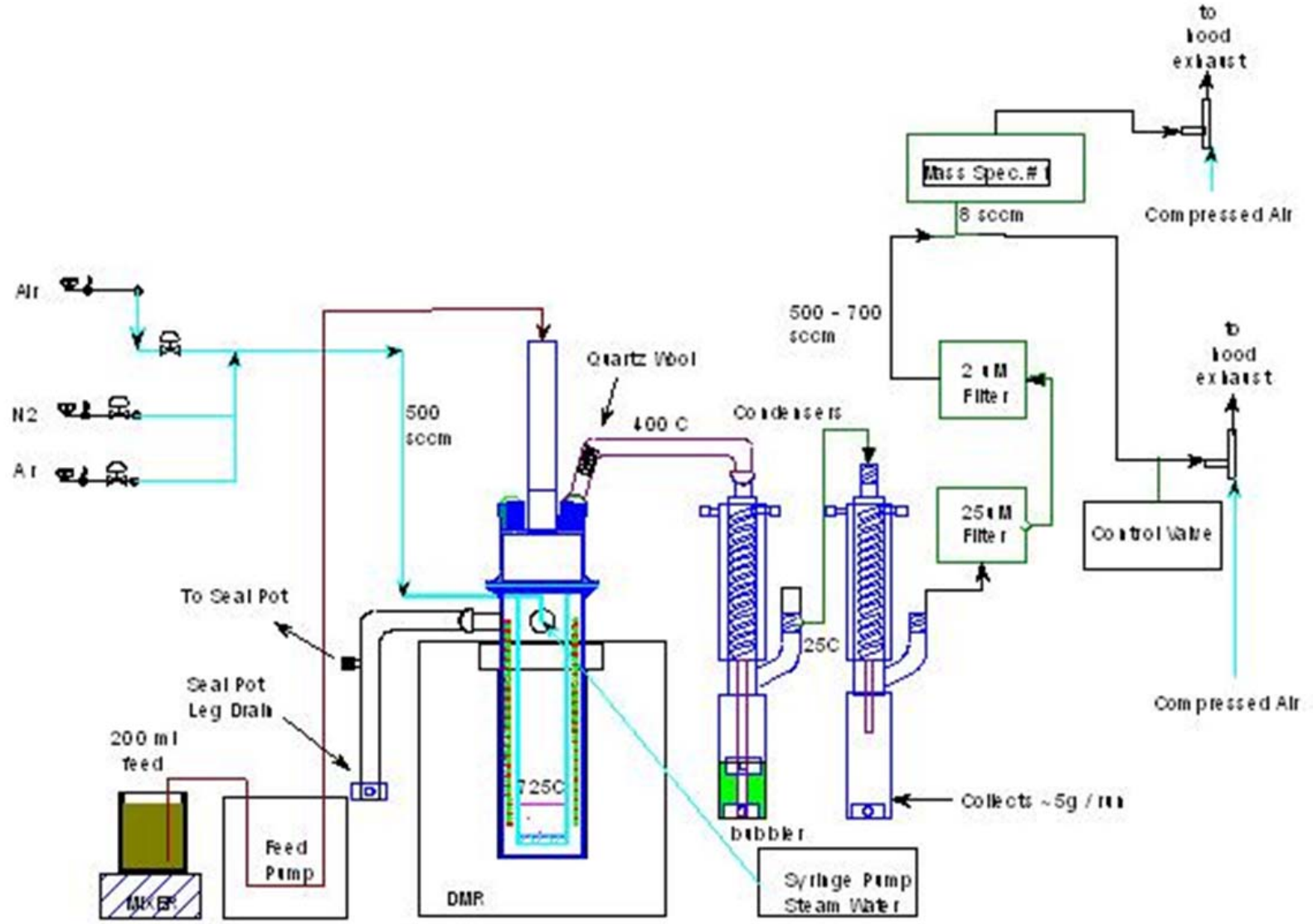

Figure 4.10.Schematic of the Bench-Scale Steam Reformer.

The SRNL BSR DMR inner reaction chamber dimensions are $70 \mathrm{~mm}$ ID x $385 \mathrm{~mm}$ tall with a porous bottom. The bottom $50 \mathrm{~mm}$ ( 2 inches) is filled with yttria-stabilized zirconia beads Figure 4.11 . The zirconia beads were heavy enough not to be suspended by the gases and steam flowing up past them, acted as a base for the product to form on, allowed easy removal of the product from the reaction chamber, allowed easy separation of the product from the beads for analytic purposes, and provided a heat transfer medium for the gases that flow up through them. ${ }^{25,27}$

The DMR outer chamber dimensions are $120 \mathrm{~mm}$ ID x $400 \mathrm{~mm}$ tall and provides connections for the outer chamber pressure relief and measurement line, and each of the two 20 foot coils which are housed between the DMR inner reaction chamber and the outer chamber. The outer chamber is sealed by the top flange of the inner chamber, and thus has a pressure relief line going to a seal pot which relieves at about 15 inwc. Water, $\mathrm{N}_{2}$, Ar, and air enter the DMR via the coils which are between the inner and outer walls of the DMR and are converted to superheated steam and hot gases with heat provided by the furnace that contained the DMR. The steam and gases exit the coils and flow through the bottom of the DMR inner reaction chamber, the zirconia beads, the product, and finally flow out through the top of the DMR to the DMR condenser. The $\mathrm{N}_{2}$, Ar, and Air total flow rates were held at a constant to improve process control. $^{25,27}$ 


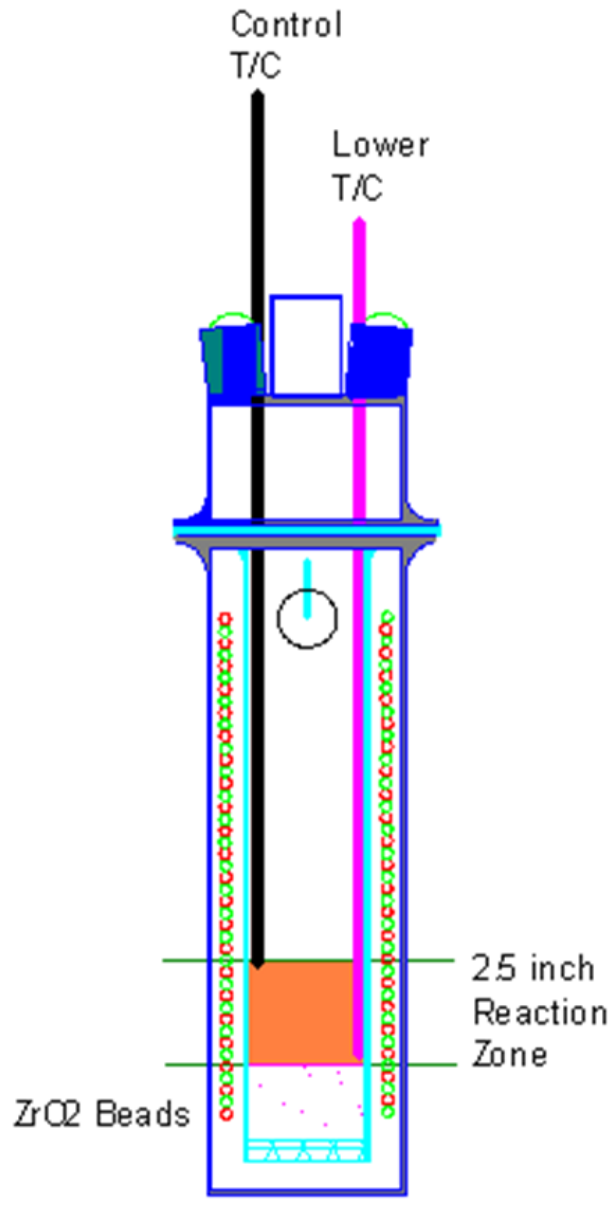

Figure 4.11. DMR chamber showing the 2.5 inch reaction zone. ${ }^{27}$

During a typical run, the feed slurry was kept agitated with a stir bar mixer while a peristaltic pump fed the slurry through the center feed port in the lid of the DMR. A mineralized product formed in the DMR (Figure 4.11) in the presence of superheated steam, clay, and carbon and the off-gases flow toward the DMR condenser.

\subsubsection{BSR Processing Conditions}

The processing parameters used in the BSR are scaled from the actual FBSR parameters (Table 4.12). The first two data columns in Table 4.12 show the parameters in different units. The feed rate of $\sim 1$ $\mathrm{ml} / \mathrm{min}$ for the DMR was established based on the equipment's ability to pump the clay/coal/waste slurries and the DMR's ability to convert it to mineral product without the presence of unreacted product. Coal was fed at a rate of $0.20 \mathrm{~g} / \mathrm{min}$, which is less than the $0.35 \mathrm{~g} / \mathrm{min}$ scaled equivalent because the BSR does not use coal to auto-catalytically heat the DMR and excess unreacted coal in the product is undesirable. Total gas flow was limited based on observed solids carry over. The DMR temperatures were the same as in the engineering and pilot scale FBSR. The BSR ran at a slightly negative pressure where the FBSR runs at a slightly positive pressure. ${ }^{27}$ 
SRNL-STI-2011-00525

Revision 0

Table 4.12. Relative Scaling of Process Operating Parameters of the BSR Compared to the FBSR for the Hanford LAW simulants.

\begin{tabular}{||l|c|c|c||}
\hline Parameter & FBSR & Scaled BSR & Actual BSR \\
\hline Feed Rate & $757 \mathrm{ml} / \mathrm{min}$ & $1 \mathrm{ml} / \mathrm{min}$ & $1 \mathrm{ml} / \mathrm{min}$ \\
\hline Coal Rate & $265 \mathrm{~g} / \mathrm{min}$ & $0.35 \mathrm{~g} / \mathrm{min}$ & $0.2 \mathrm{~g} / \mathrm{min}$ \\
\hline Gas Rate & $2885 \mathrm{SLM}$ & $3.8 \mathrm{SLM}$ & $0.5 \mathrm{SLM}$ \\
\hline Steam Rate & & & $24 \mathrm{ml} / \mathrm{hr}$ \\
\hline $\mathbf{H}_{2}$ Conc. & $1-2 \%$ & & $1.5 \%-3 \%$ \\
\hline $\mathbf{O}_{2}$ Conc. & & & $<2 \%$ \\
\hline DMR Temp. & $720{ }^{\circ} \mathrm{C}$ & & $725^{\circ} \mathrm{C}$ \\
\hline Pressure & Positive & & -2 inwc \\
\hline
\end{tabular}

\subsection{4 $\underline{\mathrm{XRD}}$}

The XRD plots in Figure 4.12 and Figure 4.13 confirm the predicted mineral phases, nepheline, quartz, and nosean ${ }^{26}$ are present in the samples. Based on the projected compositions shown in Figure 4.9, the high aluminate content has an additional alumina (corundum) mineral present in the waste form.

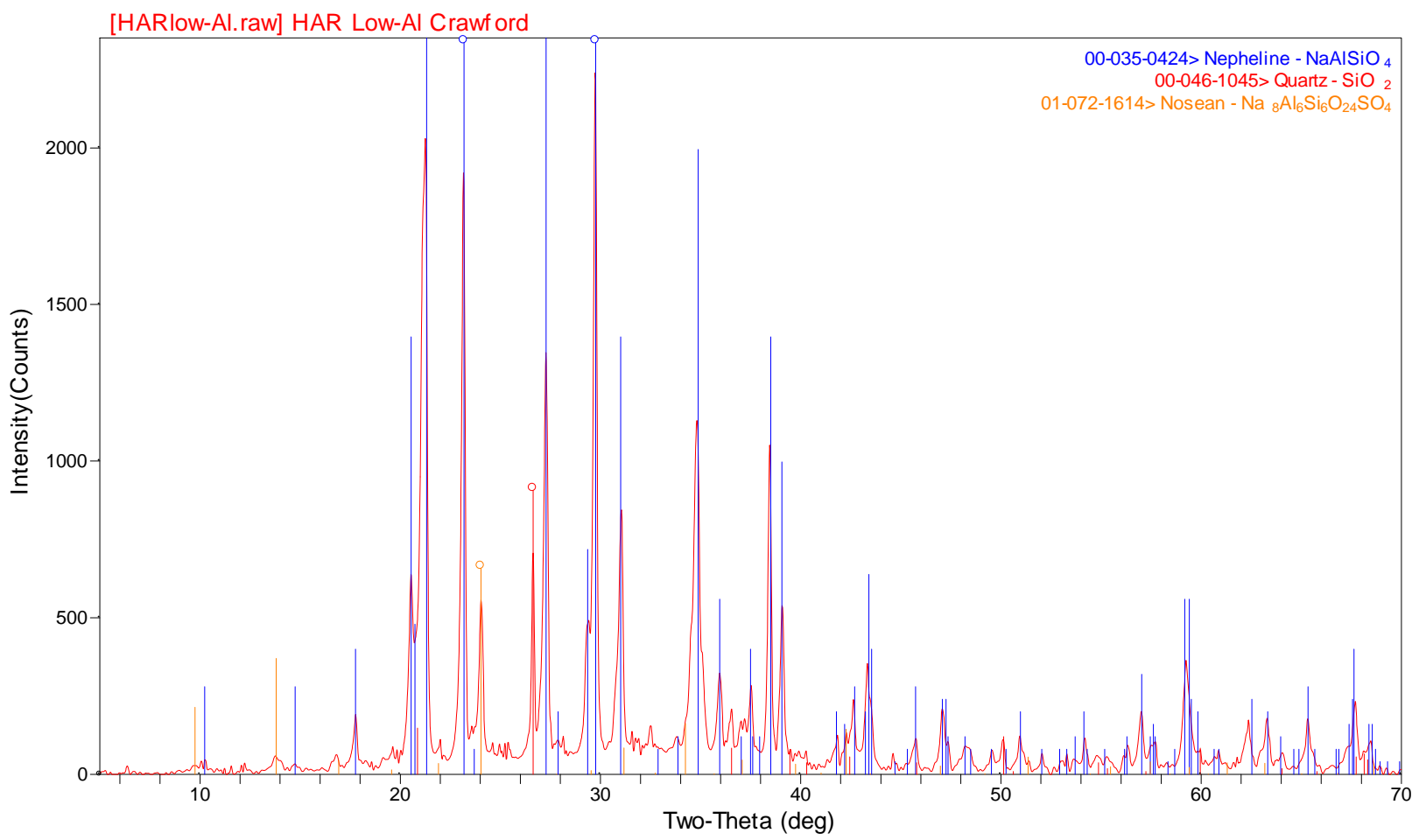

Figure 4.12. XRD plot of BSR product formulated with low aluminate simulant. Phases present are expected based on ternary phase diagram. 
SRNL-STI-2011-00525

Revision 0

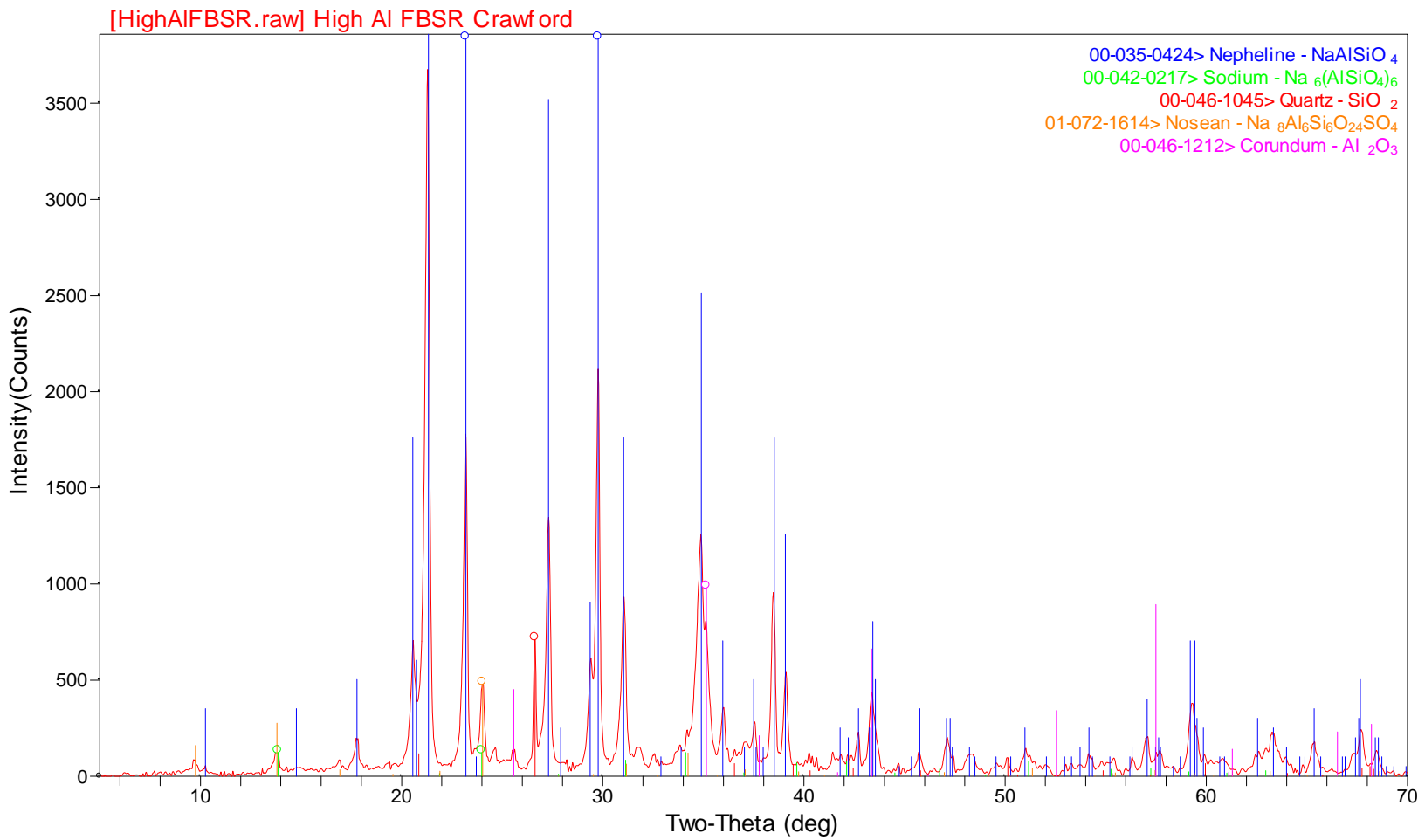

Figure 4.13. XRD plot of BSR product formulated with high aluminate simulant. Phases present are expected based on ternary phase diagram.

\subsubsection{Projected Waste Loadings}

The projected waste volume and mass factors for the BSR monolith product are listed in Table 4.13. The predicted waste loadings were not confirmed since monoliths of the BSR product were not prepared at the time of this report.

Table 4.13. Projected Waste Loadings for BSR Monolith Product.

\begin{tabular}{||c|c|c||}
\hline \multicolumn{3}{|c|}{ By Volume in Monolith Product } \\
\hline $\begin{array}{c}\text { Volume of Waste } \\
(\mathrm{L})\end{array}$ & $\begin{array}{c}\text { Volume of Monolith } \\
(\mathrm{L})\end{array}$ & Volume Factor \\
\hline 1.0 & $0.49-0.56$ & $0.49-0.56$ \\
\hline \hline \multicolumn{3}{|c|}{ By Mass in Monolith Product } \\
\hline \hline $\begin{array}{c}\text { Mass of 1 L of Waste } \\
(\mathrm{g})\end{array}$ & $\begin{array}{c}\text { Mass of Monolith } \\
(\mathrm{g})\end{array}$ & Mass Factor \\
\hline $1086-1147$ & $917-1049$ & $0.84-0.92$ \\
\hline
\end{tabular}

\subsection{Geopolymer Waste Forms}

The overall approach for low temperature geopolymeric waste forms consisted of immobilization of the LAW waste streams after aluminum dissolution (stream \# 1) and after aluminum dissolution and $\mathrm{NaOH}$ recovery (stream \# 2). Geopolymers require alkali activation and the LAW stream \# 1 already has a sufficient concentration of alkali and can therefore be immobilized directly thereby eliminating the $\mathrm{NaOH}$ 
recovery step. This alternative removes the need for the additional $\mathrm{NaOH}$ recovery process but must be balanced against the use of higher quantities of $\mathrm{NaOH}$. At this stage of the task, only direct geopolymerization of the low aluminate waste stream \# 1 has been performed.

Geopolymers are produced through activation of aluminosilicate materials. Typical activating solutions include alkali hydroxide and alkali silicates, where the alkali is typically sodium or potassium. Aluminosilicate sources for geopolymer synthesis typically consist of fly ash, blast furnace slag, or metakaolin. Fly ash, in particular Class F fly $\mathrm{ash}^{28}$, has been the subject of several studies on geopolymers. ${ }^{29-31}$ This class of fly ash has a lower calcium content and higher aluminum and silicon content when compared to Class $\mathrm{C}$ fly ashes. Aluminosilicate powders that also have high calcium contents may lead to formation of some portland cement reaction products such as calcium silicate hydrate or calcium hydroxide. The combination of both types of reaction product may lead to a weakened material. ${ }^{32}$ The design of geopolymer mixtures has typically been done using trial-and-error methods to select the proper activating solution, aluminosilicate powder, and curing conditions. Geopolymer mixture proportions have not yet been developed based on thorough knowledge of the constituent materials found in the fly ash, since a definition of- and testing method for- reactive constituents has not yet been developed. A trial and error approach was used in the current task for developing geopolymer mixtures for immobilization of the waste streams 1 and 2.

\subsubsection{Cementitious Materials and Simulants}

The fly ashes selected spanned a range of calcium contents, with two being classified as Class F fly ash based on ASTM C $618^{28}$ and the third as Class C. The choice to select fly ashes based on calcium content was made because calcium is often indicated as an important factor in early strength gains when geopolymers are cured at room temperature. ${ }^{33}$ The granulated blast furnace slag was obtained from Holcim (directly from the SRS Saltstone Production Facility (SPF)) and tested both as the sole aluminosilicate powder and as a replacement for portions of the fly ash in geopolymer mixtures. Table 4.14 summarizes the chemistry of the raw materials.

Table 4.14. Oxide compositions of aluminosilicate powders based on Inductively Coupled PlasmaEmission Spectroscopy (ICP-ES).

\begin{tabular}{|c|c|c|c|c||}
\cline { 2 - 5 } \multicolumn{1}{c|}{} & \multicolumn{4}{c||}{ Aluminosilicate Source (weight \%) } \\
\hline \hline Oxide & Big Brown FA & Belews Creek FA & Boral Class C FA & Holcim BFS \\
\hline $\mathrm{Al}_{2} \mathrm{O}_{3}$ & 18.4 & 30.5 & 17.2 & 7.5 \\
\hline $\mathrm{CaO}$ & 14.1 & 1.2 & 25.3 & 36.7 \\
\hline $\mathrm{Fe}_{2} \mathrm{O}_{3}$ & 8.0 & 4.6 & 5.9 & 0.4 \\
\hline $\mathrm{K}_{2} \mathrm{O}$ & 1.1 & 2.3 & 0.6 & 0.4 \\
\hline $\mathrm{MgO}$ & 2.2 & 0.7 & 5.9 & 13.0 \\
\hline $\mathrm{Na}_{2} \mathrm{O}$ & 0.6 & 0.3 & 2.0 & 0.3 \\
\hline $\mathrm{SO}_{4}$ & 0.8 & 0.1 & 1.7 & 1.7 \\
\hline $\mathrm{SiO}_{2}$ & 48.3 & 55.8 & 35.7 & 39.2 \\
\hline $\mathrm{TiO}_{2}$ & 1.2 & n/a & 1.2 & 0.4 \\
\hline total: & 94.9 & 95.4 & 96.5 & 99.5 \\
\hline
\end{tabular}

The caustic activating solutions used for these mixtures were simulant solutions for radioactive salt solutions after caustic leaching of Hanford HLW (waste stream \# 1). The compositions are summarized in Table 4.15. The free hydroxide molarity for the low aluminate simulant was $4 \mathrm{M}$ and the free hydroxide molarity for the high aluminate simulant was $4.5 \mathrm{M}$. The molarity of each constituent in the simulants is shown in Table 4.15. At the time of this report only the low aluminate mixes are discussed. 
SRNL-STI-2011-00525

Revision 0

Table 4.15. Chemical Constituents and Concentrations of Simulants.

\begin{tabular}{|c|c|c|}
\hline Compound & $\begin{array}{c}\text { Low Aluminate } \\
(\text { moles/L) }\end{array}$ & $\begin{array}{c}\text { High Aluminate } \\
(\text { moles/L) }\end{array}$ \\
\hline $\mathrm{NaOH}$ & 5.000 & 7.500 \\
\hline $\mathrm{NaNO}_{3}$ & 0.147 & 0.160 \\
\hline $\mathrm{NaNO}_{2}$ & 0.054 & 0.050 \\
\hline $\mathrm{Na}_{2} \mathrm{CO}_{3}$ & 0.055 & 0.055 \\
\hline $\mathrm{Na}_{2} \mathrm{C}_{2} \mathrm{O}_{4}$ & 0.001 & 0.001 \\
\hline $\mathrm{Na}_{2} \mathrm{SO}_{4}$ & 0.001 & 0.018 \\
\hline Aluminum Nitrate $\left(9 \mathrm{H}_{2} \mathrm{O}\right)$ & 0.250 & 0.750 \\
\hline Sodium Phosphate $\left(12 \mathrm{H}_{2} \mathrm{O}\right)$ & 0.002 & 0.000 \\
\hline
\end{tabular}

\subsubsection{Experimental Design and Batching}

The mixtures were designed to achieve high waste loading while resulting in little or no bleed water and a minimum 28 day compressive strength of 500 psi. The standard water to powder ratio was 0.60 , with some exceptions. The test matrix of mixtures is shown in Table 4.16. Two of the three fly ashes were blended with low aluminate solutions. The slag was used as a partial replacement for fly ash, comprising $15 \mathrm{wt} \%$ of the aluminosilicate powder, and each of the three fly ashes was tested as a blend with slag. A slag and low aluminate simulant mixture was completed; however the resulting mixture was deemed unstable in air. Therefore, mixes with the high aluminate simulant were mixed with both slag and fly ash to minimize the reactivity in air. Mixing was completed using a shear mixer with a four-blade vane style attachment. The solution was added to the mixing vessel and the initial mixer was set at $300 \mathrm{rpm}$. The powder was added to the vessel over approximately 1 minute. The speed of the mixer was increased to a range of 600-700 rpm, depending on the consistency of the mixture. Mixing was completed for a total of approximately 3 minutes, after visually confirming that the solids had been completely incorporated with the liquid portion. 
SRNL-STI-2011-00525

Revision 0

Table 4.16. Test Matrix for Geopolymer Mixtures with the Low Aluminate Waste Stream 1.

\begin{tabular}{||l|c|c||}
\cline { 2 - 3 } \multicolumn{1}{c|}{} & $\begin{array}{c}\text { Low Aluminate } \\
(4.0 \mathrm{M})\end{array}$ & $\begin{array}{c}\text { Water to Powder } \\
\text { Ratio }\end{array}$ \\
\hline Class C (Boral) & $\mathrm{x}$ & 0.70 \\
\hline Class F (Big Brown Raw) & $\mathrm{x}$ & 0.70 \\
\hline Class C (Boral) & $\mathrm{x}$ & 0.60 \\
\hline Class F (Big Brown Raw) & $\mathrm{x}$ & 0.60 \\
\hline Slag & $\mathrm{x}$ & 0.60 \\
\hline Class C / Slag (85/15) & $\mathrm{x}$ & 0.60 \\
\hline Class F (BBR) / Slag (85/15) & $\mathrm{x}$ & 0.60 \\
\hline Class F (Belews) / Slag (85/15) & $\mathrm{x}$ & 0.60 \\
\hline \hline
\end{tabular}

\subsubsection{Measurement of Fresh and Cured Properties}

Fresh state testing for the gel time of the mixture under static conditions was completed on specimens placed in $1 \mathrm{~mL}$ vials. The vials were filled approximately $2 / 3$ full and one vial was inverted every 10 minutes until the mixture no longer flowed out of the vial when turned upside down. The time to this point was recorded as the mixture's gel time. The other specimens made included bleed water specimens and compressive strength cylinders. The bleed water specimens were cast in $125 \mathrm{~mL}$ bottles with screwtop lids. The specimen was weighed and the lid attached. The specimens were placed in a temperaturecontrolled $23^{\circ} \mathrm{C}$ room until the bleed water was measured at 24 hours. To measure the bleed water, water remaining on the surface of the specimen after 24 hours was pipetted off and weighed. The water was returned to the specimen and the specimen was re-sealed. Compressive strength specimens were cast in $50 \mathrm{~mm} \times 100 \mathrm{~mm}$ (2" x 4") plastic cylinder molds. The cylinders were filled to the top, and sealed with the snap-on lids. The cylinders were stored in a temperature-controlled $23{ }^{\circ} \mathrm{C}$ room until they were demolded and tested for compressive strength at 28 days. In order to test for compressive strength, the cylinders were capped with sulfur compound such that any surface unevenness was eliminated.

The gel time, normalized bleed water, and compressive strength for all mixtures are presented in Table 4.17. The gel time is the only fresh state property measured for these mixtures. The Big Brown Raw Class F fly ash mixtures without slag had the longest gel times at approximately one hour, while the slag, Class C fly ash, and blended slag/fly ash mixtures had short gel times of 10-20 minutes. The Belews Creek/slag gel time using low aluminate simulant had an intermediate gel time of 30 minutes. The results show that an increased calcium content in the cementitious materials resulted in decreased gel times. The bleed water masses for each specimen are normalized to a $100 \mathrm{~g}$ of geopolymer, since the bleed specimen size varied from batch to batch. The systems containing slag and/or Class $\mathrm{C}$ fly ash had little or no bleed at 24 hours. 
SRNL-STI-2011-00525

Revision 0

Table 4.17. Gel time, normalized bleed water and compressive strength for all geopolymer mixtures tested.

\begin{tabular}{||l|c|c|c|c||}
\cline { 2 - 5 } \multicolumn{1}{c|}{} & $\begin{array}{c}\text { Water to Powder } \\
\text { Ratio }\end{array}$ & $\begin{array}{c}\text { Gel Time } \\
\text { (min) }\end{array}$ & $\begin{array}{c}\text { Bleed } \\
\text { Water (g) }\end{array}$ & $\begin{array}{c}\text { Compressive } \\
\text { Strength (psi) }\end{array}$ \\
\hline Class C (Boral) & 0.70 & 20 & 0.1 & 294 \\
\hline Class F (Big Brown Raw) & 0.70 & 50 & 2.0 & 558 \\
\hline Class C (Boral) & 0.60 & 20 & none & 421 \\
\hline Class F (Big Brown Raw) & 0.60 & 40 & 1.8 & 818 \\
\hline Clas & 0.60 & & none & 1935 \\
\hline Class F (BBR) / Slag (85/15) & 0.60 & 10 & none & 2658 \\
\hline $\begin{array}{l}\text { Class F (Belews) / Slag } \\
(85 / 15)\end{array}$ & 0.60 & 10 & none & 4602 \\
\hline
\end{tabular}

Compressive strength testing results are presented in Table 4.17. Only select mixtures resulted in compressive strength values at 28 days that exceeded those required by the project parameters. The Class $\mathrm{C}$ fly ash mix did not exceed the strength requirements. The mean compressive strength of the waste form shall be determined by testing representative non-radioactive samples. The compressive strength shall be at least 3.45E6 Pa when tested in accordance with ASTM C39/C39M-99 or an equivalent testing method. $^{21}$ The remaining mixtures with low aluminate simulant all exceeded 500 psi (3.45E6 Pa) at 28 days and were considered as good contenders for waste immobilization in geopolymers.

\subsubsection{Scanning Electron Microscopy}

SEM analyses were performed on specimens in which curing was stopped using ethanol at 14 days. After 14 days of curing, the bleed specimen was cut open using a concrete saw with cutting oil lubricant. A portion of the specimen was cut that was approximately $50 \mathrm{~mm}$ in diameter and $20 \mathrm{~mm}$ thick. This portion was placed in a beaker filled with an excess volume of ethanol. The specimen was allowed to soak for approximately 48 hours, removed, dried with paper towels, and placed in a vacuum desiccator for further drying. The specimen was cut down to SEM samples of approximately $10 \mathrm{~mm} \times 10 \mathrm{~mm} \times 1$ $\mathrm{mm}$ thick. These specimens were dried in the vacuum desiccator for 24 hours prior to vacuum impregnation. Vacuum impregnation was completed using the following method. Molds measuring approximately $32 \mathrm{~mm}$ in diameter and $25 \mathrm{~mm}$ high were wiped with mold release oil on the sides and joints. The specimen was placed face-up in the mold, and the mold was placed in the vacuum impregnation unit. The unit was equipped with a turntable, such that multiple specimens could be made at once. The specimen was vacuumed to $25 \mathrm{~mm} \mathrm{Hg}$ and held for approximately 10 minutes while the epoxy was mixed. The epoxy used in this process was manufactured by Logitech and was a two-part epoxy for which the resin/ hardener ratio was $4: 1$ by mass. The epoxy was dispensed into a cup at the center of the vacuum chamber while still under vacuum and allowed to rest until air bubbles introduced during the dispensing process were allowed to rise to the surface and fully escape the epoxy. Next, each specimen mold was filled with epoxy to approximately $6 \mathrm{~mm}$ by tilting the paper cup over each mold. The specimens were allowed to rest for 30 minutes under vacuum with the epoxy. The vacuum was slowly released, and the specimens were allowed to rest for another 30 minutes. Finally, the specimens were cured for a minimum of 24 hours at room temperature before grinding and polishing. 
Grinding was completed by hand with $\mathrm{SiC}$ papers and no lubricant using the following grades of $\mathrm{SiC}$ paper: $\# 60,180,400,600$, and 1200 . The coarsest paper, \#60, was used to expose approximately $70 \%$ of the area of the geopolymer paste surface. The remaining papers were used to remove material at decreasing rates. Once the grinding was completed, the specimens were polished using an automated polishing head with $5 \mathrm{lbf}$ of force to the polishing cloth and approximately $60-80 \mathrm{rpm}$. Twill polishing cloths mounted on a platen diamond paste applied. The diamond pastes included $6 \mu \mathrm{m}, 3 \mu \mathrm{m}, 1 \mu \mathrm{m}$, and $1 / 4 \mu \mathrm{m}$. In many instances, the specimens were submerged in a beaker of ethanol and placed in the ultrasonic cleaner for approximately 10 seconds before moving to a finer diamond paste in order to dislodge any remaining diamond paste. The specimens were coated with carbon to approximately 20-25 $\mathrm{nm}$ thick using the brass substrate method $^{34}$ prior to analysis in the SEM.

SEM microanalyses were completed on the geopolymer pastes that exceeded the 500 psi compressive strength requirement. The images were assessed for the presence of unreacted particles (circular for fly ash and angular for slag), for general integrity i.e. cracking, and for the apparent density of the reaction product. X-ray mapping proved inconclusive for determining composition of the reaction product, due to widespread presence of elements in the reaction product. Unreacted particles were identified with x-ray mapping. Figure 4.14 is a micrograph of the Big Brown Raw fly ash mixed with low aluminate simulant solution after 14 days of curing. Minimal unreacted fly ash (bright circle-shaped particles), was observed in the image, while reaction products appeared to be of varying composition due to the contrast between different areas of the specimen.

Figure 4.15 is a backscattered electron image of the Big Brown Raw fly ash and slag blend, mixed with low aluminate simulant. Unreacted spherical fly ash particles were visible as light gray and white circles, while reaction product surrounded the particles. The microstructure of the geopolymer appeared to be somewhat uncompacted, with a porous appearance. Some cracking was apparent, but it was not widespread. This figure contrasts with the Class C/slag and Belews Creek/ slag blends mixed with low aluminate simulant mixtures (Figure 4.16 and Figure 4.17). The Class $\mathrm{C}$ fly ash and slag blend resulted in greater reaction product than the two class F fly ashes. The Belews Creek fly ash/slag blend geopolymer appeared to have the least reaction product, given the many unreacted particles present in the image, which appear as circular particles with smooth textures. Figure 4.14 through Figure 4.17 have the same field width of approximate 600 micrometers, to facilitate comparison. 
SRNL-STI-2011-00525

Revision 0

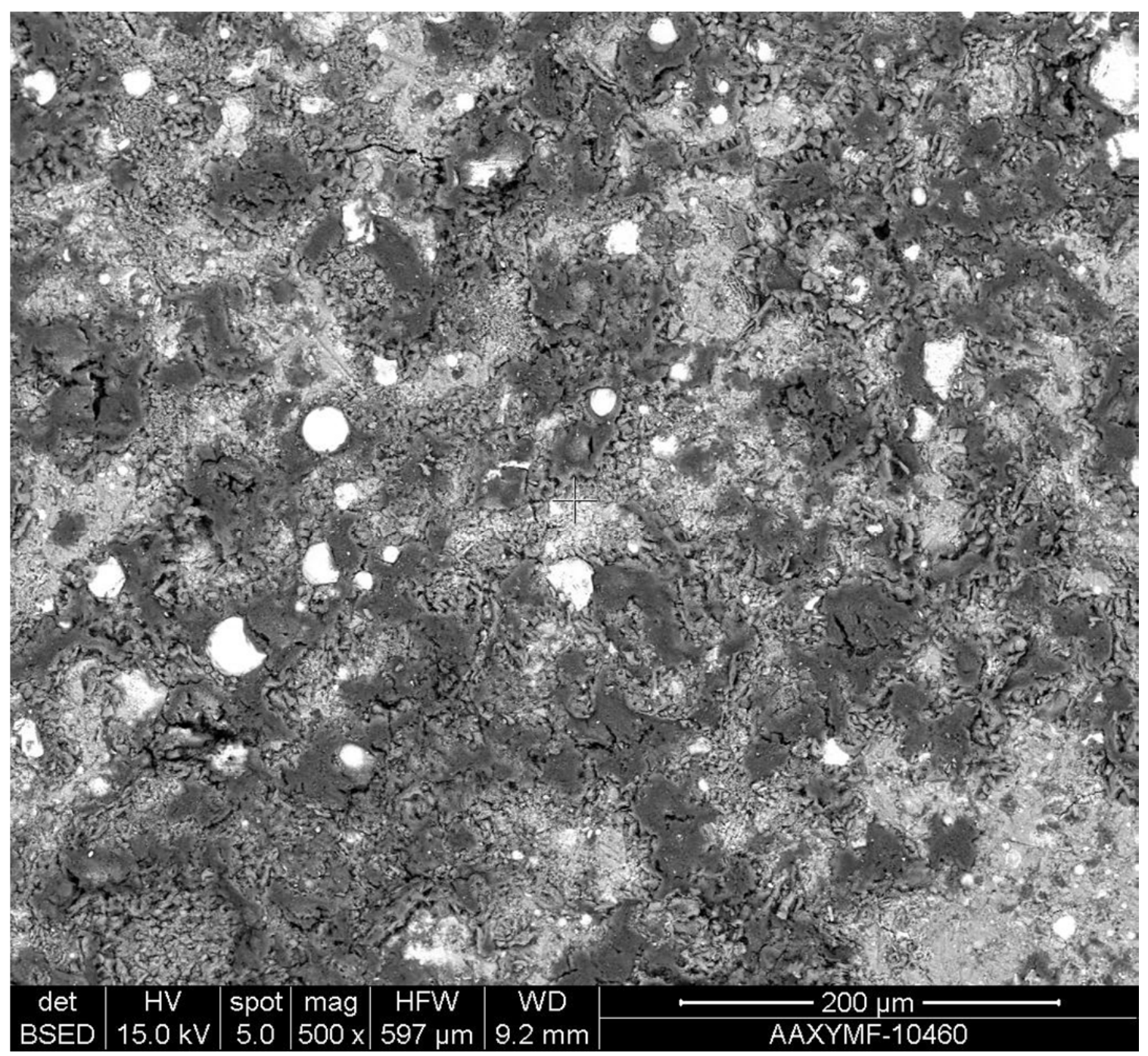

Figure 4.14. Low aluminate simulant and Big Brown Raw fly ash geopolymer paste after 14 days of curing at room temperature. 
SRNL-STI-2011-00525

Revision 0

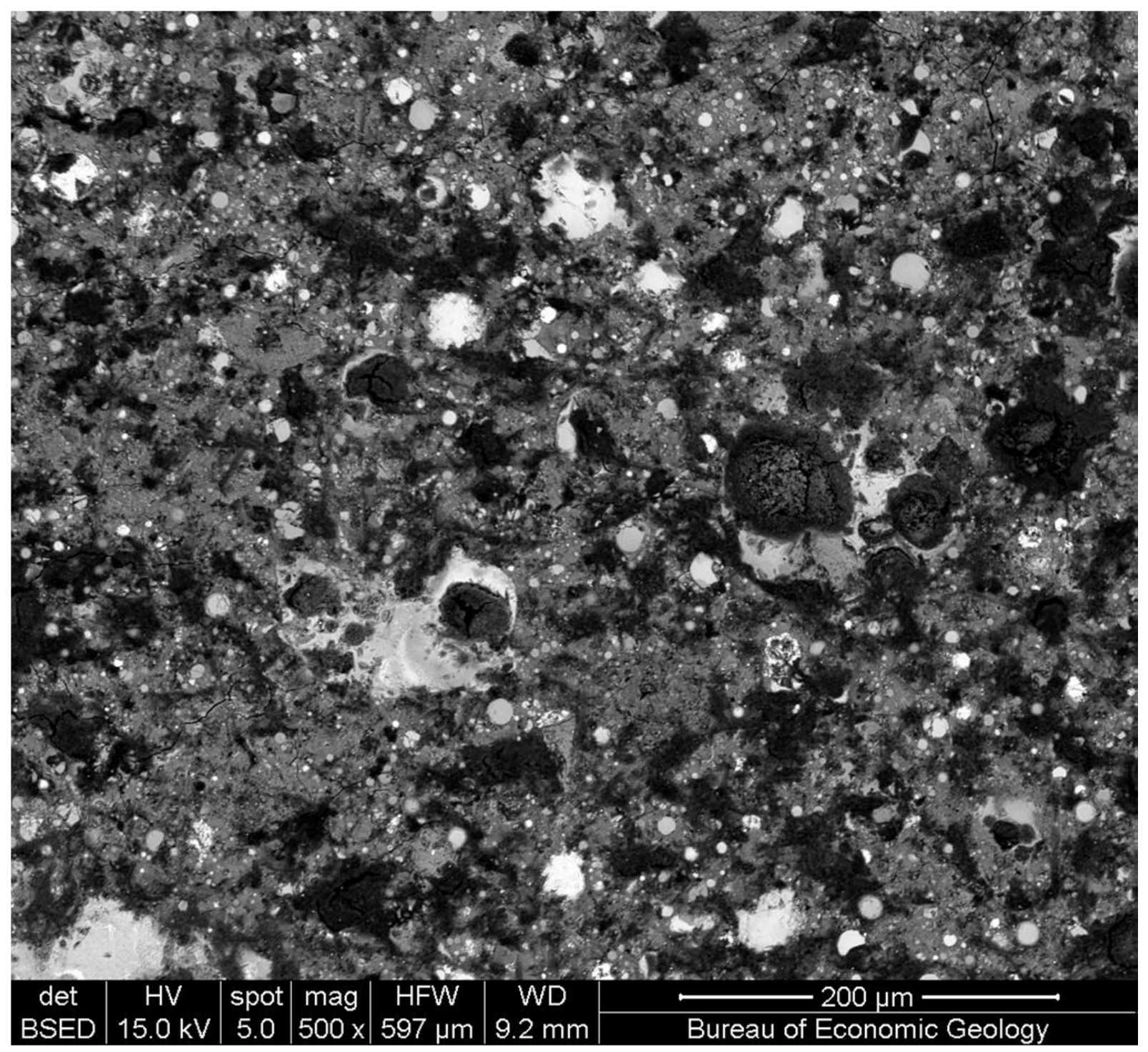

Figure 4.15. Low aluminate simulant mixed with big brown raw and slag geopolymer pastes after 14 days of curing at room temperature. 
SRNL-STI-2011-00525

Revision 0

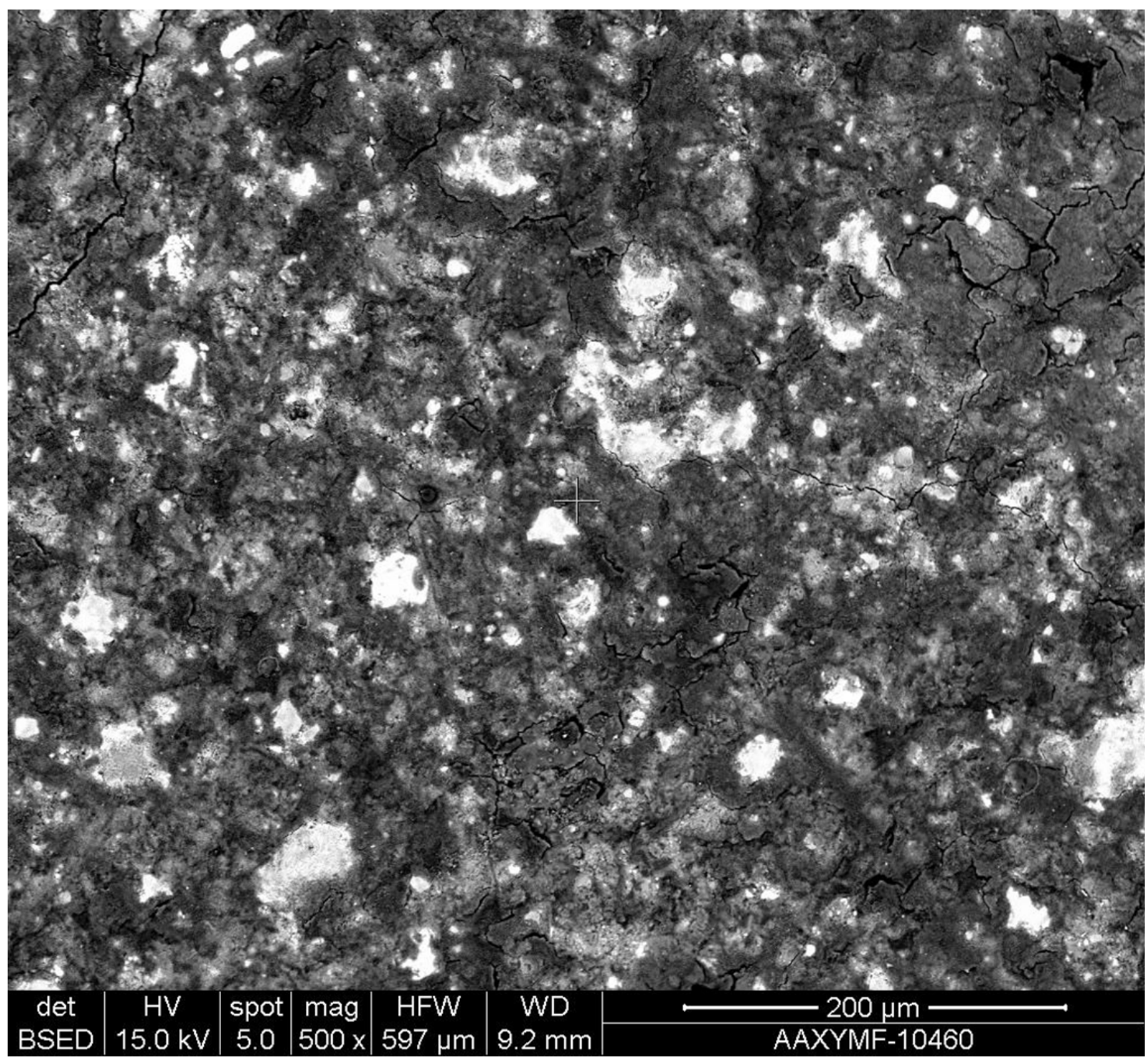

Figure 4.16. Low aluminate simulant mixed with Class $C$ fly ash and slag geopolymer after 14 days of curing at room temperature 


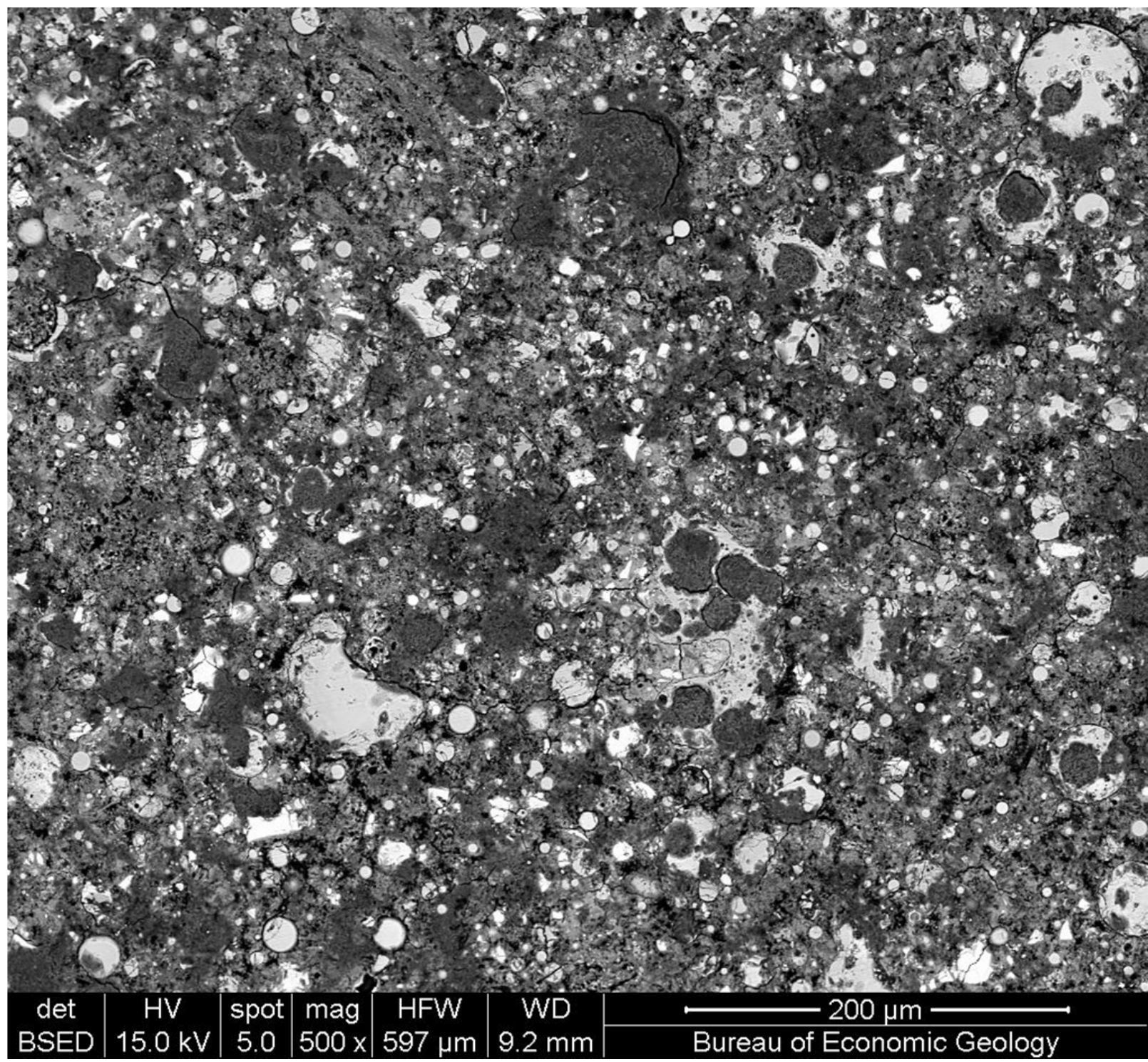

Figure 4.17. Low aluminate simulant mixed with Belews Creek fly ash and slag, geopolymer paste after 14 days of curing at room temperature

\subsubsection{Heat Generation}

The heat flow and integrated heat output for two of the blended mixes were measured using an isothermal calorimeter operated at $25{ }^{\circ} \mathrm{C}$ as previously described. ${ }^{35}$ The first mix measured contained $85 \mathrm{wt} \%$ Big Brown Raw Class F Fly Ash and 15 wt \% slag with the low aluminate simulant at a 0.60 water to powder ratio (Figure 4.18). The second mix contained 85 wt \% Class C Fly Ash and $15 \mathrm{wt} \%$ slag with the low aluminate simulant ( 0.60 water to powder ratio) shown in Figure 4.19. The amount of heat generated is significant and approaches or exceeds that observed with Saltstone mixes under similar conditions. ${ }^{36}$ 
SRNL-STI-2011-00525

Revision 0

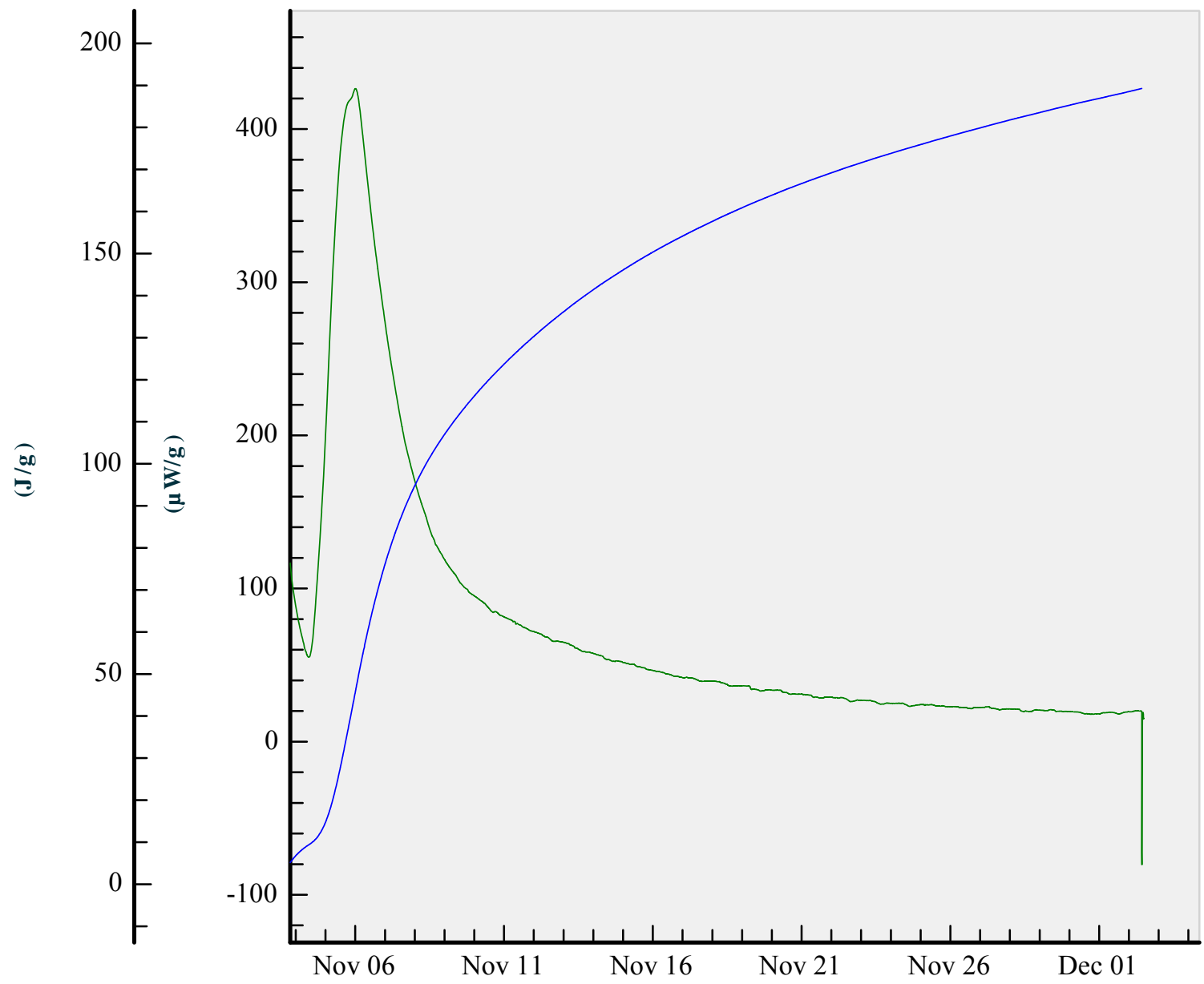

Figure 4.18. Isothermal calorimetry output for a mix of low aluminate waste stream \# 1 with a premix composed of 85 wt \% Big Brown Raw Class F fly ash and 15 wt \% slag. 
SRNL-STI-2011-00525

Revision 0

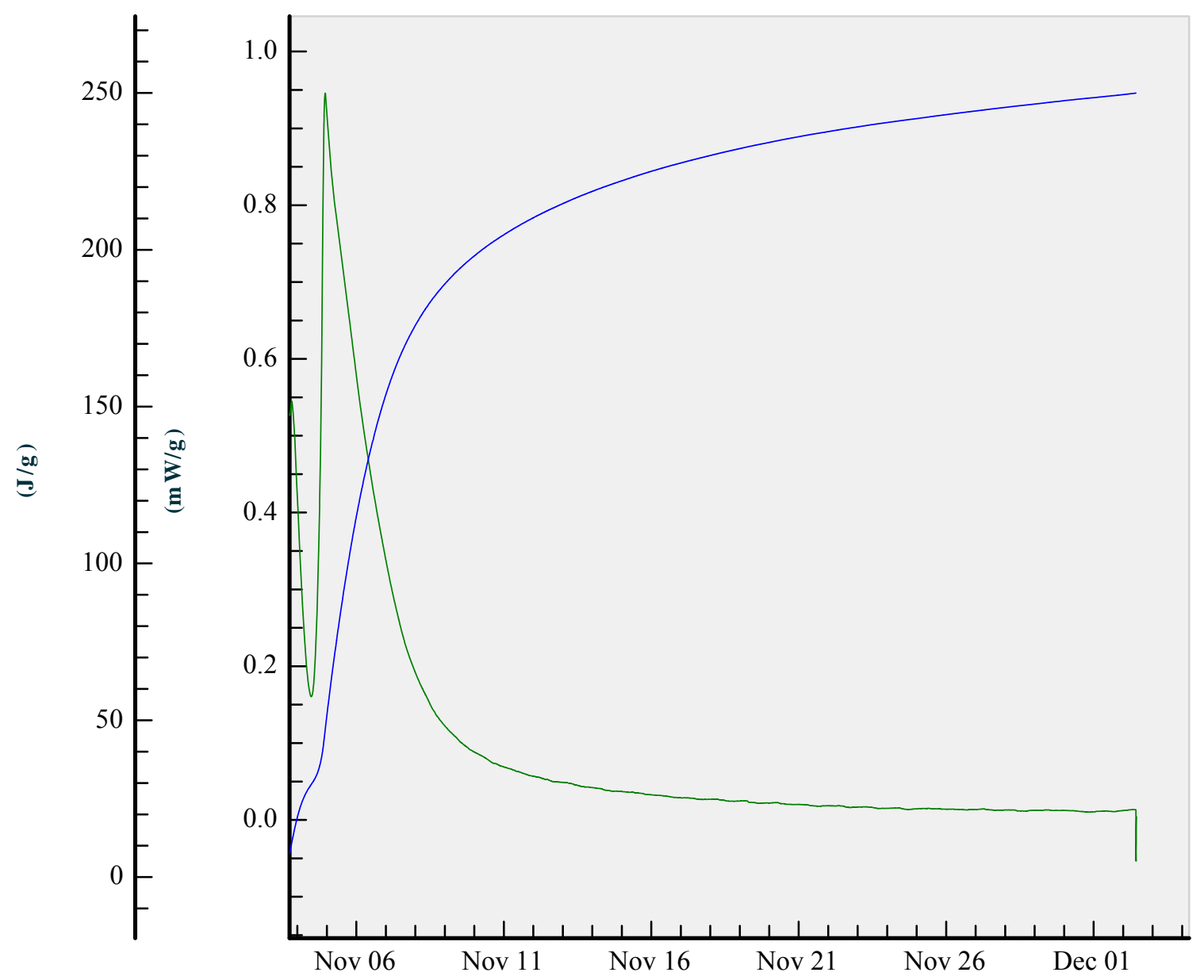

Figure 4.19. Isothermal calorimetry output for a mix of the low aluminate waste stream \# 1 with a premix composed of 85 wt \% Class C fly ash and 15 wt \% slag.

\subsubsection{Volume and Mass Factors}

Waste volume and mass factors will be close to those of the Saltstone/Cast Stone mixes discussed in section 4.5. However, they are slightly different due to the higher concentrations of $\mathrm{NaOH}$ in the waste stream \# 1 after aluminum dissolution vs. waste stream \# 2 which has reduced $\mathrm{NaOH}$ due to recovery.

Table 4.18. Volume and mass fractions of geopolymer waste form.

\begin{tabular}{||c|c|c|c|}
\hline \hline \multicolumn{5}{|c|}{ By Volume } \\
\hline Volume of Waste (L) & \% Loading (in grout) & Volume of Grout (L) & Volume Factor \\
\hline 1.0 & 40 & 1.6 & 1.6 \\
\hline \hline \multicolumn{3}{|c|}{ By Mass } \\
\hline \multicolumn{3}{|c|}{ Mass of Grout } & Mass Factor \\
\hline \multicolumn{2}{|c|}{2700} & 2.5 \\
\hline
\end{tabular}




\subsubsection{Future Work}

Retention of I and Re will be measured as discussed in Section 4.5. Blast furnace slag was added to the mixes to provide a reductant that will reduce pertechnetate to $\mathrm{Tc}^{4+}$. A separate getter may be required for retention of I-129.

Initial mixes revealed compressive strengths that are less than 500 psi for the high aluminate mixes. Additional formulation work will therefore be performed with the high aluminate mixes to achieve higher compressive strengths. Formulation development will also need to be performed on waste streams \# 2. Geopolymer formulations made with fly ashes available in the Hanford area must also be evaluated since the composition can vary greatly between fly ashes.

\subsection{Saltstone/Cast Stone Waste Form}

A cementitious waste form has the advantage that the process is performed at ambient conditions and consequently, has lower power consumption than glass production without the need for a complex off-gas treatment system. Saltstone was developed for the low level waste stream generated at SRS while Cast Stone was developed as a treatment option for Hanford LAW. This method of waste treatment has been deployed and is currently operating at SRS with the grout waste form disposed of in covered vaults which eventually will be completely covered. The current grout formulation (mix design) for Saltstone (which is essentially equivalent to the Cast Stone formulation) was tested with the two waste streams. For this initial testing, a water to premix ration of 0.60 was selected.

\subsubsection{Saltstone Formulation}

The cementitious materials for these mixes (Table 4.19) were obtained from the SPF. Table 4.19 also contains the weight percent contribution of each material used to make the premix. The fly ash used in this study was a material that had been thermally treated by the Vendor to remove most of the carbon and ammonia (carbon burnout or CBO fly ash).

Table 4.19 Cementitious Materials Used in Saltstone/Cast Stone Waste Form.

\begin{tabular}{||c|c|c|c||}
\hline Material & Category & Vendor & Premix wt \% \\
\hline \hline Portland Cement & Type II & Holcim & 10 \\
\hline Blast Furnace Slag & Class 1 & Holcim & 45 \\
\hline Fly Ash & Class F & Holcim & 45 \\
\hline
\end{tabular}

The isothermal calorimetric data for these two mixes at $25{ }^{\circ} \mathrm{C}$ are shown in Figure 4.20. The high aluminate mix has an induction period which can account for the higher set time for this mix compared to the low aluminate mix. The high aluminate mix also produces more heat (normalized to the mass of cementitious materials) than the low aluminate mix and produces a waste form with higher Young's modulus and lower permeability. ${ }^{35,36}$ 


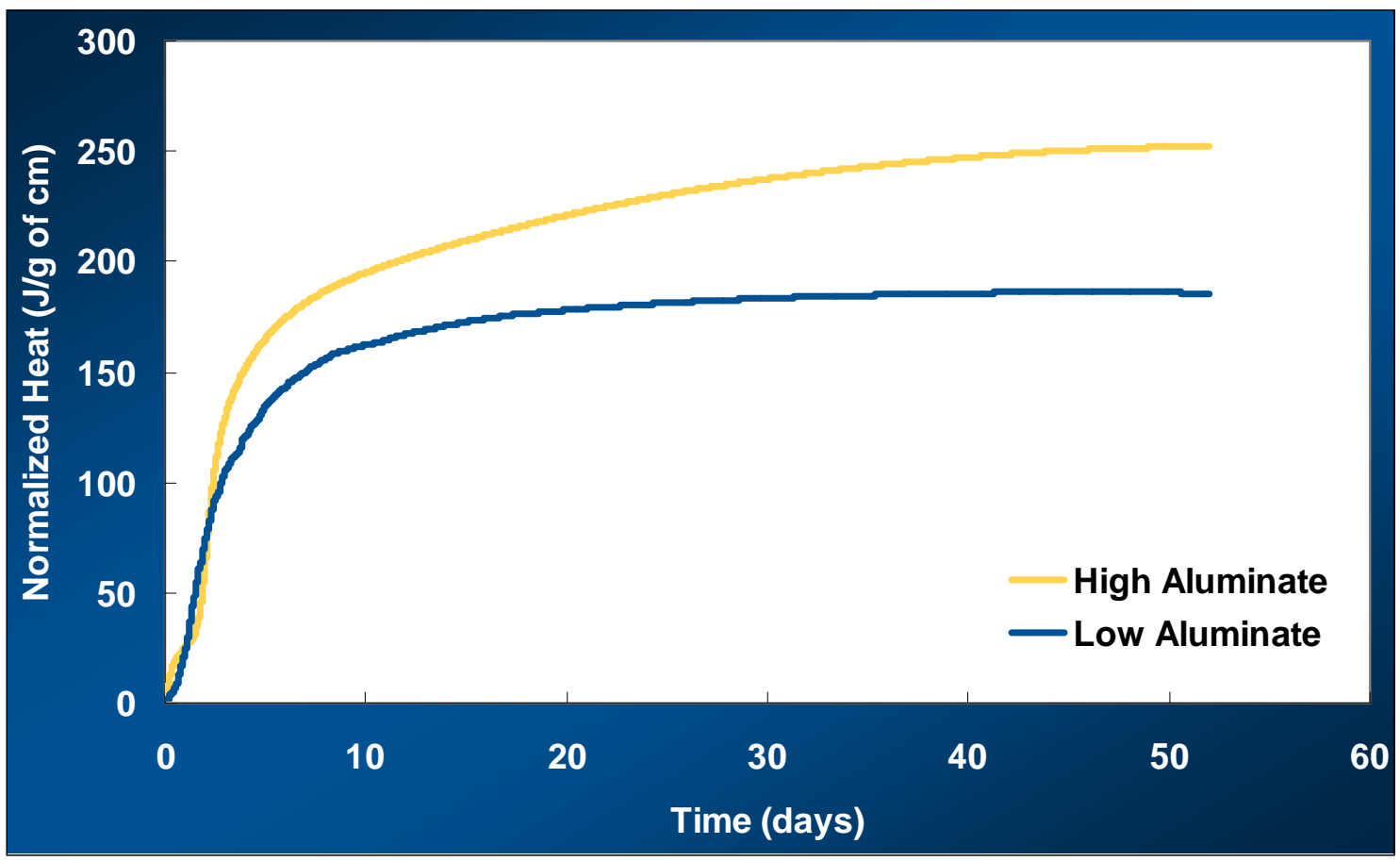

Figure 4.20. Normalized heat production $(\mathrm{J} / \mathrm{g}$ of $\mathrm{cm})$ for low and high aluminate mixes at $25{ }^{\circ} \mathrm{C}$.

\subsubsection{Performance Properties of Saltstone}

Table 4.20 lists the processing properties for the low and high aluminate simulated waste streams. No effort was made to extend the gel time by addition of a set retarder. The three day set time is typical for waste streams containing higher aluminate levels. ${ }^{36}$ The yield stress and consistency are lower for the higher aluminate mixes as previously determined. ${ }^{36}$

Table 4.20. Processing properties for simulated low and high aluminate waste streams.

\begin{tabular}{||c|c|c||}
\hline Properties & Low Aluminate & High Aluminate \\
\hline \hline Gel Time & 10 minutes & 20 minutes \\
\hline Set Time & 1 day & 3 days \\
\hline Bleed Volume & None & None \\
\hline Density & $1.67 \mathrm{~g} / \mathrm{mL}$ & $1.71 \mathrm{~g} / \mathrm{mL}$ \\
\hline Yield Stress & $7.1 \mathrm{~Pa}$ & $2.0 \mathrm{~Pa}$ \\
\hline Consistency & $0.08 \mathrm{~Pa} \cdot \mathrm{s}(80 \mathrm{cP})$ & $0.02 \mathrm{~Pa} \cdot \mathrm{s}(20 \mathrm{cP})$ \\
\hline
\end{tabular}

The value of the dynamic Young's modulus (E) provides evidence on the strength and elasticity of the cured grout waste forms and on the performance properties in general. The values of $\mathrm{E}$ for the samples cured at $20{ }^{\circ} \mathrm{C}$ are between 7 and $8 \mathrm{GPa}$. However, Figure 4.21 shows that $\mathrm{E}$ is sensitive to the curing temperature and that the higher aluminate mix is more sensitive than the low aluminate mix. Curing temperature can play a role in the final performance properties depending on the size of the container, rate of filling, and the environmental conditions under which the pour is conducted. ${ }^{37}$ 


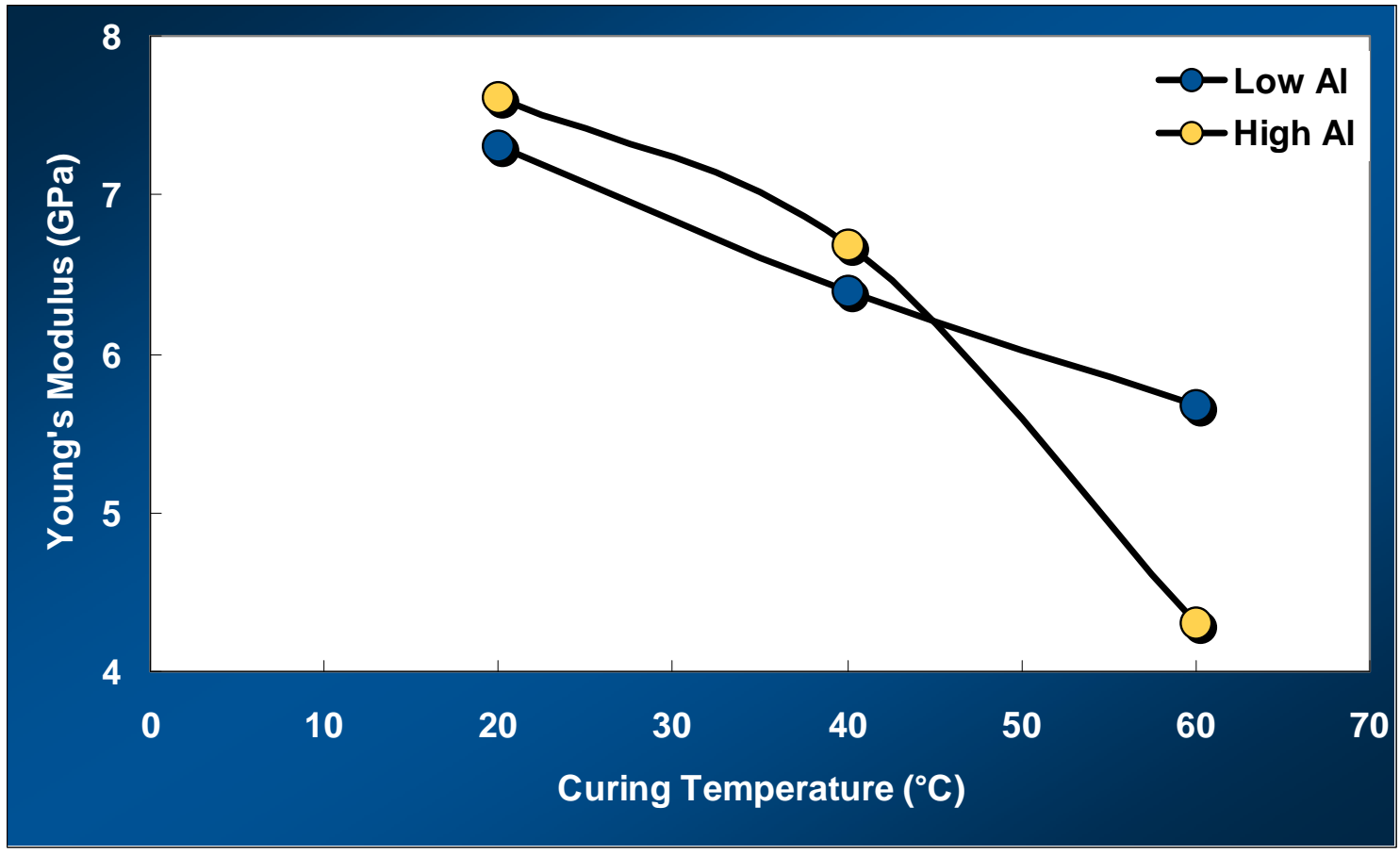

Figure 4.21. Dependence of Young's modulus on the curing temperature of the grouts.

\subsubsection{Radionuclide Retention}

The retention of I-129 and Tc-99 within the grout waste form is important for the PA of the IDF. Therefore, a technique was developed which will allow for the measurement of the retention of these species within the grout waste form through measurement of the composition of the pore solution. Nonradioactive iodide and rhenium (as a surrogate for technetium) were introduced into the simulated waste form.

Pore solution can be separated from the cured grout samples using the Unsaturated Flow Apparatus (UFA) centrifuge system ${ }^{38}$ (Figure 4.22). The hydraulic conductivity can be calculated from the flow of liquid through the porous medium over time. ${ }^{39}$ Using the UFA system the pore solution can be removed by two methods: (1) centrifugation only and (2) by centrifugation with continuous replenishment and flow of water through the system (as normally done when measuring liquid permeability of grouts). ${ }^{39}$ The second method maintains permeant flow during centrifugation. For these samples, the permeant was fed gravitationally to the sample which promotes and maintains saturation of the samples.

Figure 4.23 plots the total sodium concentration of the pore solution as a function of time with continuous replenishment of the pore solution by water during centrifugation. The sodium ion concentration is relatively constant for the first 5 to 10 grams collected. After that the water begins to mix with the pore solution and the total sodium ion concentration is reduced. For this sample there are $\sim 22$ grams total of pore solution in the sample. Therefore collection of the first 5 grams of pore solution will provide a representative sample for chemical analysis. The retention of I and Re in the sample is calculated from the concentration in original waste stream and the concentration in the collected pore solutions. 


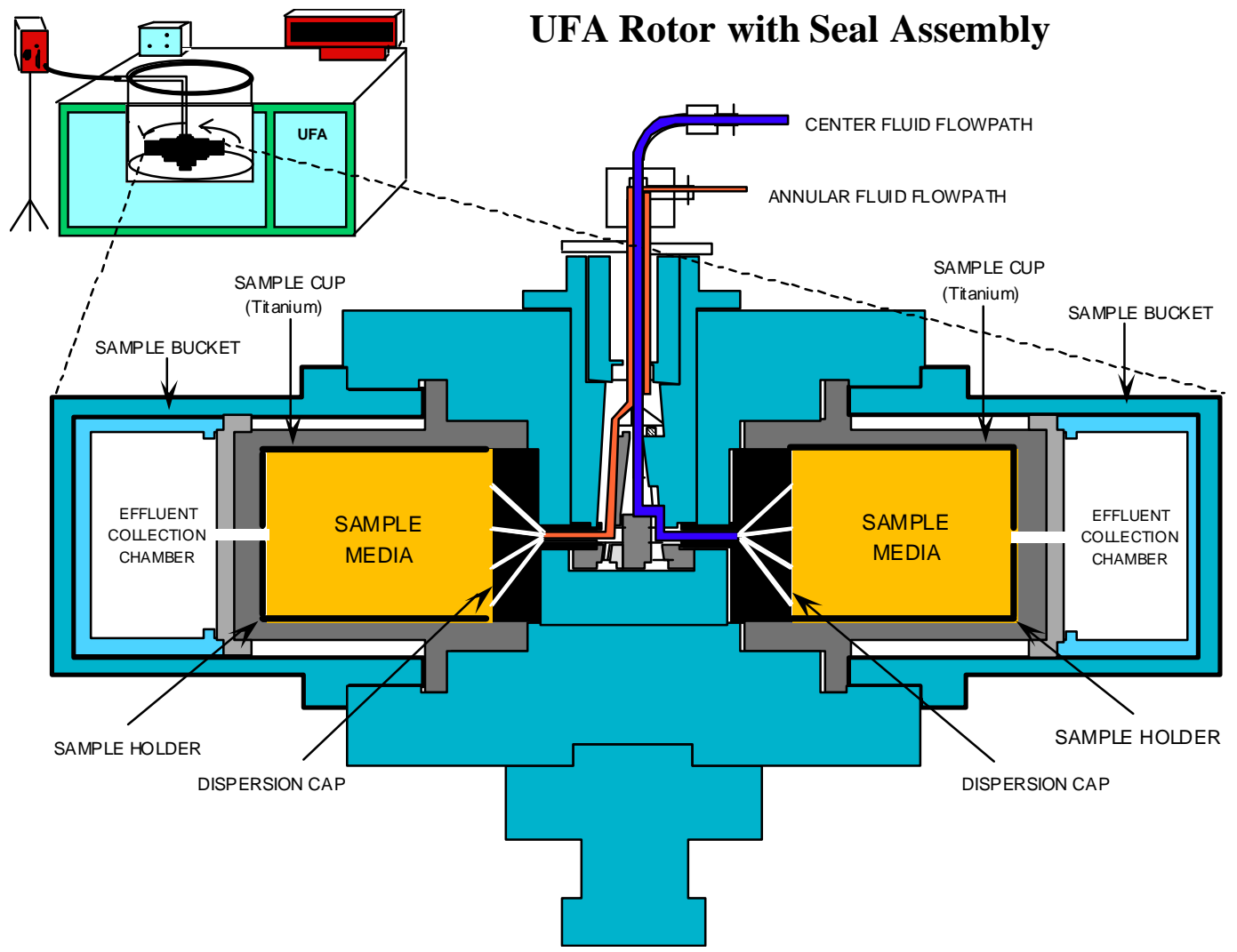

Figure 4.22. The UFA centrifuge system for measuring permeability and capturing pore solution.

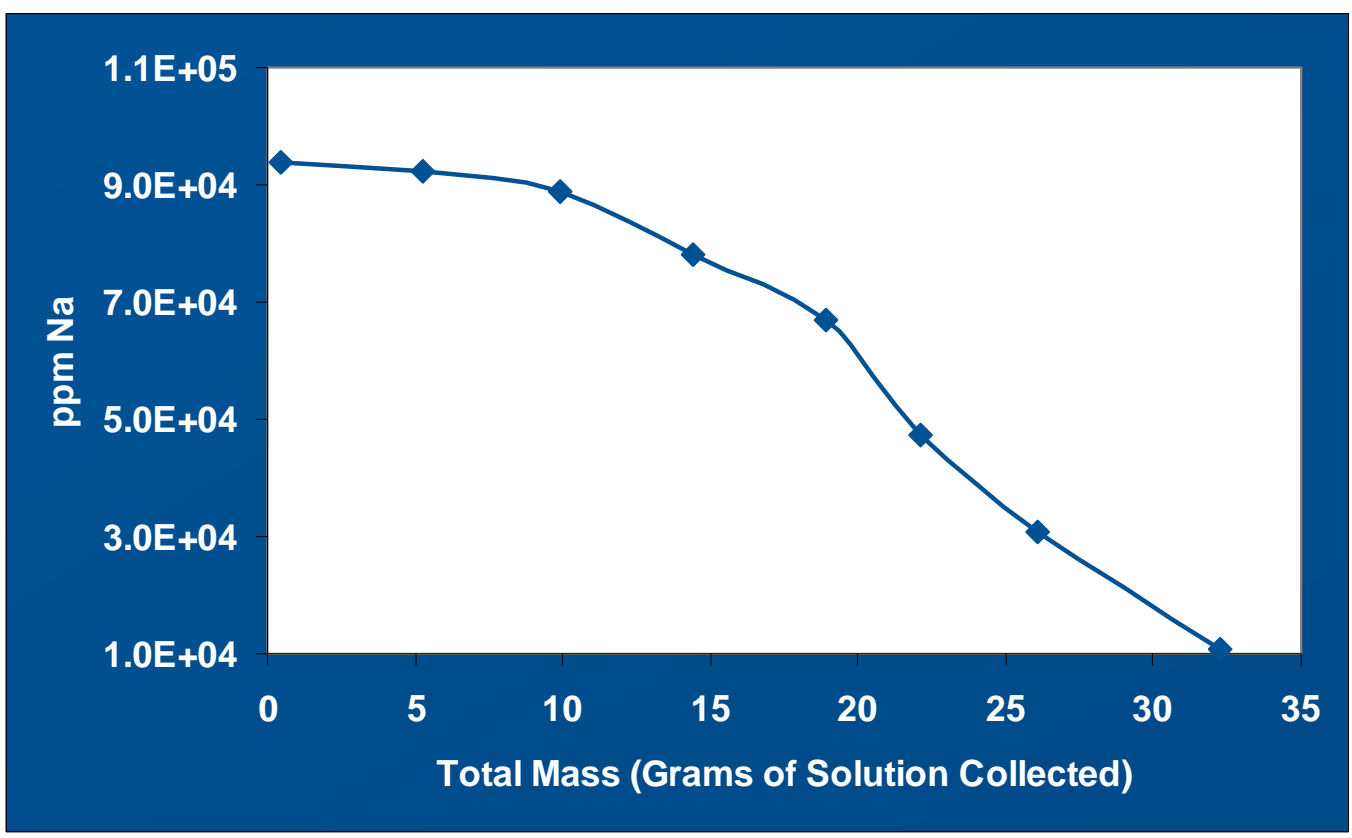

Figure 4.23. Total Na ion concentration (ppm) for each sample taken as a function of the total amount of solution collected. 
SRNL-STI-2011-00525

Revision 0

A feasibility study was performed in which the Re-doped simulants were mixed with premix at a 0.60 water to premix ratio and allowed to cure. For this test, 2 inch diameter cured grout cylinders were placed in the centrifuge and the pore solution collected after centrifugation at $4000 \mathrm{rpm}$ for 2 hours. The Re concentrations in the pore solutions were significantly reduced relative to the original concentrations in the low and high simulants (Table 4.21). Therefore, the method is applicable to a determination of retention of Re, I and any other soluble species of concern. The volume and mass factors for the mixes are provided in Table 4.22 .

Table 4.21. Re Retention in the Low and High Aluminate Mixes

\begin{tabular}{|c|c|c|c|}
\cline { 2 - 4 } \multicolumn{1}{c|}{} & $\begin{array}{c}\text { Re in Simulant } \\
(\mathrm{ppm})\end{array}$ & $\begin{array}{c}\text { Re in Pore Solution } \\
(\mathrm{ppm})\end{array}$ & $\begin{array}{c}\text { Re Retention } \\
(\%)\end{array}$ \\
\hline Low Aluminate & $3.07 \mathrm{E}+05$ & $3.60 \mathrm{E}+03$ & 98.8 \\
\hline High Aluminate & $2.99 \mathrm{E}+05$ & $6.88 \mathrm{E}+03$ & 97.7 \\
\hline
\end{tabular}

Table 4.22. Waste Loadings and Associated Volume and Mass Factors for the Mixes.

\begin{tabular}{||c|c|c|c||}
\hline \hline \multicolumn{5}{|c|}{ By Volume } \\
\hline Volume of Waste (L) & \% Loading (in grout) & Volume of Grout (L) & Volume Factor \\
\hline 1.0 & 40.1 & $1.58-1.61$ & $1.58-1.61$ \\
\hline \hline \multicolumn{5}{|c|}{ By Mass } \\
\hline \multicolumn{5}{|c|}{ Mass of Grout } & Mass Factor \\
\hline \multicolumn{5}{|c|}{ Mass of 1 L of Waste } & $2680-2705$ & $2.34-2.49$ \\
\hline
\end{tabular}

\subsubsection{Future Work}

The Saltstone/Cast Stone samples need to be tested for compressive strength to ensure they are within the required limits for WTP. In addition, further correlations between the grout formulation and performance properties needs to be evaluated to ensure that all waste streams immobilized as a cementitious waste form meets the contract requirements. 


\subsection{Conclusions and Path Forward}

Five waste forms were evaluated for immobilization of LAW at Hanford after the sodium recovery process. The waste forms considered for these two waste streams include low temperature processes (Saltstone/Cast stone and geopolymers), intermediate temperature processes (steam reforming and phosphate glasses) and high temperature processes (vitrification). These immobilization methods and the waste forms produced were evaluated for (1) compliance with the Performance Assessment (PA) requirements for disposal at the IDF, (2) waste form volume (waste loading), and (3) compatibility with the tank farms and systems.

The iron phosphate glasses tested using the product consistency test had normalized release rates lower than the waste form requirements although the CCC glasses had higher release rates than the quenched glasses. However, the waste form failed to meet the vapor hydration test criteria listed in the WTP contract. In addition, the waste loading in the phosphate glasses were not as high as other candidate waste forms. Vitrification of HLW waste as borosilicate glass is a proven process; however the HLW and LAW streams at Hanford can vary significantly from waste currently being immobilized. The ccc glasses show lower release rates for $\mathrm{B}$ and $\mathrm{Na}$ than the quenched glasses and all glasses meet the acceptance criterion of $<4 \mathrm{~g} / \mathrm{L}$. Glass samples spiked with $\mathrm{Re}_{2} \mathrm{O}_{7}$ also passed the PCT test. However, further vapor hydration testing must be performed since all the samples cracked and the test could not be performed. The waste loading of the iron phosphate and borosilicate glasses are approximately 20 and $25 \%$ respectively.

The steam reforming process produced the predicted waste form for both the high and low aluminate waste streams. The predicted waste loadings for the monolithic samples is approximately $39 \%$, which is higher than the glass waste forms; however, at the time of this report, no monolithic samples were made and therefore compliance with the PA cannot be determined.

The waste loading in the geopolymer is approximately $40 \%$ but can vary with the sodium hydroxide content in the waste stream. Initial geopolymer mixes revealed compressive strengths that are greater than 500 psi for the low aluminate mixes and less than 500 psi for the high aluminate mixes. Further work testing needs to be performed to formulate a geopolymer waste form made using a high aluminate salt solution.

A cementitious waste form has the advantage that he process is performed at ambient conditions and is a proven process currently in use for LAW disposal. The Saltstone/Cast Stone formulated using low and high aluminate salt solutions retained at least $97 \%$ of the Re that was added to the mix as a dopant. While this data is promising, additional leaching testing must be performed to show compliance with the PA. Compressive strength tests must also be performed on the Cast Stone monoliths to verify PA compliance.

Based on testing performed for this report, the borosilicate glass and Cast Stone are the recommended waste forms for further testing. Both are proven technologies for radioactive waste disposal and the initial testing using simulated Hanford LAW waste shows compliance with the PA. Both are resistant to leaching and have greater than $25 \%$ waste loading. 


\subsection{Acknowledgements}

The authors would like to recognize the contributions of: David Best, Paul Burket, Gene Daniels, and Vickie Williams at SRNL, David Windgard and Clemson University for SEM micrographs, MO-SCI Corporation and PNNL for glass formulation and testing, and the University of Texas at Austin for geopolymer formulation and testing. 


\subsection{REFERENCES}

1. Allen, D.I., Raymond, R.E., Brouns, T.M., Choho, A.F., et al., "Recommendation for Supplemental Technologies for Hanford River Protection Project Potential Mission Acceleration," Waste Management Symposia, Tucson, AZ, 2003.

2. Kosson, D.S., Gallay, D.R., Pegg, I.L., Wymer, R.G., et al., "External Technical Review of System Planning for Low-Activity Waste Treatement at Hanford," 2008.

3. Harbour, J.R., "Waste Form Development for the Waste Stream Exiting Sodium Recovery after Aluminum Leaching of Hanford LAW," Savannah River National Laboratory, Aiken, SC, SRNLRP-2010-00127, January 2010.

4. Snow, L., Lumetta, G., Fiskum, S., and Peterson, R., "Boehmite Actual Waste Dissolution Studies," Separation Science and Technology, 43, 2900-16 (2008).

5. Peterson, R. and Fiskum, S. and Geeting, J. and Smith, H., et al., "Hanford Boehmite/Chromium Dissolution Data", Batelle-Pacific Northwest Division, PowerPoint Presentation.

6. McCabe, D.J., Peterson, R., Pike, J.A., and Wilmarth, W.R., "Aluminum and Chromium Leaching Workshop Paper," Savannah River National Laboratory, WSRC-STI-2007-00168, April 25, 2007.

7. Apps, J.A., Neil, J.M., and Jun, C.H., "Thermochemical Properties of Gibbsite, Bayerite, Boehmite, Diaspore, and the Aluminate Ion Between 0 and $350^{\circ} \mathrm{C}$," Lawrence Berkeley Laboratory, NUREG/CR-5271, LBL-21482, 1989.

8. Reynolds, J.G. and Reynolds, D.A., "A Modern Interpretation of the Barney Diagram for Aluminum Solubility in Tank Waste," Waste Management Symposia, Phoenix, AZ, 2010.

9. Agnew, S.F., Reynolds, J.G., and Johnston, C.T., "Aluminum Solubility Model for Hanford Tank Waste Treatment," Waste Management Symposia, Phoenix, AZ, 2009.

10. Peterson, R., Russell, R., Sams, T., and Brasel, B., "Continuous Sludge Leaching", http://srnl.doe.gov/owp techex09/denver_webcast/slides/04-5_Peterson.pdf, 2005.

11. Sresty, G., Brasel, B., and Peterson, R., "Advanced Remediation Technologies: Continuous Sludge Leaching", Parsons Infrastructure \& Technology Group and Battelle Memorial Institute, PowerPoint Presentation, 2007.

12. "Briefing for DOE-EM Technical Expert Group: Near Tank Treatment System", Parsons, 2010.

13. Fountain, M.S. and Kurath, D.E. and Sevigny, G.J. and Poloski, A.P., et al., "Caustic Recycle from Hanford Tank Waste Using NaSICON Ceramic Membrane Salt Splitting Process," Pacific Northwest National Laboratory, PNNL-18216, Rev. 0, 2009.

14. Harbour, J.R., "Development of Hanford LAW Simulants for Waste Streams Resulting from Aluminum Leaching of HLW and Subsequent Sodium Recover (Near-Tank Treatment System)," Savannah River National Laboratory, SRNL-L3100-2010-00066, March 24, 2010. 
15. Wilmarth, W.R., Hobbs, D.T., Averill, W.A., Fox, E.B., et al., "Review of Ceramatec's Caustic Recovery Technology," WSRC-STI-2007-00366 Rev. 0, 2007.

16. Balagopal, S. and Bhavaraju, S.V. and Clay, D.A. and Schatten, K.L., et al., "Recycling Caustic from LAW Stream using NaSICON Membrane Based Elecrochemical Technology", PowerPoint Presentation, Ceramatec, Inc.

17. Geniesse, D., "A Process for Removal of Aluminum Oxides from Aqueous Media," PCT/US2008/076589, 2008.

18. Geniesse, D., "Test Program for Alumina Removal and Sodium Hydroxide Regeneration from Hanford Waste by Lithium Hydrotalcite Precipitation (Draft)", Prepared for Areva FS, Inc., 2009.

19. Duncan, J. and Huber, H., "Scouting Experiments for Alumina Reduction in WTP Feed", http://www.hanford.gov/files.cfm/CAL_DST_Lithium_Hydrotalcite.pdf.

20. Peterson, R., to J. R. Harbour, Personal Communication 2010.

21. "WTP Contract " Contract No. DE-AC27-01RV14136, Conformed Thru Modification No. M153,

22. "Standard Test Methods for Determining Chemical Durability of Nuclear, Hazardous, and Mixed Waste Glasses and Multiphase Glass Ceramics: The Product Consistency Test," ASTM International, ASTM C1285.

23. "Standard Test method for Measuring Waste Glass or Glass Ceramic Durability by Vapor Hydration Test," ASTM International, C 1663 - 09.

24. Jantzen, C.M., "Fluidized Bed Steam Reformer (FBSR) Monolith Formation," Savannah River National Laboratory.

25. Burket, P.R. and Daniel, W.E. and Jantzen, C.M. and Nash, C.A., et al., "Steam Reforming Technology Demonstration for the Destruction of Organics on Actual DOE Savannah River Site Tank 48H Waste," Waste Management Symposia, Phoenix, AZ, 2009.

26. Jantzen, C.M., Marra, J., and Mason, B., "MINCALC(TM)", Savannah River National Laboratory, 2004.

27. Crawford, C.L. and Burket, P.R. and Cozzi, A.D. and Daniel, W.E., et al., "Radioactive Demonstration of Mineralized Waste Forms Made from Hanford Waste Treatment Plant Secondary Waste (WTP-SW) By Fluidized Bed Steam Reformation (FBSR)," Savannah River National Laboratory, SRNL-STI-2011-00331 Revision 0, August 2011.

28. "Standard Specification for Coal Fly Ash and Raw or Calcined Natural Pozzolan for Use in Concrete," ASTM International, C618-08a, Octoboer 2008.

29. Bakharev, T., "Geopolymeric Materials Prepared Using Class F Fly Ash and Elevated Temperature Curing," Cement and Concrete Research 35, 1224-32 (2005).

30. Fernández-Jiménez, A. and Palomo, A., "Characterization of Fly Ashes: Potential Reactivity as Alkaline Cements," Fuel, 82, 2259-65 (2003). 
31. Lloyd, R.R., "The Durability of Inorganic Polymer Cements"; Ph.D. Thesis. University of Melbourne, Melbourne, Australia, 2008.

32. Tailby, J. and MacKenzie, K.J.D., "Structure and Mechanical Properties of Aluminosilicate Geopolymer Composites with Portland Cement and its Constituent Materials," Cement and Concrete Research, 40, 787-94 (2010).

33. Sofi, M., van Deventer, J.S.J., Mendis, P.A., and Lukey, G.C., "Engineering Properties of Inorganic Polymer Concretes (IPCs)," Cement and Concrete Research, 37, 251-7 (2007).

34. Kerrick, D.M., "The Role of Carbon Film Thickness in Electron Microprobe Analysis," American Mineralogist, 58, 920-5 (1973).

35. Harbour, J.R., Edwards, T.B., and Williams, V.J., "Performance Properties of Saltstone Produced Using SWPF Simulants," Savannah River National Laboratory, SRNL-STI-2009-00810, December 2009.

36. Harbour, J.R., Edwards, T.B., and Williams, V.J., "Key Factors That Influence the Performance Properties of ARP/MCU Saltstone Mixes," Savannah River National Laboratory, SRNL-STI2009-00546, September 2009.

37. Harbour, J.R., Edwards, T.B., and Williams, V.J., "Impact of Time/Temperature Curing Conditions and Aluminate Concentration on Saltstone Properties," Savannah River National Laboratory, SRNL-STI-2009-00184, Rev. 0, 2009.

38. Harbour, J.R. and Williams, M.F., "Impact of Curing Temperature on the Saturated Liquid Permeability of Saltstone," Savannah River National Laboratory, SRNL-STI-2010-00745, February 2011.

39. "Standard Test Methods of Measurement of Hydraulic Conductivity of Saturated Porous Materials Using a Flexible Wall Permeameter," ASTM International, D5084-10, July 2010. 